VERÔNICA CORREIA MANOEL

AVALIAÇÃO DE MARCADORES IMUNOHISTOQUÍMICOS DE RESISTÊNCIA À MÚLTIPLAS DROGAS NOS CARCINOMAS MAMÁRIOS EM FELINOS

São Paulo

2019 


\section{AVALIAÇÃO DE MARCADORES IMUNOHISTOQUÍMICOS DE RESISTÊNCIA À MÚLTIPLAS DROGAS NOS CARCINOMAS MAMÁRIOS EM FELINOS}

Dissertação apresentada ao Programa de Pós-Graduação em Patologia Experimental e Comparada da Faculdade de Medicina Veterinária e Zootecnia da Universidade de São Paulo para a obtenção do título de Mestre em Ciências

Departamento:

Patologia

Área de concentração:

Patologia Experimental e Comparada

Orientador:

Prof. Dr. Bruno Cogliati

São Paulo 
Autorizo a reprodução parcial ou total desta obra, para fins acadêmicos, desde que citada a fonte.

\section{DADOS INTERNACIONAIS DE CATALOGAÇÃO NA PUBLICAÇÃO}

(Biblioteca Virginie Buff D’Ápice da Faculdade de Medicina Veterinária e Zootecnia da Universidade de São Paulo)

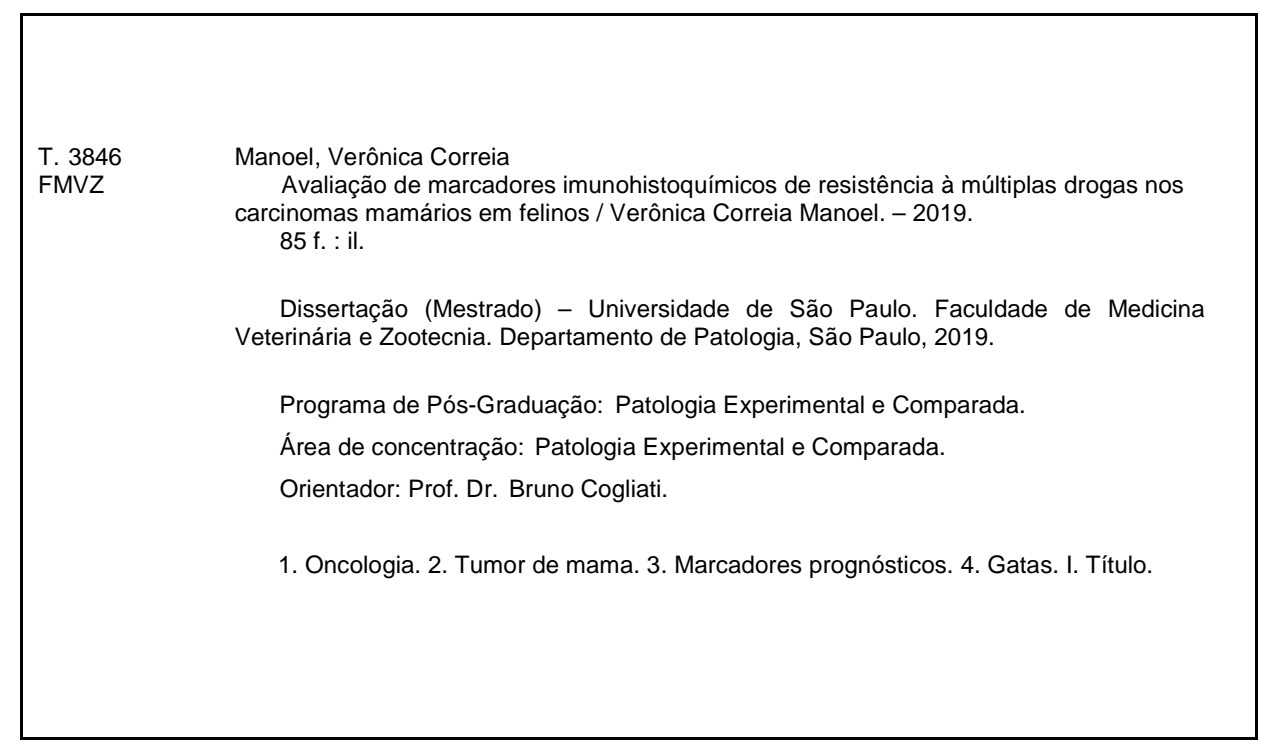

Ficha catalográfica elaborada pela bibliotecária Denise Yamashita, CRB-8/8931, da FMVZ/USP. 
ERRATA

MANOEL, V. C. Avaliação de marcadores imunohistoquímicos de resistência à múltiplas drogas nos carcinomas mamários em felinos. 2019.84 f. Dissertação (Mestrado em Ciências) - Faculdade de Medicina Veterinária e Zootecnia, Universidade de São Paulo, São Paulo, 2019

\section{Página}

FICHA

CATALOGRÁFICA

RESUMO

ABSTRACT

$$
\text { Onde se lê }
$$

$85 \mathrm{f}$

$85 f$
Leia-se

$84 \mathrm{f}$.

$84 \mathrm{f}$.

$84 \mathrm{f}$. 


\section{CERTIFICADO}

Certificamos que a proposta intitulada "Avaliação de marcadores imunohistoquímicos de resistência à múltiplas drogas no carcinoma mamário em felinos", protocolada sob o CEUA no 8835310817 (ID 004321), sob a responsabilidade de Bruno Cogliati e equipe; Verônica Correia Manoel - que envolve a produção, manutenção e/ou utilização de animais pertencentes ao filo Chordata, subfilo Vertebrata (exceto o homem), para fins de pesquisa científica ou ensino - está de acordo com os preceitos da Lei 11.794 de 8 de outubro de 2008, com o Decreto 6.899 de 15 de julho de 2009, bem como com as normas editadas pelo Conselho Nacional de Controle da Experimentação Animal (CONCEA), e foi aprovada pela Comissão de Ética no Uso de Animais da Faculdade de Medicina Veterinária e Zootecnia da Universidade de São Paulo (CEUA/FMVZ) na reunião de 06/12/2017.

We certify that the proposal "Immunohistochemical evaluation of multidrug resistance markers in feline mammary carcinoma", utilizing 112 Cats (112 females), protocol number CEUA 8835310817 (ID 004321), under the responsibility of Bruno Cogliati and team; Verônica Correia Manoel - which involves the production, maintenance and/or use of animals belonging to the phylum Chordata, subphylum Vertebrata (except human beings), for scientific research purposes or teaching - is in accordance with Law 11.794 of October 8, 2008, Decree 6899 of July 15, 2009, as well as with the rules issued by the National Council for Control of Animal Experimentation (CONCEA), and was approved by the Ethic Committee on Animal Use of the School of Veterinary Medicine and Animal Science (University of São Paulo) (CEUA/FMVZ) in the meeting of 12/06/2017.

Finalidade da Proposta: Pesquisa

Vigência da Proposta: de 10/2017 a 10/2019 Área: Patologia Experimental E Comparada

Origem: $\quad$ Animais de proprietários

Espécie: Gatos sexo: Fêmeas $\quad$ idade: 0 a 20 anos $\quad 112$

Linhagem: Variada $\quad$ Peso: 0 a $20 \mathrm{~kg}$

Local do experimento: Não se aplica

São Paulo, 14 de agosto de 2019

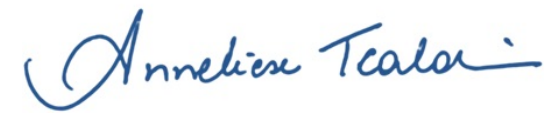

Profa. Dra. Anneliese de Souza Traldi Presidente da Comissão de Ética no Uso de Animais Faculdade de Medicina Veterinária e Zootecnia da Universidade de São Paulo

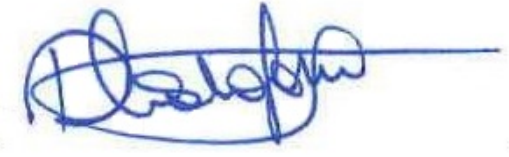

Roseli da Costa Gomes Secretária

Faculdade de Medicina Veterinária e Zootecnia da Universidade de São Paulo 


\section{FOLHA DE AVALIAÇÃO}

Autor: MANOEL, Verônica Correia

Título: Avaliação de marcadores imunohistoquímicos de resistência à múltiplas drogas nos carcinomas de mama em felinos

Dissertação apresentada ao Programa de Pós-Graduação em Patologia Experimental e Comparada da Faculdade de Medicina Veterinária e Zootecnia da Universidade de São Paulo para a obtenção do título de Mestre em Ciências

Data:

1

\section{Banca Examinadora}

Prof. Dr.

Instituição: Julgamento:

Prof. Dr.

Instituição: Julgamento:

Prof. Dr.

Instituição: Julgamento: 


\section{DEDICATÓRIA}

Dedico à minha família;

À minha mãe, Vera Lucia Correia, que sempre me incentiva a ser mais do que eu mesmo acredito, me encoraja a ir atrás de cada um dos meus sonhos e que, em especial durante este Mestrado, me proporcionou as condições necessárias para alcançar essa realização profissional. Mãe, obrigada pelo suporte, carinho, força e amor.

Ao meu pai, Reginaldo Pitorri, por acreditar em mim, em todas as oportunidades, até nas que nem eu acreditava, por todo suporte nos momentos em que precisei. Obrigada pelo encorajamento e conversas longas sobre objetivos e sonhos, e como falamos "choques de realidade". Obrigada pelas inúmeras acolhidas e por me fazer sentir segura.

Ao meu irmão, Raphael Pitorri, por se preocupar, cuidar e amar. Por ser irmão, amigo e parceiro. Pelas vezes que nos entendemos só pelo olhar. Obrigada por me mostrar, acompanhar e incentivar a ter a melhor terapia que existe - andar de moto. Obrigada pelas risadas, pelas broncas e pela parceria.

À minha amada sobrinha, Maria Antônia, que chegou a pouco menos de 2 anos, e transbordou a minha vida de um amor incondicional.

Às esposas do meu pai e do meu irmão, Sandra e Eduarda, pelos momentos em família, demonstrações de carinho e afeto, acolhidas, conversas, risadas e momentos de descontração.

Às minhas avós, Cecira e Esther, pelas preocupações características das vózinhas, o amor e o carinho de sempre. Vó Cecira pelas demonstrações diárias de carinho e amor em pequenos gestos como o café quentinho todos os dias de manhã, ou o jantar pronto para quando eu chegar. Vó Esther, apesar de não estar aqui fisicamente, espero que esteja orgulhosa da neta veterinária.

Às minhas duas afilhadas gêmeas, que ganhei durante o curso do Mestrado, Isabella e Gabriela ou simplesmente Bella e Gabi; mais dois incentivos para a madrinha aqui tentar ser uma pessoa melhor e servir de exemplo a essas duas vidinhas que foram dadas de presente para mim. 


\section{AGRADECIMENTOS}

Ao Prof. Dr. Bruno Cogliati, meu orientador nesta empreitada chamada Mestrado, me aceitando como orientada mesmo sem qualquer experiência em laboratório, recém-formada e um tanto apavorada quanto ao tamanho do desafio proposto. Obrigada por todas as vezes que bati a porta da sua sala - nestes últimos meses foram várias vezes, por me ensinar pacientemente todos processos desde a coleta do material para que esse projeto pudesse acontecer, pelo apoio durante os testes das imunohistoquímicas com a dificuldade de chegar a um resultado satisfatório, até as inúmeras correções do texto; por todos os "puxões de orelhas" necessários durante todo o Mestrado, pelas concessões cedidas nos momentos que precisei... O Mestrado é um processo encantador, porém desafiador, mas faria de novo com a sua orientação. Dizer obrigada seria muito pouco, para sempre minha Gratidão e Admiração por me ajudar em mais esse degrau profissional.

A Teresa Cristina da Silva, por sempre se prontificar a ajudar, deixando muitas vezes o que estava fazendo em segundo plano, para contribuir. Sempre disposta e pronta a ensinar, não importando sobre o que fosse. Obrigada por ter aceitado neste meio tempo, o desafio de orientar meu TCC na especialização; eu sei que dei trabalho. E além de tudo, pela companhia e conversas diárias de laboratório. Obrigada pela amizade e pela demonstração de exemplo de dedicação profissional.

A professora Dra. Felisbina Queiroga, pela importante contribuição junto a este trabalho, com suas considerações e analises estatísticas. Obrigada pelo pronto atendimento e pela disposição de ajudar mesmo de longe.

Aos membros da banca, obrigada por aceitar participar e colaborar com esse projeto, pelas colocações, e por participar do meu crescimento profissional.

Ao Marcelo Monte Mor Rangel, que abriu as portas da VetCâncer para que eu pudesse estagiar, e durante muitas das nossas conversas surgiu com a ideia do Mestrado. Ser humano incrível com a mente sempre atualizada em prol da Medicina Veterinária e sempre pronto a "plantar sementinhas" na cabeça de quem estiver disposto a novos desafios. Esse Mestrado não aconteceria sem as nossas 
conversas.

A Krishna Oliveira, que contribuiu para que eu abrisse meus olhos para a Patologia e por me mostrar sua importância na área que decidi seguir: a Oncologia. Por incentivar ao estudo contínuo, pelas inúmeras conversas dentro e fora do âmbito veterinário. Obrigada pelas aulas de Patologia durante uma ou outra cirurgia na clínica ou na copa, durante um bate papo.

A Jennifer Freytag, primeiramente me orientado na clínica e na cirurgia durante meu tempo na VetCâncer, depois me dando dicas de como "sobreviver" ao Mestrado, ainda se prontificando a ler meus textos quando eu já nem sabia mais o que estava escrevendo e, por fim, pelas conversas sobre o futuro profissional e pessoal. Querida e amiga para sempre.

A Gabriela Seabra, aluna de iniciação cientifica do LAPMOL por um ano, que me ajudou com os inúmeros blocos para cortar para confecção das lâminas, com as tardes preparando tampões e anticorpos para rodar as imunos. Pela ajuda com as organizações e formatações de textos. E além, claro, das vezes que saímos do laboratório para um cinema, uma comidinha diferente e jogar conversa fora. Espero ter contribuído também um pouquinho na sua vida profissional. Obrigada pela amizade, do laboratório para a vida.

A Rebeca Rodrigues, inicialmente mais uma estagiária do laboratório, mas que se tornou uma amiga especial, por todos os meses que passou comigo no laboratório, pela troca de experiências, pelas vezes que me ajudou nos meus experimentos, ou que simplesmente me fez companhia; espero ter contribuído um pouco para a sua formação também. Mais uma amizade que também começou no LAPMOL e que quero levar para sempre.

A Verônica Govoni, a Vê ruiva, minha antecessora, que também trabalhou com mamas de gatas, e que sempre foi muito gentil e atenciosa em todos os momentos que precisei de informações, ou ajuda no inicio, no meio e agora no final do meu projeto. E que deixou tudo super organizado e de fácil acesso para mim. Obrigada!

A professora Dra. Aline Zoppa, coordenadora do Hospital Escola Veterinário da Anhembi Morumbi por todos os casos de tumores felinos que gentilmente nos avisava e permitia a coleta do material e a comunicação com os tutores. Muito Obrigada! 
A médica veterinária Camila Utrera, coordenadora da cirurgia do Hospital Escola Veterinário da FMU, por se prontificar a ajudar sempre que surgiam casos de gatas com neoplasias mamária, obrigada pela parceria, juntamente com sua equipe de residentes. E muito obrigada por se prontificar a procurar os dados das gatas durante o seguimento para contribuir com os dados apresentados neste estudo.

Ao Pedro Luis Telles de Carvalho, seu trabalho contribuiu muito para inspirar meu projeto, agradeço a colaboração nas primeiras análises de imunihistoquímica.

Aos demais integrantes e ex-integrantes que passaram pelo Laboratório de Patologia Morfológica e Molecular (LAPMOL) da FMVZ/USP: Isis, David, Danilo, Juliana, Julieta, Diego, Jamile, Rafaela, Tassia, obrigada pela ajuda; às vezes nas coletas de material, as vezes no processamento do material, na troca de informações ou experiências, no intercâmbio de ideias.

A todos os demais familiares; os que moram perto e os que moram longe, que de uma forma ou de outra mostraram seu apoio, suporte e incentivo nesses dois anos de Mestrado. Que estão sempre presentes na minha vida. Obrigada!

Aos amigos, os da época do colégio, da $1^{\underline{a}}$ graduação (Educação Física), da $2^{\underline{a}}$ graduação e atual profissão, Medicina Veterinária, e os que ganhei com as inúmeras viagens de moto; que entenderam minhas ausências, e ainda assim demonstraram de alguma forma o seu apoio, carinho e amizade. Obrigada! Ao programa de PósGraduação em Patologia Experimental e Comparada do Departamento de Patologia da Faculdade de Medicina Veterinária e Zootecnia da Universidade de São Paulo.

A secretaria e todos os funcionários do VPT, pelo suporte e paciência.

E por fim, mas não menos importantes, aliás, talvez o ponto principal desse enredo, aos animais: gatos, peixes, tartarugas, passarinhos, coelhos e cães que passaram pela minha vida. E aqui não posso deixar de mencionar aquele que sem dúvida foi o maior incentivador da minha carreira veterinária oncológica, Zion, meu Bernese. Meu companheiro fiel desde seu primeiro dia, por seu amor incondicional, por sua gigante delicadeza, sua enorme lealdade e por me ensinar até o fim o quão conflitante, mas gratificante ser tutora e veterinária seriam, mostrando o quão tênue é esse laço que une a fria medicina do caloroso amor por eles. Para sempre deixou sua marca no meu coração. Para sempre Meu Querido! 
O presente trabalho foi realizado com apoio da Coordenação de Aperfeiçoamento de Pessoal de Nível Superior - Brasil (CAPES) - Código de Financiamento 001. 
"Quem não tem formação química ou na medicina talvez não perceba quão difícil é a questão do tratamento do câncer. É quase - não tanto, mas quase - tão difícil como descobrir um agente capaz de dissolver a orelha esquerda, por exemplo, e deixar a direita intacta. Tão pequena é a diferença entre a célula cancerosa e seu ancestral normal..." 


\section{RESUMO}

MANOEL, V. C. Avaliação de marcadores imunohistoquímicos de resistência à múltiplas drogas nos carcinomas mamários em felinos. [Immunohistochemical evaluation of multidrug resistance markers in feline mammary carcinomas]. 2019. 85f. Dissertação (Mestrado em Ciências) - Faculdade de Medicina Veterinária e Zootecnia, Universidade de São Paulo, São Paulo, 2019.

O tumor mamário é a terceira neoplasia mais incidente na espécie felina, cerca de 95\% dos tumores mamários são malignos e a doença tende a apresentar um comportamento altamente agressivo. $\mathrm{O}$ tratamento de eleição para essas neoplasias é a cirurgia radical, seguida de quimioterapia adjuvante. Ainda assim, a mortalidade associada à recidiva tumoral e/ou metástases é frequente, indicando uma falha nos procedimentos terapêuticos, mais precisamente na quimioterapia. Assim, o presente estudo teve como objetivo determinar a imunoexpressão de proteínas associadas à resistência à múltiplas drogas nos carcinomas mamários em felinos, correlacionando-as com aspectos clínico-patológicos e sobrevida. Participaram deste estudo 46 gatas atendidas e operadas em hospitais veterinários públicos e particulares. Os tumores foram submetidos à análise histopatológica, seguida pela análise imunohistoquímica para detecção da glicoproteína $\mathrm{P}$ (GlicoP), proteína relacionada a resistência de pulmão (LRP) e metalotioneína (MT). Os parâmetros clinicopatológicos foram correlacionados com a sobrevida pelo teste de Log-rank $(P<0,05)$. A presença de metástase à distância, estadiamento clinico, tipo de cirurgia adotada e o uso de quimioterapia adjuvante apresentaram associação com a sobrevida. A GlicoP e a LRP demonstraram, respectivamente, imunoexpressão intensa em $45,6 \%$ e $47,8 \%$ dos casos; enquanto a MT apresentou imunoexpressão discreta em $45,7 \%$ dos casos. Porém, todas as proteínas foram expressas em algum grau em todas as amostras. Foi encontrada correlação positiva entre a GlicoP e a graduação histológica $(P=0,049)$, e da MT com os subtipos moleculares $(P=0,023)$. Porém, não houve correlação de nenhuma das proteínas analisadas com a sobrevida. Estes dados indicam a presença de múltiplas proteínas de resistência aos antineoplásicos em carcinomas mamários em felinos, além de sua correlação com o alto grau de malignidade destas neoplasias. Apesar de não haver correlação com a sobrevida, estes marcadores podem indicar um pior prognóstico, além de uma possível baixa resposta à quimioterapia adjuvante.

Palavras-chave: Oncologia. Tumor de mama. Marcadores prognósticos. Gatas. 


\begin{abstract}
MANOEL, V. C. Immunohistochemical evaluation of multidrug resistance markers in feline mammary carcinomas. [Avaliação de marcadores imunohistoquímicos de resistência à múltiplas drogas nos carcinomas mamários em felinos]. 2019. 85f. Dissertação (Mestrado em Ciências) - Faculdade de Medicina Veterinária e Zootecnia, Universidade de São Paulo, São Paulo, 2019.
\end{abstract}

Mammary tumors are ranked as the third neoplasm with most incidents within the feline species. Around $95 \%$ of the mammary tumors tend to be malignant and such disease tends to develop an aggressive behavior pattern. In order to treat the neoplasm, radical surgery followed by adjuvant chemotherapy should be performed. Even so, there is a high frequency within the mortality rate and metastasis, point out to some sort of failure related to therapeutical procedures, specifically in chemotherapy. With that, the present case study had the purpose of exposing the immunoexpression related to proteins that are associated with building drug resistance within the mammary carcinoma found in felines. 46 female cats were used in this study and were surgically operated in both publicly and privately owned hospitals. All tumors were submitted into histopathological analysis, followed by immunohistochemistry in order to successfully detect P-Glycoprotein, the protein which is related to the lung's resistance and metalotioneína (MT). The clinical pathological parameters were correlated through the Log-rank $(\mathrm{P}<0,05)$ testing. The presence of distant metastasis, hospital admittance, type of surgery performed and the use of adjuvant chemotherapy was directly associated with survival rates. Both GlycoP and LRP showed, respectively, an intense immune expression of $45,6 \%$ and $47,8 \%$ of all the cases, meanwhile, the MT presented a discrete immune expression on $45.7 \%$ of the cases. However, all proteins were expressed within some degree on the scale. It was also noticed that there is a positive correlation between GlycoP and histological graduation $(P=0,049)$, and MT with molecular subtypes $(P=0,023)$. However, there were no correlations found between the studied proteins and survival. The data collected pointed to the presence of multiple types of resistance-related proteins to antineoplastic breast carcinoma found in felines as well as high correlation with the degree of malignancy found in the neoplasm. Even though those were not correlated with survival, these points may lead to a possible worse prognostic, as well as an eventual low positive response to the adjuvant chemotherapy.

Keywords: Oncology. Mammary tumors. Prognostic markers. Queens. 


\section{SUMÁRIO}

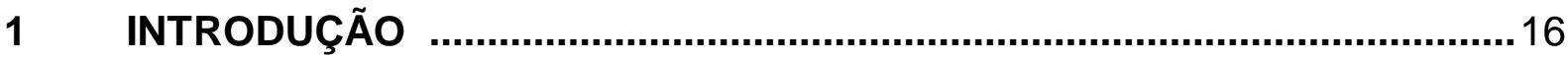

2 REVISÃO DE LITERATURA .............................................................17

2.1 ASPECTOS CLÍNICO-EPIDEMIOLÓGICOS ............................................17

2.2 ASPECTOS ANATOMOPATOLÓGICOS .....................................................19

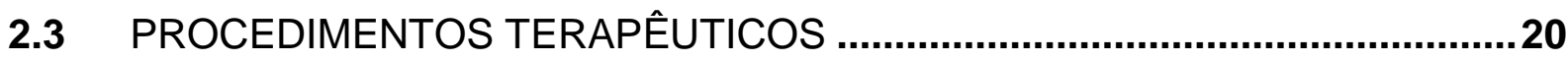

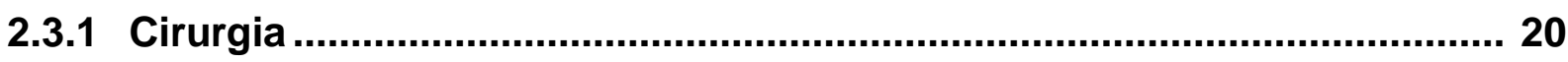

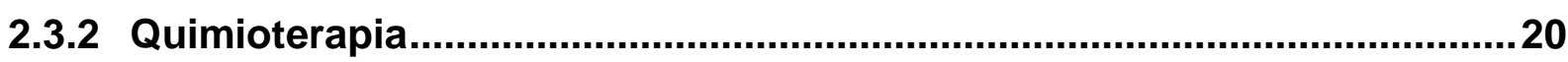

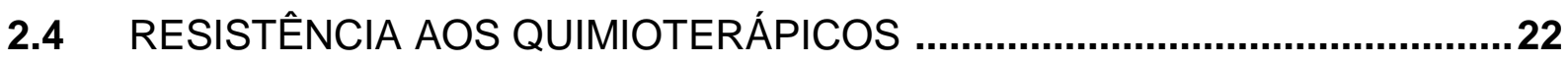

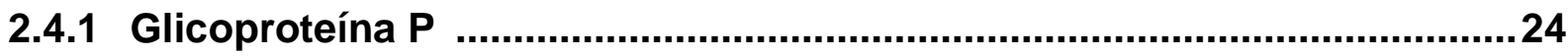

2.4.2 Proteína relacionada a resistência de pulmão ….....................................26

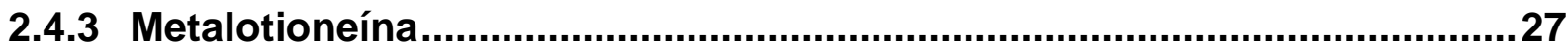

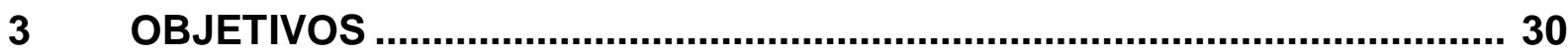

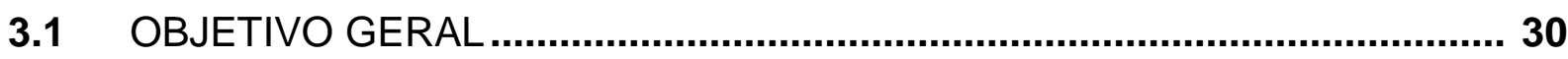

3.2 OBJETIVOS ESPECÍFICOS …............................................................30

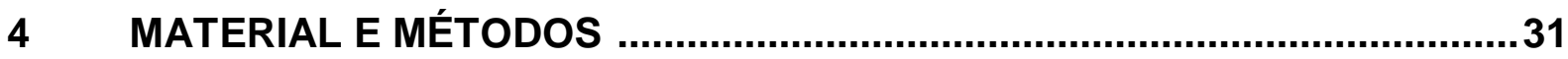

4.1 CASUÍSTIVA E DADOS CLÍNICO-EPIDEMIOLÓGICOS .............................31

4.2 ESTADIAMENTO CLÍNICO .......................................................................32

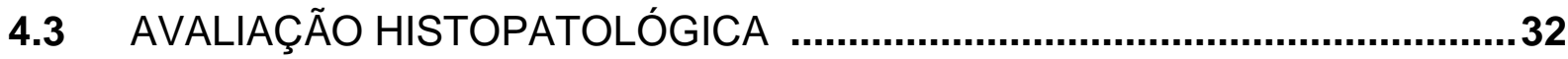

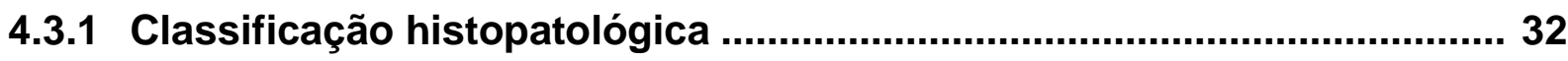

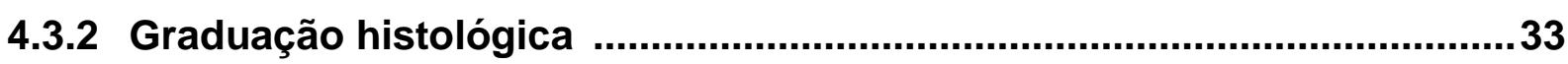

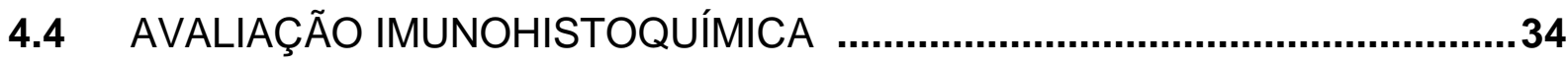

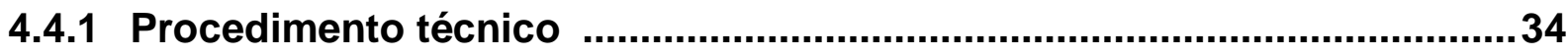

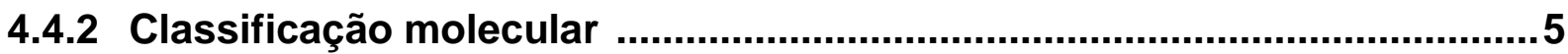

4.4.3 Avaliação das proteínas de resistência a múltiplas drogas .....................37

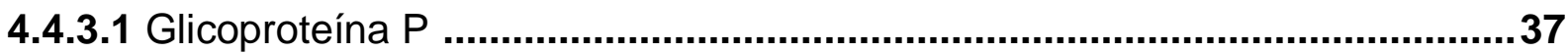

4.4.3.2 Proteína de resistência pulmonar (LRP) ....................................................... 38

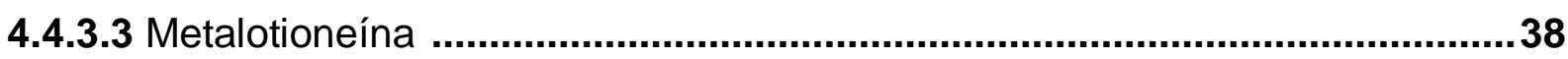

4.5 SEGMENTO CLÍNICO E SOBREVIDA ....................................................39

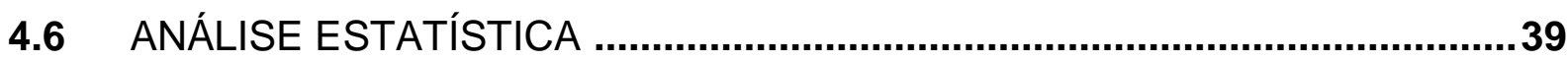

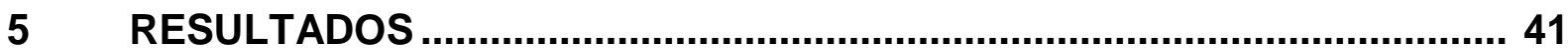

5.1 CARACTERIZAÇÃO CLÍNICO-EPIDEMIOLÓGICA E ANATOMOPATOLÓGICA ....41

5.2 MARCADORES DE RESISTÊNCIA A MULTIPLAS DROGAS .....................44 
5.3 ASSOCIAÇÃO COM PARÂMETROS CLÍNICO-PATOLÓGICOS ......................49

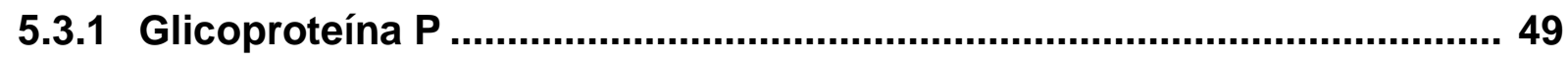

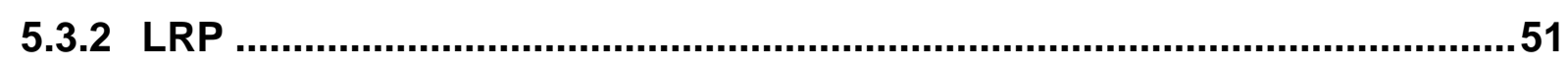

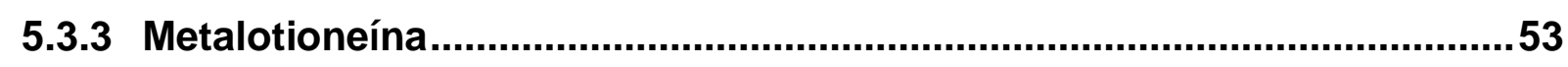

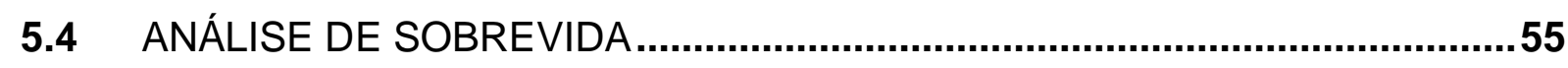

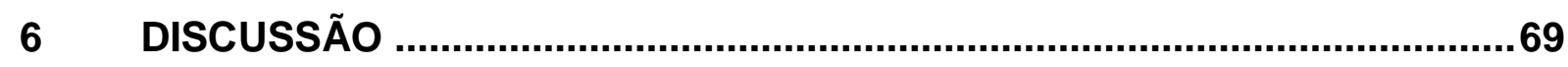

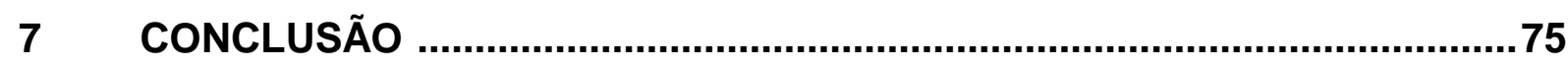

REFERÊNCIAS .............................................................................. 


\section{INTRODUÇÃO}

O diagnóstico do câncer em cães e gatos está cada vez mais frequente na rotina das clinicas veterinárias, principalmente devido à uma maior longevidade destes animais em decorrência às constantes melhorias na nutrição, prevenção de doenças infecciosas e nos métodos diagnósticos e terapêuticos (BENTUBO et al., 2007). Neste sentido, faz-se necessário um maior investimento em pesquisas relacionadas às neoplasias, focadas no diagnóstico precoce dos diferentes tipos neoplásicos e em suas classificações morfológicas e moleculares, assim como na caracterização de terapias alvo e mecanismos envolvidos na resposta tumoral aos fármacos (MORENTE et al.; 2008).

Estudos recentes apontam que a neoplasias caninas, como linfoma, câncer de mama e de ossos, apresentam grande similaridade aos mesmos tipos tumorais em seres humanos, tornando-se, assim, ótimos modelos para estudos comparativos e translacionais (GROENEVELD et al., 2016). Segundo a Oncologia Comparada, área que associa a ocorrência do câncer em humanos e animais, os nossos pets representam excelentes modelos de comparação para câncer, principalmente pelo fato dessa afecção ocorrer de forma espontânea em ambas as espécies (THAMM; DOW, 2009). Nesse mesmo contexto, as neoplasias em felinos, como os carcinomas de mama, linfomas gastrointestinais e os carcinomas de células escamosas também representam potenciais modelos para estudos comparativos e translacionais com a espécie humana (CANNON, 2015).

O carcinoma mamário em gatas é reconhecido, desde 1980, como modelo para o mesmo câncer em mulheres, pois compartilham características epidemiológicas, morfológicas e prognósticas (MISDORP; WEIJER, 1980; ZAPPULLI et al., 2005). Assim, alguns autores estabeleceram comparativos em muitos aspectos destas neoplasias (RANIERI et al., 2013). Tais similaridades entre neoplasias em humanos e animais domésticos incluem características biológicas, anatômicas, genéticas, moleculares e histológicas. Algumas delas podem estar relacionadas pelo fato de humanos e animais domésticos dividirem o mesmo ambiente e, portanto estarem expostos aos mesmos riscos (PAOLONI; KHANNA, 2008). Além disso, ainda há a associação com incidência de metástase e a resposta à terapia, considerando o 
consenso de que a terapia cirúrgica, somente, não se mostra eficaz em ambas as espécies (ZAPPULLI et al., 2005; MISDORP; WEIJER, 2013).

Em mulheres, assim como em gatas, o uso da quimioterapia como terapia adjuvante para o tratamento do câncer mamário é similar (ZAPPULLI et al., 2005). A quimioterapia é uma das opções quando se trata de câncer, seja local ou disseminado, porém, ela não é capaz de responder de maneira eficaz na totalidade dos casos. Atualmente, uma das hipóteses para a falta de resposta está relacionada aos mecanismos de resistência aos antineoplásicos, os quais podes ser adquiridos por diversas formas (GOTTESMAN, 2002; LUQMANI, 2008). Estes mecanismos também parecem estar presentes na espécie felina (DOYLE et al., 1998; TAKARA et al., 2004).

Os dados de resistência tumoral à múltiplas drogas em tumores em felinos são escassos na literatura e não há informações relacionadas aos protocolos quimioterápicos usados após a mastectomia em gatas. Sendo assim, três proteínas comumente relacionadas aos mecanismos de resistência à múltiplas drogas foram selecionadas, sendo elas: glicoproteína $P$, proteína relacionada a resistência de pulmão (LRP) e metalotioneína. Estas proteínas foram investigadas nos carcinomas de mama em felinos para investigar sua imunoexpressão tecidual, assim como sua correlação com aspectos clínico-epidemiológicos e sobrevida dos animais. Ainda, estes marcadores foram associados com os fármacos utilizados nos protocolos quimioterápicos veterinários, incluindo doxorrubicina, vincristina e ciclofosfamida. Estes dados podem trazer novas informações sobre os mecanismos de resistência das células tumorais frente aos tratamentos quimioterápicos, permitindo que novos protocolos terapêuticos sejam estabelecidos para estes tumores em felinos.

\section{REVISÃO DE LITERATURA}

\subsection{ASPECTOS CLÍNICO-EPIDEMIOLÓGICOS E ANATOMOPATOLÓGICOS}

O tumor mamário é o terceiro tumor mais frequente nos felinos, correspondendo a $25 \%$ das neoplasias ocorridas nesta espécie (DORN et al., 1967; BROWN; HAYES; MOONEY, 1985; OVERLEY et al., 2005; CUNHA et al., 2016). Porém, um estudo realizado no Brasil elenca as neoplasias mamárias como o 
segundo tumor mais frequente nesta espécie (TOGNI et al., 2013). Alguns estudos estabelecem a raça Siamesa como predisponente ao câncer mamário (ZAPPULLI et al., 2005), porém outros não demonstram esta relação, talvez pela heterogeneidade de raças na população estudada (CUNHA et al., 2016). Os animais mais acometidos são fêmeas inteiras, entre 8 e 10 anos de idade, submetidas à ovariosalpingohisterectomia ( $\mathrm{OSH})$ mais tardiamente; ou ainda animais submetidos ao uso contínuo de anticoncepcionais (BROWN; HAYES; MOONEY, 1985; OVERLEY et al., 2005). Sabe-se que gatas castradas antes dos 6 meses tem um risco de desenvolver neoplasias mamárias reduzido em $91 \%$, enquanto animais castrados depois dos 13 meses essa redução é de apenas 11\% (HAYDEN; NIELSEN, 1971; OVERLEY et al., 2005).

Os tumores mamários podem ser únicos ou múltiplos, e geralmente apresentam crescimento e disseminação rápidos. Quanto à localização, as glândulas mamárias são anatomicamente distribuídas em quatro pares nos felinos: axilar, torácica, abdominal e inguinal; todas podem ser igualmente acometidas pela neoplasia (HAYDEN; NIELSEN, 1971; HAYES; MOONEY, 1985; MILLS et al., 2015), há algumas divergências quanto a incidência da localização das neoplasias, porém há mais dados sobre as mamas abdominais (CASSALI et al., 2018). As neoplasias podem apresentar-se intactas ou ulceradas, aderidas ou não; e a parcela que apresenta ulceração normalmente estão associadas a grandes áreas necróticas e a um pior prognóstico (ZAPPULLI et al., 2005).

Cerca de 85 a 93\% dos tumores de mama em felinos são considerados malignos (FILGUEIRA et al., 2014). Assim, apesar das gatas apresentarem-se em boas condições clínicas no momento do diagnóstico, a maioria já apresenta metástases ou micrometástases (OVERLEY et al., 2005). Dessa forma, o prognóstico desta doença está diretamente relacionado com a extensão e o estágio na qual se encontra, variando de reservado a ruim. As micrometástases, presentes em cerca de $90 \%$ dos casos, e a invasão do tecido adjacente ocorrem quando o quadro já é avançado. Comumente, os carcinoma mamários ocasionam infiltrações neoplásicas em linfonodos regionais, seguido pelos pulmões e fígado (OVERLEY et al., 2005; FILGUEIRA et al., 2014). Desta forma, O tratamento primário recomendado é o procedimento cirúrgico para a remoção completa da cadeia mamária acometida, assim como de seus linfonodos sentinelas, seguido da 
associação com quimioterapia adjuvante (DORN et al., 1967; CUNHA et al., 2016). No entanto, a sobrevida destes animais pode variar de alguns meses até um ano, com uma variação média de 7,7 até 12 meses (OVERLEY et al., 2005; CUNHA et al., 2016).

\subsection{ASPECTOS ANATOMOPATOLÓGICOS}

Nas felinas, as glândulas mamárias são distribuídas anatomicamente em quatro pares: axilar, torácica, abdominal e inguinal, há um consenso de que as mamas inguinais e abdominais são mais frequentemente acometidas do que os pares anteriores (ZAPPULLI et al., 2005; CASSALI et al., 2018).

A respeito da drenagem linfática, existe a concordância de que as mamas craniais drenam para o linfonodo axilar, e as mamas caudais drenam em direção aos linfonodos inguinais, recentemente alguns autores mencionaram sobre formas de drenagens divergentes, como a mama torácica drenar para as duas direções, axilar e inguinal e a mama abdominal também para ambos (RAHARISON; SAUTET, 2006). Para tanto se faz necessário o uso de corantes como o Azul Patente para observar para qual linfonodo acontece a drenagem e retirá-lo no momento da cirurgia, devido a alta incidência de metástases.

Na rotina clínica mais de $50 \%$ dos animais apresentam nódulos múltiplos, em sua maioria o diagnóstico se dá de maneira tardia, por não serem notados até que seja palpáveis pelos tutores ou em exames de rotina pelo médico veterinário, desta forma podem estar aderidos e ou podem apresentar-se ulcerados, o que consequentemente leva ao estagio avançado no momento do exame (GIMÉNEZ et al.; 2010). Em 25\% dos casos os tumores estão ulcerados e ou com presença de extensa área necrótica, os mamilos envolvidos estão frequentemente edemaciados e podem expelir algum tipo de fluido (BERGMAN, 2006).

Dentre os tumores mamários felinos, 80\% é maligno (VAIL; MACEWEN, 2000). Destes podemos observar os tipos histológicos mais frequentes, tubulopapilar, sólido, cribiforme e in situ (GIMÉNEZ.et al; 2010). Ainda no contexto da análise de malignidade dos tumores a classificação histopatológica é de extrema importância prognóstica, essa classificação é baseada nos tipos de formação, pleomorfismo nuclear e contagem mitótica (ELSTON; ELLIS, 1991; MILLS et al., 2015). 
O tamanho tumoral é caracterizado como um importante fator prognóstico, a literatura aponta para tumores com mais de 3 centímetros com um menor tempo de sobrevida (BORREGO et al.; 2009).

\subsection{PROCEDIMENTOS TERAPÊUTICOS}

\subsubsection{Cirurgia}

O tratamento recomendado é o procedimento cirúrgico para a remoção completa da cadeia mamária acometida (mastectomia uni ou bilateral), assim como de seus linfonodos sentinelas (DORN et al., 1967). A remoção completa das cadeias mamárias (mastectomia bilateral ou radical) apresenta correlação positiva com uma maior sobrevida dos animais, porém não tem efeito curativo na maior parte dos casos devido à severidade da doença e ao seu alto poder de disseminação sistêmica (AMBUDKAR et al., 1999; NOVOSAD, 2003). Nos casos mais precoces, a cirurgia mais agressiva, aumenta o tempo de sobrevida dos animais (BENTUBO et al.; 2007). O procedimento recomendado e mais utilizado em clinicas e hospitais veterinários refere-se à mastectomia radical, com a remoção concomitante dos linfonodos regionais/sentinelas, sendo os inguinais como parte das mamas do mesmo segmento, e os axilares se estiverem reativos ou apresentarem células neoplásicas após exames citológicos (CIRILLO, 2008). No entanto, em casos que haja pouca margem cirúrgica e/ou pele para a exérese cirúrgica, recomenda-se a mastectomia unilateral, seguida da segunda cadeia após trinta dias, aproximadamente. No caso de tumores muito aderidos, recomenda-se a remoção conjunta da fáscia muscular (QUEIROZ et al., 2013).

\subsubsection{Quimioterapia}

Nas gatas, devido a agressividade da doença, preconiza-se a associação com quimioterapia adjuvante sempre que possível que, por definição, é justamente a quimioterapia que se segue após a cirurgia. Esta terapia adjuvante tem como principal objetivo eliminar as possíveis células neoplásicas residuais locais ou sistêmicas, na tentativa de controlar recidivas locais ou metástases à distância 
(BONADONNA et al., 1965). A quimioterapia como monoterapia é utilizada somente quando os tumores são inoperáveis. $O$ uso de quimioterapia adjuvante aumenta o tempo de sobrevida dos pacientes, diminui a incidência de recidiva local e do surgimento de metástases à distância (CIRILLO, 2008). Normalmente, a escolha do protocolo quimioterápico deve levar em consideração o estado clínico do paciente, e a escolha da droga deve corroborar com o diagnóstico do exame histopatológico (CIRILLO, 2008; KLOPFLEISCH, KOHN; GRUBER, 2016). Para tal, utiliza-se a dose máxima tolerada por curto período de tempo, na tentativa de destruir a maioria das células neoplásicas restantes (CIRILLO, 2008). Comumente, são usados quimioterápicos como a doxorrubicina, ciclofosfamida ou vincristina (IZQUIERDO et al., 1996a).

A doxorrubicina é um antibiótico antitumoral ou, ainda, um agente intercalante de DNA, que impede a síntese de DNA e RNA (LUQMANI, 2008), sendo amplamente utilizada na medicina veterinária como mono ou poliquimioterapia (DE ALMEIDA et al., 2005). Administrada na dose de $30 \mathrm{mg} / \mathrm{m}^{2}$, somente por via intravenosa, pode ser usada sozinha ou em associação com a ciclofosfamida, resultando em regressão completa ou parcial (CIRILLO, 2008; KLOPFLEISCH; KOHN; GRUBER, 2016). No entanto, a doxorrubicina pode desenvolver um importante quadro de nefrotoxicidade em felinos, como efeito colateral (CIRILLO, 2008). Em um estudo retrospectivo, gatas em estágio clínico III, que receberam 5 aplicações de doxorrubicina (1 $\mathrm{mg} / \mathrm{kg}$ - IV por 3 semanas) após a remoção cirúrgica do tumor primário, tiveram uma sobrevida de 641 dias, ao contrário de animais que fizeram apenas a cirurgia como terapia sugerida, os quais tiveram uma sobrevida medida de 180 dias (BERGMAN, 2006).

A ciclofosfamida é um agente alquilante, que inibe a síntese e a divisão do DNA e não tem afinidade por uma fase única do ciclo celular (DE ALMEIDA et al., 2005). Em felinos, este fármaco é administrado em doses de 50 a $250 \mathrm{mg} / \mathrm{m}^{2}$, por via oral ou intravenosa, geralmente associado à doxorrubicina para controle de micrometástases após a mastectomia (MAULDIN et al., 1988). Como efeito colateral, os animais podem apresentar cistite hemorrágica e mielossupressão (CIRILLO, 2008). Por sua vez, a vincristina (sulfato de vincristina) é um alcaloid que atua impedindo a segregação dos cromossomos durante a mitose e leva à morte celular, 
sendo normalmente empregada junto com a ciclofosfamida e a doxorrubicina (CIRILLO, 2008; FREIRE et al., 2014).

Mesmo quando a quimioterapia adjuvante é abordada de forma adequada durante o seguimento pós-cirúrgico, nota-se que alguns animais não respondem adequadamente ao controle de recidivas e/ou metástases à distância (DE CAMPOS et al., 2016). Esse fato pode estar relacionado à comorbidades do paciente ou, ainda, com uma possível resistência das células neoplásicas às drogas antitumorais. Neste último caso, as células tumorais desenvolvem mecanismos de resistência às drogas as quais nunca foram expostas previamente, de maneira intrínseca ou adquirida. Esse mecanismo é amplamente estudado na oncologia humana, com mulheres portadoras de neoplasias mamárias (TAKARA et al., 2004).

\subsection{RESISTÊNCIA AOS QUIMIOTERÁPICOS}

Em 1942, médicos relataram a primeira forma de resistência à drogas antineoplásicas em um paciente com linfoma. A terapia foi eficaz neste paciente por um determinado período de tempo, porém depois houve a recidiva do tumor e detecção de resistência ao quimioterápico utilizado no tratamento primário (NIERO et al., 2014). Desde então, a resistência ao uso dos antineoplásicos vem sendo relatada em pacientes humanos e animais limitando, assim, a eficácia do tratamento em longo prazo (LINN et al., 1997). Na medicina humana, a resistência aos antineoplásicos é pode estar relacionada com até $90 \%$ das causas de insucesso do tratamento contra o câncer (COLEY, 2009). Na medicina veterinária ainda não há um consenso sobre essa porcentagem, o que se sabe é que a resistência aos quimioterápicos existe e é uma forma significativa de falha no tratamento (BERGMAN, 2003).

Estudos visando uma melhor compreensão dos mecanismos de resistência aos antineoplásicos vem sendo desenvolvidos nos últimos anos, os quais podem ser divididos em três vertentes. A resistência ao antineoplásicos pode ser intrínseca, ou seja, alguns fatores pré-existentes nas células tumorais tornam a terapia ineficaz logo no inicio do tratamento. Por outro lado, a resistência pode ser extrínseca ou adquirida, na qual determinados fatores tornam o tratamento ineficiente, como por exemplo a repetida exposição a determinados fármacos, muitas vezes combinado 
com a instabilidade genética do tumor. E, para alguns autores, a resistência induzida, na qual as células neoplásicas tornam-se quimiorresistentes após alterações epigenéticas (COLEY, 2009; ZANDVLIET; TESKE, 2015).

$\mathrm{Na}$ oncologia veterinária, Zandvliet e Teske (2015) relatam a dificuldade de determinar se houve um mecanismo de resistência intrínseca ou extrínseca, uma vez que os tratamentos quimioterápicos são baseados em respostas clínicas. Sendo assim, se a maioria das células tumorais apresentarem resposta ao antineoplásico, a resposta clínica será completa. Porém, se uma pequena porcentagem de células persistir, com o tempo haverá recidiva tumoral, levando a uma falsa impressão de resistência adquirida aos fármacos. Este fenômeno não é difícil de ocorrer devido a alta heterogeneidade do tumor, inclusive com a presença de células tronco tumorais, que contribui para a resistência (DEAN; FOJO; BATES, 2005). Uma pequena população remanescente das células tronco, pode induzir as demais em sua totalidade por meio de adaptações que ocorrem dentro do microambiente tumoral. Essas adaptações, por sua vez, fornecem uma barreira criada pela hipóxia, acidose e pelo número de células tumorais quiescentes, tornando o microambiente tumoral insensível aos quimioterápicos (TRÉDAN et al., 2007).

A ação da resistência pode ocorrer por meio de um único agente quimioterápico ou por vários compostos (DEELEY; COLE, 1997). Alguns mecanismos são apontados como mediadores da resistência aos antineoplásicos, como: 1) mudanças nos alvos terapêuticos, nas quais o alvo perde ou diminui sua expressão; 2) Inativação de drogas pelas células tumorais, em qualquer uma das fases de detoxificação, ou seja, absorção, metabolismo e excreção; 3) sistema ineficiente de reparo ao dano no DNA, podendo levar a inibição do efeito citotóxico nas células; 4) falha no mecanismo de apoptose devido o quimioterápico não atingir o alvo terapêutico, permitindo que as células neoplásicas aumentam sua resistência a apoptose (COLEY, 2009; BAGULEY, 2010a)

O principal mecanismo de resistência elucidado e ponto chave para este estudo é o efluxo de drogas (SCHECK, 1996; NIERO et al., 2014). Várias proteínas de membrana estão associadas a resistência aos antineoplásicos, devido à promoção do efluxo das drogas das células-alvo; ou ainda, pelo sequestro das drogas em vesículas para posterior eliminação por exocitose (BAGULEY, 2010a). Dentre estas proteínas de membrana, destaca-se o grupo da superfamília de 
transportadores $\mathrm{ABC}$, em especial a glicoproteína $\mathrm{P}$ (GlicoP) e a proteína relacionada a resistência de pulmão (LRP) (KLOPFLEISCH; KOHN; GRUBER, 2016). Os membros do grupo $A B C$ são capazes de eliminar lipídios e, portanto, várias drogas hidrofóbicas, incluindo alguns quimioterápicos (LUQMANI, 2008; NIERO et al., 2014; ZANDVLIET; TESKE, 2015).

A ação de resistência ocorre, em sua maioria, pela superexpressão de proteínas que estão diretamente relacionadas a ineficácia dos tratamentos quimioterápicos (DEELEY; COLE, 1997). Essas proteínas, em condições sadias, são um instrumento de defesa celular para a proteção contra agentes citotóxicos (LESLIE; DEELEY; COLE, 2005). A superexpressão dos transportadores de drogas ABC, como a GlicoP e LRP, e a metalotioneína (MT) em células neoplásicas estão associadas com uma alta incidência de resistência aos quimioterápicos (DORN et al., 1967). Consequentemente, estes pacientes apresentam prognóstico ruim devido à baixa sensibilidade celular das células tumorais aos agentes quimioterápicos (LESLIE; DEELEY; COLE, 2005).

Muleya et al. (1999) demonstraram que células tumorais mamárias isoladas de uma gata submetida ao tratamento quimioterápico com vincristina mostrou-se mais resistente à este quimioterápico em testes de sensibilidade in vitro, enquanto mostrou maior sensibilidade ao teste com a doxorrubicina. Estes dados demonstram a heterogeneidade das células neoplásicas em relação as diversas drogas e, portanto, a necessidade de atenção ao assunto, quanto a promoção da resistência à ação dos fármacos antineoplásicos.

$\mathrm{Na}$ oncologia humana, muitos esforços estão sendo feitos em relação à esses fenômenos, no intuito de deter a resistência e tornar o tratamento quimioterápico eficaz (FLETCHER et al., 2010). A veterinária caminha logo atrás, inicialmente com a compreensão dos mecanismos de resistência aos quimioterápicos, e seguindo com estudos de drogas para prevenir ou superar esses mecanismos (KLOPFLEISCH; KOHN; GRUBER, 2016).

\subsubsection{Glicoproteína P}

A GlicoP, proteína pertencente a superfamília dos transportadores $A B C$, foi um dos maiores avanço nas descobertas relacionadas a resistência à múltiplas 
drogas (BAGULEY, 2010b). Foi descrita pela primeira vez em 1976, em um estudo chinês para resistência em células ovarianas de hamster (JULIANO, 1976). Esta proteína desempenha um papel importante na fisiologia celular, como regulação e transporte de substâncias endógenas (HEYDEN; CHIERS; DUCATELLE, 2009). Seu principal mecanismo consiste em uma bomba de efluxo de drogas, dependente de adenosina trifosfato (ATP). Estudos apontam que ela está envolvida no transporte de nutrientes e outras moléculas biológicas do meio intracelular para o meio extracelular. Além disso, pode detectar e se ligar a uma série de drogas que adentram o citoplasma, aumentando o efluxo celular e diminuindo a concentração intracelular dos fármacos, expulsando-os de forma ativa das células neoplásicas (AMBUDKAR et al., 1999; GOTTESMAN, 2002; LESLIE; DEELEY; COLE, 2005; HIFUMI et al., 2010; NIERO et al., 2014). Dessa maneira, essa bomba de efluxo faz com que o agente citotóxico seja expulso da célula, reduzindo sua concentração intracelular, ocorrendo a diminuição na sua toxicidade e, consequentemente, em sua ação terapêutica no alvo celular (MOLLAZADEH et al., 2018).

Pelo seu importante papel na fisiologia celular, a GlicoP está presente em inúmeros tecidos em cães e humanos. De maneira similar, foi constatada sua imunoexpressão em tecidos do fígado, pâncreas, vesícula biliar, estômago, intestino, adrenal, glândula salivar, bexiga urinária, rins, cérebro e medula espinhal na espécie felina (HEYDEN; CHIERS; DUCATELLE, 2009). O conhecimento da função da GlicoP é clinicamente útil em diversas espécies, como o clássico exemplo da contra indicação de uso da ivermectina em cães das raças Collie, Old English Sheep Dog e Pastor Alemão. Os animais destas raças podem apresentar uma mutação no gene $A B C B 1$, que codifica para a proteína GlicoP, sendo, portanto, inibida nestes animais. Assim, devido a incapacidade das células controlarem a concentração intracelular desta droga, os animais apresentam um quadro grave de neurotoxicidade após a aplicação do fármaco (VIRKEL et al., 2017). Ainda alguns estudos associam a expressão da GlicoP em neoplasias com a resistência aos quimioterápicos em cães (HONSCHA et al.; 2009; PAWLOWSKI et al., 2013).

A GlicoP tem sido amplamente estudada no câncer por ser apontada como um importante fator de resistência aos fármacos quimioterápicos (VAN DER HEYDEN et al., 2011). A expressão de GlicoP em células tumorais age de forma que as moléculas dos agentes antineoplásicos sejam transportadas para o meio 
extracelular, diminuindo sua concentração intracelular (MOLLAZADEH et al., 2018). Um estudo com 20 mulheres com câncer mamário, 17 em estágio avançado, porém local e 3 com metástases comprovadas, foram submetidas a teste para a avaliação da expressão de GlicoP antes da quimioterapia. Destas, 17 amostras demonstraram uma superexpressão de GlicoP e, em associação, uma baixa resposta à quimioterapia neoadjuvante (FREDERIC et al., 1991).

Em estudo realizado com tumores mamários felinos, Van der Heyden et al. (2011) observaram uma expressiva imunomarcação membranosa da GlicoP em carcinomas mamários, principalmente em áreas com crescimento infiltrativo e aglomerado de células menos diferenciadas. Células metastáticas em linfonodos também foram positivas para esta proteína. Os autores não correlacionaram a expressão de GlicoP com o grau de malignidade do tumor, porém ressaltam que a expressão da proteína em células tumorais é um importante fator de resistência aos antineoplásicos (VAN DER HEYDEN et al., 2011).

Dentre os antineoplásicos usados na Medicina Veterinária e que exibem algum grau de resistência quando na presença da GlicoP, destacam-se a vincristina, vinblastina, doxorrubicina, mitoxantrona, actinomicina $D$ e corticoides (AMBUDKAR et al., 1999; GOTTESMAN, 2002; HIFUMI et al., 2010). O uso de corticoides pode estar relacionado com a indução da atividade da GlicoP, e portanto é desencorajado antes do tratamento de linfoma canino, por induzir um pior prognóstico (BERGMAN, 2003).

\subsubsection{Proteína relacionada a resistência de pulmão}

A proteína relacionada a resistência de pulmão (LRP, do inglês lung resistance-related protein), foi descoberta em 1986 (KEDERSHA; ROME, 1986), quando linhagens de células neoplásicas pulmonares foram resistentes a doxorrubicina, porém não expressavam a proteína de resistência GlicoP (SCHEPER et al., 1993). Apesar de sua função ser pouco elucidada, ao que tudo indica exerce uma importante ação no transporte núcleo-citoplasmático de substâncias. A função de regular o transporte de substâncias do núcleo para o citoplasma sugere que possa estar envolvida no transporte de agentes citotóxicos para fora da célula, e ainda estar envolvida na manutenção do citoesqueleto (IZQUIERDO et al., 1996a; 
ZON et al., 2003). A LRP está presente em diversos tipos celulares e a maioria localiza-se no citoplasma, como forma de proteger o núcleo celular de agentes tóxicos. Alguns autores apontam seu envolvimento em tecidos com alto índice de metabolismo de xenobióticos e/ou agentes citotóxicos e tecidos com alto índice metabólico (SCHEFFER et al., 2000).

Em humanos, a LRP também é conhecida como proteína "vault". Esse nome advém da sua estrutura morfológica, parecida com os arcos das abóbadas das catedrais, e por conter partículas de ribonucleoproteínas citoplasmáticas (ZON et al., 2003). A expressão da LRP em humanos foi detectada em tecidos expostos a xenobióticos como brônquios, trato digestório e rins. Além disso, sua expressão vêm sendo descrita em vários tecidos neoplásicos (PÉREZ-TOMÁS, 2006).

A expressão da LRP está associada com uma baixa ou moderada resistência as drogas antineoplásicas (IZQUIERDO et al., 1996b), tais como doxorrubicina, mitoxantrona, vincristina e citarabina. Alguns estudos envolvendo núcleos celulares incubados com doxorrubicina, e outros com anticorpos antiMVP (Major Vaut Protein), mostraram que o núcleo com o anticorpo recebeu mais droga que o outro, provando a relação direta da proteína com o transporte de drogas e, consequentemente, com a resistência a ela (ZON et al., 2003; PEREZ-TOMAS, 2006).

Há alguns poucos estudos relacionados a LRP na Medicina Veterinária. Em um deles, Fukushima et al. (2016) avaliou a relação da expressão de LRP com a resistência a doxorrubicina em linfomas felinos, porém os autores não encontraram nenhuma associação. Em outro estudo, Hifumi et al. (2010) detectaram uma alta expressão de proteínas ligadas a resistência às múltiplas drogas, dentre elas a LRP, em carcinomas pulmonares em cães e gatos que apresentavam baixa resposta à quimioterapia. Não foi encontrada nenhuma informação sobre a expressão desta proteína em tumores mamários em cães e gatos.

\subsubsection{Metalotioneína}

A metalotioneína (MT), descoberta em 1957 por Margoshes e Vallee, tem baixo peso molecular, possui uma afinidade seletiva por metais pesados do grupo II e está presente em tecidos normais e neoplásicos, (THIRUMOORTHY et al., 2007). 
Mesmo com sua descoberta há mais de 60 anos, suas funções não estão completamente elucidadas. O que se sabe é seu papel essencial no metabolismo do zinco $(\mathrm{Zn})$ e cobre $(\mathrm{Cu})$, na homeostase dos íons de metais pesados e na proteção das células quanto ao estresse oxidativo. Ainda, descreve-se sua influência em processos de proliferação celular e apoptose, e seu envolvimento na carcinogênese durante a progressão e desenvolvimento de alguns tipos de cânceres (THEOCHARIS; MARGELI; KOUTSELINIS, 2003; JIN et al., 2004). A MT é essencial para a proteção celular contra os efeitos adversos provocados por metais pesados, já que mantém elementos como $\mathrm{Zn}$ e $\mathrm{Cu}$ em concentrações normais, além de controlar os radicais livres, que em desequilíbrio podem se tornar danosos e até levar ao surgimento de células neoplásicas (THIRUMOORTHY et al., 2007).

A expressão de MT já foi descrita em tecidos saudáveis de mama, colón, rim, fígado, pulmão, ovários, glândula salivar e tireoides. No caso de neoplasias mamárias em humanos, padrões específicos de expressão da MT são correlacionadas com um pior prognóstico, menor tempo de sobrevida e maior taxa de recidiva tumoral (CHERIAN; JAYASURYA; BAY, 2003; JIN et al., 2004; HIFUMI et al., 2010). Na veterinária, Dincer et al. (2001) avaliaram a expressão da MT em tumores de mama e melanomas cutâneos em cães e gatos. Dos 47 tumores mamários em felinos, 30\% dos tumores apresentam expressão de MT, de maneira similar aos resultados encontrados em tumores mamários humanos.

Durante a carcinogênese, a MT tem influência na proliferação e morte celular por ser ciclo-dependente. Alguns autores demostraram que existe um pico de MT durante as fases G1 e G1-S do ciclo celular, corroborando com o fato de participar da proliferação celular desordenada das neoplasias (THEOCHARIS; MARGELI; KOUTSELINIS, 2003; JIN et al., 2004). A marcação imunohistoquímica da MT, ora em citoplasma, ora em núcleo, corrobora com a afirmação de alguns autores que correlacionam sua expressão a determinadas fases do ciclo celular (GOMULKIEWICZ et al., 2010). Existe ainda a correlação da expressão de MT com células mioepiteliais, que secretam fatores de crescimento, tais como TGF- $\alpha$ e $\beta$ FGF, necessários na proliferação celular (DZIEGIEL, 2004). Ainda, a MT apresenta baixa concentração em tecido mamário normal, assim como em neoplasias lobulares e in situ em humanos. Porém, altas concentrações são encontradas em neoplasias ductais (JIN et al., 2004) 
As funções da MT em proteger as células contra o estresse oxidativo e a toxicidade de metais pode influenciar no crescimento e sobrevida tumoral, através de dois mecanismos principais. Um deles é doando o $\mathrm{Zn}$ durante a transcrição do gene p53, um conhecido gene supressor tumoral. Na presença do Zn, a MT facilita a transcrição normal do DNA; porém, em caso de depleção deste metal, pode haver uma ação reversa, causando dano ao DNA e, consequentemente, mutação no gene p53, favorecendo o crescimento celular desordenado (THEOCHARIS; MARGELI; KOUTSELINIS, 2003). O segundo mecanismo é devido sua propriedade de controle através do sequestro dos radicais livres (DINCER et al., 2001; CHERIAN; JAYASURYA; BAY, 2003).

Alguns autores apostam na MT como um marcador de proliferação celular, pois existe uma correlação entre esta proteína e o marcador Ki-67 (BAY et al., 2006). Ainda, esses autores observaram a expressão da MT em tumores mamários negativos para os receptores de estrógeno (ER), que sugere uma maior agressividade e pior prognóstico destes tumores. Estes achados correlacionam a presença da proteína com um alto potencial proliferativo e rápida progressão tumoral (DZIEGIEL, 2004; GOMULKIEWICZ et al., 2010).

Por conta do sequestro de radicais livres, drogas e seus metabólitos, a MT pode causar a inibição da interação dos agentes antineoplásicos com o alvo-celular, diminuindo seu efeito quimioterápico. A expressão in vivo da MT forma ligações covalentes com agentes alquilantes (Melfalan), favorecendo o fenômeno de resistência ao mesmo (CHERIAN, 1994). A cisplatina também apresenta resistência quando há expressão de MT em tumores sólidos, inativando a ação da droga (CHERIAN; JAYASURYA; BAY, 2003; THEOCHARIS; MARGELI; KOUTSELINIS, 2003; ARTICLE, 2004; JIN et al., 2004). 


\section{OBJETIVOS}

\subsection{OBJETIVO GERAL}

Avaliar a imunoexpressão de proteínas relacionadas com resistência à múltiplas drogas no carcinoma mamário em felinos e correlacionar estes achados com os dados clínico-epidemiológicos, anatomopatológicos e de sobrevida destes animais.

\subsection{OBJETIVOS ESPECÍFICOS}

3.2.1 Avaliar a imunoexpressão da Glicoproteína P (GlicoP), proteína relacionada a resistência de pulmão (LRP) e metalotioneína (MT) nos carcinomas mamários em felinos;

3.2.2 Correlacionar a imunoexpressão dos marcadores GlicoP, LRP e MT nos carcinomas mamários com os parâmetros clínico-epidemiológicos e anatomopatológicos destes animais;

3.2.3 Correlacionar a imunoexpressão dos marcadores GlicoP, LRP e MT nos carcinomas mamários com a sobrevida destes animais. 


\section{MATERIAL E MÉTODOS}

Este estudo foi desenvolvido no Laboratório de Patologia Morfológica e Molecular (LAPMOL), localizado no Departamento de Patologia (VPT) da Faculdade de Medicina Veterinária e Zootecnia (FMVZ) da Universidade de São Paulo (USP).

\subsection{CASUÍSTICA E DADOS CLÍNICO-EPIDEMIOLÓGICOS}

Foram analisados os tumores de mama provenientes de 46 gatas, as quais foram atendidas em Hospitais Veterinários Públicos e Particulares. Todos os animais foram submetidos ao procedimento cirúrgico para mastectomia uni ou bilateral, no período compreendido entre os anos de 2017 e 2018. Os dados clínicos e epidemiológicos desta população foram obtidos juntamente aos prontuários médicos e/ou tutores de cada animal, incluindo os parâmetros de idade, raça, peso, multiplicidade de lesões, dimensões e volume das lesões, presença de ulceração e/ou aderência, presença de metástases em linfonodos regionais ou à distância, status reprodutivo, uso de anticoncepcionais e tratamentos quimioterápicos neoadjuvantes. Após a mastectomia, as formações tumorais destes animais foram fotografadas e mensuradas em três dimensões (comprimento, profundidade e espessura, em $\mathrm{cm}$ ), com o auxílio de um paquímetro digital, sendo calculado seu volume $\left(\mathrm{cm}^{3}\right)$ pela multiplicação destes diâmetros. Fragmentos representativos de todas as lesões observadas, assim como das margens cirúrgicas e linfonodos regionais (inguinais e/ou axilares), foram coletados para avaliação histopatológica e imunohistoquímica.

Os tutores foram informados sobre o estudo através de explicações sobre os objetivos do projeto, assim como pela leitura e assinatura do Termo de Consentimento Livre e Esclarecido (TCLE), previamente aprovado pela Comissão de Ética no uso de animais da Faculdade de Medicina Veterinária e Zootecnia da Universidade de São Paulo (protocolo CEUA o 8835310817). 


\subsection{ESTADIAMENTO CLÍNICO}

O estadiamento clínico dos animais com carcinomas mamários foi realizado de acordo com o sistema preconizado pela OMS (OWEN; 1980), posteriormente adaptado para felinos (MORRIS, 2013), conhecido como TNM. Esse sistema consiste nos seguintes critérios principais: a) tamanho do tumor $(T)$, correspondente ao maior diâmetro do nódulo mamário; b) envolvimento dos linfonodos regionais $(\mathrm{N})$, comprovados por exame citológico ou histopatológico; e c) ocorrência de metástase à distância $(\mathrm{M})$. As variáveis do sistema TNM são apresentadas no Quadro 1.

Quadro 1- Sistema TNM modificado para o estadiamento clínico em felinos

\begin{tabular}{|llll|}
\hline $\begin{array}{l}\text { Estágio } \\
\text { Clínico }\end{array}$ & $\begin{array}{l}\text { Diâmetro } \\
\text { Tumoral (T) }\end{array}$ & $\begin{array}{l}\text { Comprometimento dos } \\
\text { Linfonodos Regionais (N) }\end{array}$ & $\begin{array}{l}\text { Metástases } \\
\text { Distantes (M) }\end{array}$ \\
\hline I & $<2 \mathrm{~cm}(\mathrm{~T} 1)$ & Negativo (N0) & Negativo (M0) \\
II & $2-3 \mathrm{~cm}(\mathrm{~T} 2)$ & Negativo (N0) & Negativo (M0) \\
III & $>3 \mathrm{~cm}(\mathrm{~T} 3)$ & Negativo ou Positivo (N0 ou N1) & Negativo (M0) \\
IV & $\leq 3 \mathrm{~cm}(\mathrm{~T} 1$ ou T2) & Positivo (N1) & Positivo (M1) \\
\hline
\end{tabular}

Fonte: Morris (2013)

\subsection{AVALIAÇÃO HISTOPATOLÓGICA}

\subsubsection{Classificação histopatológica}

Os fragmentos do tecido tumoral, margens e linfonodos foram fixados em solução de formalina $10 \%$, durante 24 horas. Posteriormente, as amostras foram processadas histologicamente e incluídas em parafina. Cortes de $5 \mu \mathrm{m}$ de cada amostra foram corados pela técnica de Hematoxilina e Eosina (HE), para avaliação histopatológica, a qual foi realizada de acordo com os critérios propostos pela OMS (MISDORP et al., 1999). No caso de animais com tumores múltiplos, todos os nódulos foram analisados e classificados separadamente. Nos tumores com mais de 
um padrão histopatológico no mesmo nódulo, foi considerado o subtipo predominante para a classificação final.

\subsubsection{Graduação histológica}

A graduação histológica foi realizada de acordo com o sistema de Nottinghann (Quadro 2), desenvolvido para uso em humanos, porém já validado e preconizado na espécie felina (ELSTON; ELLIS, 1991). Adicionalmente, a graduação histológica foi realizada por um sistema desenvolvido especificamente para os tumores mamários em felinos (Quadro 3), recentemente proposto por MILLS et al. (2015).

Quadro 1- Sistema de Nottingham utilizado para a graduação de tumores mamários em mulheres e em gatas

\begin{tabular}{|lll|}
\hline Variável & & Escore \\
\hline \multirow{3}{*}{ Formação tubular } & $>75 \%$ & 1 \\
& 10 a $75 \%$ & 2 \\
& $<10 \%$ & 3 \\
\hline \multirow{3}{*}{ Pleomorfismo nuclear } & Discreto & 1 \\
& Moderado & 2 \\
& Acentuado & 3 \\
\hline \multirow{3}{*}{ Contagem mitótica } & $0-8$ & 1 \\
& $9-16$ & 2 \\
\hline Score total & $>17$ & 3 \\
\hline $3-5$ & & Grau \\
$6-7$ & & I \\
$8-9$ & & II \\
\hline
\end{tabular}

Fonte: Adaptado de acordo com o tamanho do campo de microscopia utilizadas neste estudo $=0,55$ mm. Elston e Ellis $(1991,1998)$. 
Quadro 2- Novo sistema de graduação proposto para carcinomas mamários invasivos felinos

\begin{tabular}{|c|c|c|}
\hline Variáve & & Score \\
\hline \multicolumn{3}{|c|}{ Invasão vascular } \\
\hline & Ausente & 0 \\
\hline & Presente & 1 \\
\hline \multicolumn{2}{|c|}{ Forma nuclear* } & \\
\hline & $\leq 5 \%$ anormal & 0 \\
\hline & $>5 \%$ anormal & 1 \\
\hline \multicolumn{2}{|c|}{ Contagem mitótica $^{\star \star}$} & \\
\hline & $\leq 62$ & 0 \\
\hline & $>62$ & 1 \\
\hline \multicolumn{2}{|l|}{ Score } & Grau \\
\hline \multicolumn{2}{|l|}{0} & $\mathrm{I}$ \\
\hline \multicolumn{2}{|l|}{1} & II \\
\hline \multicolumn{2}{|l|}{$2-3$} & III \\
\hline
\end{tabular}

Fonte: Mills et al. (2015)

${ }^{*}$ A forma nuclear anormal inclui qualquer desvio de contorno nuclear liso ou forma nuclear redonda/oval, como fissura, angularidade, ondulação ou ameboide. Morfologia avaliada em grande aumento (objetivas de 40-60x) nas partes menos diferenciadas e/ou invasivas do tumor. O número de núcleos e a exibição da forma nuclear anormal é estimada e expressa como uma porcentagem do número total de núcleos dentro de qualquer campo.

** Número cumulativo de mitoses em 10 campos consecutivos na área mais ativamente proliferativas, com um diâmetro do campo do microscópio de 0,53 mm (objetiva de 40x).

\subsection{AVALIAÇÃO IMUNOHISTOQUÍMICA}

\subsubsection{Procedimento técnico}

Para a realização da imunohistoquímica, foram realizados cortes histológicos de $5 \mu \mathrm{m}$ de espessura nas amostras de pelo menos um tumor nos 46 animais selecionados. Os cortes histológicos foram desparafinizados, hidratados e submetidos ao desmascaramento antigênico em panela de pressão elétrica, $125^{\circ} \mathrm{C}$, durante 20 minutos, utilizando solução tampão citrato $(\mathrm{pH} \mathrm{6,0)}$ ou tampão Tris-EDTA ( $\mathrm{pH} 9,0)$. Posteriormente, as lâminas foram submetidas ao bloqueio da peroxidase endógena em solução de $\mathrm{H}_{2} \mathrm{O}_{2} 6 \%$ por 30 minutos, protegido da luz. Após lavagens em água corrente, água destilada e em tampão de lavagem TTBS, foi realizado 0 
bloqueio de proteína (Protein Block, Cod. SPD-125, Spring Bioscience, Plaeasanton, EUA) durante 10 minutos e em estufa entre 20 e $25^{\circ} \mathrm{C}$. Posteriormente, as lâminas foram incubadas com os anticorpos primários especificados na Tabela 1, diluídos em diluente de anticorpo (Cod. ADS 125, Spring Bioscience, Plaeasanton, EUA), pelo período de 16 horas (overnight), em câmara úmida escura e na geladeira $\left(4^{\circ} \mathrm{C}\right.$ ). Após incubação, as lâminas foram lavadas com tampão de lavagem TTBS e iniciado o sistema de visualização utilizando o kit Polímero Reveal HRP (Cod. SPD 125, Spring Bioscience, Plaeasanton, EUA). Primeiramente foi aplicado o Polímero Reveal HRP por 10 minutos, seguido pelo reagente HRP Conjugate HRP por 15 minutos, ambos em temperatura ambiente $\left(20-25^{\circ} \mathrm{C}\right)$. A seguir, as lâminas foram reveladas pelo cromógeno tetracloreto de 3-3' diaminobenzidina (DAB) por 5 minutos, em temperatura ambiente $\left(20-25^{\circ} \mathrm{C}\right)$. Após lavagens em água corrente $\mathrm{e}$ destilada, as lâminas foram contra coradas em Hematoxilina de Harris, lavadas em água corrente e destilada e realizados 2 banhos rápidos em água amoniacal $(0,5 \%)$. Por fim, as lâminas foram lavadas e submetidas à bateria de desidratação. Para montagem, foram utilizadas lamínulas coladas por Permount (ThermoFischer). Todas as reações foram acompanhadas de tecidos de felinos para o controle positivo de cada anticorpo. O controle negativo foi obtido pela omissão do anticorpo primário da reação.

\subsubsection{Classificação molecular}

A classificação molecular dos carcinomas de mama em felinos foi realizada segundo os critérios propostos por (Soares, Correia, et al., 2016; Soares, Madeira, et al., 2016; Soares, Ribeiro, et al., 2016), no qual o tumor foi considerado positivo para receptor de estrógeno $(\mathrm{RE})$ e/ou receptor de progesterona (RP) quando houvesse marcação em pelo menos $1 \%$ das células neoplásicas, com intensidade média ou forte. Para HER-2, o tumor foi considerado positivo quando as células neoplásicas apresentassem escores +2 ou +3 de marcação, sendo o primeiro caracterizado por marcação completa da membrana, mesmo que não uniforme ou fraca, com distribuição em pelo menos $10 \%$ das células; e o segundo caracterizado por marcação intensa e uniforme em pelo menos $10 \%$ das células invasivas do tumor. Para as CK5/6, o tumor foi considerado positivo quando houvesse marcação 
citoplasmática ou membranosa em pelo menos $1 \%$ das células neoplásicas. Quanto ao Ki-67, o tumor foi considerado com alta proliferação no caso de positividade em mais de $14 \%$ das células, as quais foram contadas as células marcadas em um total de 1000 células (objetiva de 100x). Baseado nos resultados destes marcadores moleculares, os subtipos tumorais foram classificados de acordo com os critérios estabelecidos por SOARES et al. (2016) e apresentados no quadro 4.

Tabela 1- Condições e reagentes para as reações de imunohistoquímica em tecido de felinos. São Paulo, 2019

\begin{tabular}{llllll}
\hline Marcador & Marca & Clone & $\begin{array}{l}\text { Desmascaramento } \\
\text { antigênico }\end{array}$ & $\begin{array}{l}\text { Diluição } \\
\text { anticorpo }\end{array}$ & $\begin{array}{l}\text { Tecido } \\
\text { controle* }\end{array}$ \\
\hline RE & Leica & 6F11 & Tampão Citrato $(\mathrm{pH} \mathrm{6,0)}$ & $1: 500$ & $\begin{array}{l}\text { Utero } \\
\text { RP }\end{array}$ \\
S Cruz & C-19 & Tampão Citrato $(\mathrm{pH} \mathrm{6,0)}$ & $1: 2000$ & Útero \\
HER-2 & Dako & - & Tampão Citrato $(\mathrm{pH} \mathrm{6,0)}$ & $1: 200$ & CA \\
Ki-67 & Dako & MIB-1 & Tampão Citrato $(\mathrm{pH} \mathrm{6,0)}$ & $1: 2000$ & Mama \\
CK 5/6 & Leica & XM26 & Tampão Citrato $(\mathrm{pH} \mathrm{6,0)}$ & $1: 100$ & Pele \\
Glico-P & S Cruz & - & Tampão Citrato $(\mathrm{pH} \mathrm{6,0)}$ & $1: 100$ & Fígado \\
MT & Dako & E9 & Tampão Tris-EDTA $(\mathrm{pH} \mathrm{9,0)}$ & $1: 300$ & Rim \\
LRP & S Cruz & 1014 & Tampão Tris-EDTA $(\mathrm{pH} \mathrm{9,0)}$ & $1: 500$ & Rim \\
\hline
\end{tabular}

RE: Receptor de estrógeno; RP: receptor de progesterona; HER-2: fator de crescimento epidernal-2; CK: citoqueratina; Glico-P: Glicoproteína P; LRP: proteína de resistência pulmonar; MT: metalotioneína. S Cruz: Santa Cruz; CA: carcinoma. *Tecidos de felinos.

Quadro 4- Classificação molecular dos subtipos de tumores de mama em felinos

\begin{tabular}{|c|c|c|c|c|c|c|}
\hline & \multirow[b]{2}{*}{ Luminal A } & \multicolumn{2}{|c|}{ Luminal B } & \multirow{2}{*}{$\begin{array}{c}\text { HER-2 } \\
\text { positivo }\end{array}$} & \multicolumn{2}{|c|}{ Triplo Negativo } \\
\hline & & HER-2 - & HER-2 + & & $\begin{array}{l}\text { "Basal } \\
\text {-like" }\end{array}$ & $\begin{array}{c}\text { "Normal- } \\
\text { like" }\end{array}$ \\
\hline RE & + e/ou RP+ & + e/ou RP+ & + e/ou RP+ & - & - & - \\
\hline RP & + e/ou RE+ & + e/ou RE+ & + e/ou RE+ & - & - & - \\
\hline HER-2 & - & - & + & + & - & - \\
\hline CK5/6 & indiferente & indiferente & indiferente & indiferente & + & - \\
\hline Ki-67 & $<14 \%$ & $>14 \%$ & ns & $\mathrm{ns}$ & $\mathrm{ns}$ & Ns \\
\hline
\end{tabular}

Fonte: Soares et al. (2016b, 2016c). RE: Receptor de estrógeno; RP: receptor de progesterona; HER2: fator de crescimento epidernal-2; CK: citoqueratina; ns: não significativo. 


\subsubsection{Avaliação das proteínas de resistência à múltiplas drogas}

Para a avaliação semi-quantitativa das proteínas de resistência à múltiplas drogas (Tabela 1), as lâminas de imuno-histoquímica dos carcinomas mamários felinos selecionados foram observadas em microscópio de luz, na objetiva de 40x (Leica Microsystems, Wetzlar, Alemanha). As lâminas foram avaliadas por três observadores independentes, de maneira cega, em relação ao percentual de células neoplásicas positivas para cada proteína, assim como sua intensidade de marcação. Os parâmetros de avaliação e os escores de cada proteína são descritos nos tópicos seguintes:

\subsubsection{Glicoproteína-P}

O padrão de marcação imunohistoquímica da Glicoproteína-P foi avaliado no citoplasma e membrana das células neoplásicas dos carcinomas mamários felinos, em pelo menos 10 campos aleatórios, de acordo com os critérios estabelecidos por KIM et al. (2012). O escore final foi determinado pela multiplicação dos escores semi-quantitativos de intensidade de marcação e porcentagem de células neoplásicas marcadas (Quadro 5), sendo então classificados em expressão fraca (1), moderada (2) ou intensa (3).

Quadro 5- Classificação semi-quantitativa do marcador imunohistoquímico Glicoproteína-P

\begin{tabular}{|llll|}
\hline $\begin{array}{l}\text { Intensidade de } \\
\text { marcação }\end{array}$ & Escore & $\begin{array}{l}\text { Porcentagem de células } \\
\text { Positivas }\end{array}$ & Escore \\
\hline Ausente & 0 & $<20 \%$ & 1 \\
Fraca & 1 & 20 a $50 \%$ & 2 \\
Moderada & 2 & $>50 \%$ & 3 \\
Intensa & 3 & & \\
\hline Escore Final & & \\
\hline Escore & Multiplicação dos & Expressão \\
\hline 1 & escores & Fraca \\
2 & $\leq 2$ & Moderada \\
3 & 3 ou 4 & Intensa \\
\hline
\end{tabular}

Fonte: Kim et al. (2012) 


\subsubsection{Proteína de resistência pulmonar (LRP)}

O padrão de marcação imunohistoquímica da proteína de resistência pulmonar (LRP) foi avaliado nas células neoplásicas dos carcinomas mamários felinos, em pelo menos 10 campos aleatórios, de acordo com os critérios estabelecidos por RUDAS et al. (2003). O escore final foi determinado pela multiplicação dos escores semi-quantitativos de intensidade de marcação e porcentagem de células neoplásicas marcadas (Quadro 6), sendo então classificados em expressão fraca (1), moderada (2) ou intensa (3).

Quadro 6- Classificação semi-quantitativa do marcador imunohistoquímico LRP

\begin{tabular}{|llll|}
\hline $\begin{array}{l}\text { Intensidade de } \\
\text { marcação }\end{array}$ & Escore & $\begin{array}{l}\text { Porcentagem de células } \\
\text { Positivas }\end{array}$ & Escore \\
\hline Ausente & 0 & $\leq 10 \%$ & 1 \\
Fraca & 1 & 11 a $30 \%$ & 2 \\
Moderada & 2 & 31 a $69 \%$ & 3 \\
Intensa & 3 & $\geq 70 \%$ & 4 \\
\hline Escore Final & \multicolumn{3}{|l}{} \\
\hline Escore & Multiplicação dos & Expressão \\
\hline 1 & escores & Fraca \\
2 & $\leq 2$ & Moderada \\
3 & 3 ou 4 & Intensa & \\
\hline
\end{tabular}

Fonte: Rudas et al. (2003)

\subsubsection{Metalotioneína}

O padrão de marcação imunohistoquímica da metalotioneína foi avaliado no citoplasma e núcleos das células neoplásicas dos carcinomas mamários felinos, em pelo menos 10 campos aleatórios, de acordo com os critérios estabelecidos por ERGINSOY et al. (2006). O escore final foi determinado pela multiplicação dos escores semi-quantitativos de intensidade de marcação e porcentagem de células neoplásicas marcadas (Quadro 7), sendo então classificados em expressão fraca (1), moderada (2) ou intensa (3). 
Quadro 7- Classificação semi-quantitativa do marcador imunohistoquímico metalotioneína

\begin{tabular}{|llll|}
\hline $\begin{array}{l}\text { Intensidade de } \\
\text { marcação }\end{array}$ & Escore & $\begin{array}{l}\text { Porcentagem de células } \\
\text { Positivas }\end{array}$ & Escore \\
\hline Ausente & 0 & $\leq 25 \%$ & 1 \\
Fraca & 1 & 26 a $50 \%$ & \\
Moderada & 2 & 51 a $74 \%$ & 2 \\
Intensa & 3 & $\geq 75 \%$ & 3 \\
\hline Escore Final & \multicolumn{3}{l}{} \\
\hline Escore & Multiplicação dos & Expressão \\
\hline 1 & escores & Fraca \\
2 & $\leq 2$ & Moderada \\
3 & 3 ou 4 & Intensa \\
\hline
\end{tabular}

Fonte: Erginsoy et al. (2006)

\subsection{SEGUIMENTO CLÍNICO E SOBREVIDA}

O seguimento clínico foi realizado para avaliação da sobrevida através de acompanhamento dos prontuários médicos e contato telefônico com os tutores responsáveis pelos animais. O tempo de sobrevida foi calculado em dias e considerou o período entre a data da cirurgia até o óbito relacionado ou não à doença. Aqueles animais cujos tutores estiveram inacessíveis e/ou as informações necessárias não foram obtidas, foram censurados da análise de sobrevida. Os óbitos foram atribuídos à neoplasia mamária em caso de morte natural ou eutanásia decorrentes de progressão da doença/metástase, e apenas em casos em que a metástase não pudesse ser atribuída a outro processo neoplásico concomitante. Não foi realizada necropsia em nenhum dos animais envolvidos neste estudo.

\subsection{ANÁLISE ESTATÍSTICA}

A análise estatística dos dados foi realizada no sistema SPSS (Statistical Package for the Social Sciences, Chicago, IL, EUA) versão 24.0. Os resultados foram expressos em frequências absolutas e relativas e, para as variáveis quantitativas foi efetuada a estatística descritiva com o cálculo da média, desvio padrão, erro padrão, valores máximo e mínimo. A relação entre as variáveis categóricas foi realizada recorrendo ao teste do Qui-quadrado (X2) com recurso ao 
teste exato de Fisher sempre que apropriado. A análise de sobrevida foi realizada pelo método de Kaplan-Meier e as diferenças entre as variáveis em estudo foram analisadas pelo teste de Log-rank. O nível de significância usado para todos os testes foi $\alpha=5 \%$, ou seja, um valor de $p<0,05$ foi considerado estatisticamente significativo. 


\section{RESULTADOS}

\subsection{CARACTERIZAÇÃO CLÍNICO-EPIDEMIOLÓGICA E ANATOMOPATOLÓGICA}

Foi avaliada uma lesão tumoral representativa de cada um dos 46 animais, cujas principais características clínico-epidemiológicas e anatomopatológicas estão descritas na tabela 2. Dentre as raças, a predominância deste estudo foi de animais sem raça definida (SRD), com $37(80,4 \%)$ pacientes, seguidos por animais das raças Siamês $6(13,1 \%)$ e Persa $3(6,5 \%)$. Em relação a idade, os animais apresentaram média de 12,15 $\pm 2,8(6-18)$ anos, com mediana de 12 anos. Os animais apresentaram peso médio de $3,9 \pm 1,8(2-13,7) \mathrm{Kg}$, com mediana de $3,5 \mathrm{Kg}$. Em relação ao sexo, todos os pacientes eram fêmeas. $O$ status reprodutivo foi informado em 43 gatas, sendo $33(76,7 \%)$ castradas e $10(23,3 \%)$ inteiras no momento do procedimento cirúrgico. $\mathrm{O}$ uso de progestágenos exógenos foi mencionado pelos tutores em 33 pacientes, sendo que $24(72,7 \%)$ negaram o uso e $9(27,3 \%)$ afirmaram terem aplicado o hormônio em algum momento.

A determinação das mamas acometidas pelos tumores só foi possível em 23 pacientes, sendo que $11(47,8 \%)$ foram acometidas nas mamas abdominais, 9 $(39,1 \%)$ nas mamas torácicas e $3(13 \%)$ nas mamas inguinais. Em relação ao número de nódulos por paciente, a proporção se estabeleceu igualmente entre os animais com tumores únicos (50\%) ou múltiplos (50\%). O tamanho dos nódulos foi obtido em 45 casos, sendo distribuídos em 20 (44,5\%) pacientes com tumores maiores do que $3 \mathrm{~cm}$ (T3), seguido por 11 (24,4\%) pacientes com tumores entre $2 \mathrm{e}$ $3 \mathrm{~cm}$ (T2), e, finalmente, $14(31,1 \%)$ pacientes com tumores menores do que $2 \mathrm{~cm}$ (T1). Em relação ao volume tumoral, estes mesmos 45 pacientes apresentaram volume médio de $25,8 \pm 36,52(0,13-133) \mathrm{cm}^{3}$ e mediana de $10,5 \mathrm{~cm}^{3}$. A presença ou não de ulceração foi avaliada em 36 pacientes, dos quais $16(44,5 \%)$ pacientes apresentaram ulceração tumoral. Informação sobre aderência dos tumores estava presente em 31 casos, dos quais 26 (86,8\%) tumores não apresentaram aderência e $5(13,2 \%)$ estavam aderidos à musculatura.

Em relação aos linfonodos regionais, coube aos cirurgiões retirá-los no momento da mastectomia, de acordo com o preconizado em cada caso. Do total, obtivemos informações sobre os linfonodos regionais em 33 pacientes, dos quais 19 
(57,5\%) apresentaram linfonodos comprometidos com células neoplásicas ao exame histopatológico e $14(42,5 \%)$ não apresentaram qualquer vestígio de infiltração neoplásica. Exames sugestivos de metástase a distância estavam disponíveis em 40 pacientes, dos quais as metástases foram detectadas em 13 (28,3\%) animais, enquanto $27(58,7 \%)$ animais não apresentaram sinais de metástase. Considerando as informações presentes de comprometimento dos linfonodos regionais e metástases à distância, o estadiamento pelo sistema TNM foi realizado em 33 pacientes, dos quais $4(12,1 \%)$ foram classificadas como estágio I, 1 (3,1\%) como estágio II, 16 (48,5\%) como estágio III e 12 (36,3\%) como estágio IV.

Em relação aos aspectos anatomopatológicos, a avaliação histopatológica de 46 lesões tumorais revelou $20(43,5 \%)$ carcinomas cribiformes, 14 (30,4\%) carcinomas túbulo-papilares e $12(26,1 \%)$ carcinomas sólidos. A invasão neoplásica em derme foi analisada em 40 casos, dos quais 15 (37,5\%) apresentaram invasão dérmica e os demais 25 (62,5\%) casos não apresentaram invasão tecidual. Todos os tumores foram graduados pelos sistemas de Notthinghann (Elston e Ellis et al., 1991), desenvolvidos para mulheres, e de Mills et al. (2005), proposto especificamente para os carcinomas felinos. Pelo sistema de Notthinghann, os tumores grau II foram predominantes nos animais desse estudo, representado por $24(52,2 \%)$ casos, seguidos pelo grau III em $21(45,7 \%)$ casos e o grau I apresentou apenas $1(2,2 \%)$ caso. O sistema de graduação proposto por Mills et al. (2005) seguiu o mesmo padrão, com $22(47,8 \%)$ casos graduados como grau II, seguidos pelo grau III em 16 (34,8\%) casos e, finalmente, pelo grau I em $8(17,4 \%)$ casos. Após a classificação imunohistoquímica dos carcinomas de mama em subtipos moleculares, foram observados $17(37 \%)$ casos triplo negativo "normal like", 14 $(30,4 \%)$ casos triplo negativo "basal like", 8 (17,4\%) casos HER2 positivo, 6 (13\%) casos luminal B HER2 negativo e 1 (2,2\%) caso luminal B HER2 positivo.

Todos as pacientes foram submetidas ao procedimento cirúrgico de mastectomia, sendo que $4(8,7 \%)$ gatas realizaram a mastectomia unilateral; enquanto as demais $42(91,3 \%)$ gatas foram submetidas à mastectomia bilateral (radical). Dados sobre o seguimento estavam disponíveis em 26 animais, dos quais $13(50 \%)$ pacientes realizaram quimioterapia adjuvante, enquanto $13(50 \%)$ optaram por não realizar o tratamento quimioterápico. Das pacientes que optaram pela quimioterapia, $8(61,5 \%)$ fizeram uso da doxorrubicina e $5(38,4 \%)$ da carboplatina. 
Tabela 2- Dados descritivos das características clínico-epidemiológicas e anatomopatológicas de 46 gatas diagnosticadas com carcinomas mamários. São Paulo, 2019.

\begin{tabular}{|c|c|c|c|}
\hline Características & $\mathbf{N}$ & $\%$ do Total & Valor $P$ \\
\hline \multicolumn{4}{|l|}{ Raças $(\mathrm{N}=46)$} \\
\hline$S R D$ & 37 & 80,4 & \multirow{3}{*}{$<0,001$} \\
\hline Siamês & 6 & 13,1 & \\
\hline Persa & 3 & 6,5 & \\
\hline \multicolumn{4}{|c|}{ Status reprodutivo $(\mathrm{N}=43)$} \\
\hline Castrada & 33 & 76,7 & \multirow[t]{2}{*}{$<0,001$} \\
\hline Inteira & 10 & 23,3 & \\
\hline \multicolumn{4}{|c|}{ Uso de progestágenos $(\mathrm{N}=33)$} \\
\hline Sim & 9 & 27,3 & \multirow[t]{2}{*}{0,009} \\
\hline Não & 24 & 72,7 & \\
\hline \multicolumn{4}{|l|}{ Multiplicidade $(\mathrm{N}=46)$} \\
\hline Único & 23 & 50 & \multirow[t]{2}{*}{1,000} \\
\hline Múltiplo & 23 & 50 & \\
\hline \multicolumn{4}{|l|}{ Tamanho $(\mathrm{N}=45)$} \\
\hline$T 1$ & 14 & 31,1 & \multirow{3}{*}{0,247} \\
\hline$T 2$ & 11 & 24,4 & \\
\hline T3 & 20 & 44,5 & \\
\hline \multicolumn{4}{|l|}{ Ulceração (N=36) } \\
\hline Sim & 16 & 44,5 & \multirow[t]{2}{*}{0,505} \\
\hline Não & 20 & 55,5 & \\
\hline \multicolumn{4}{|l|}{ Aderência $(\mathrm{N}=31)$} \\
\hline Sim & 5 & 13,2 & \multirow[t]{2}{*}{0,001} \\
\hline Não & 26 & 86,8 & \\
\hline \multicolumn{4}{|c|}{ Metástase em linfonodo ( $\mathrm{N}=33$ ) } \\
\hline Sim & 19 & 57,5 & \multirow{2}{*}{0,384} \\
\hline Não & 14 & 42,5 & \\
\hline \multicolumn{4}{|c|}{ Metástase à distância $(\mathrm{N}=40)$} \\
\hline Sim & 13 & 32,5 & \multirow[t]{2}{*}{0,027} \\
\hline Não & 27 & 67,5 & \\
\hline \multicolumn{4}{|l|}{ Estágio clínico $(\mathrm{N}=33)$} \\
\hline I & 4 & 12,1 & \multirow{4}{*}{0,001} \\
\hline II & 1 & 3,1 & \\
\hline III & 16 & 48,5 & \\
\hline IV & 12 & 36,3 & \\
\hline \multicolumn{4}{|c|}{ Tipos Histológicos $(\mathrm{N}=46)$} \\
\hline Sólido & 12 & 26,1 & \multirow{3}{*}{0,323} \\
\hline Túbulo-papilar & 14 & 30,4 & \\
\hline Cribiforme & 20 & 43,5 & \\
\hline \multicolumn{4}{|l|}{ Invasão Dérmica $(\mathrm{N}=40)$} \\
\hline Sim & 15 & 37,5 & \\
\hline Não & 25 & 62,5 & \\
\hline
\end{tabular}


Continuação

\begin{tabular}{lccc}
\hline Características & N & \% do Total & Valor $\boldsymbol{P}$ \\
\hline Graduação E\&E (N=46) & 1 & & \\
Grau I & 24 & 52,2 & $\mathbf{0 , 0 0 1}$ \\
Grau II & 21 & 45,7 & \\
Grau III & 8 & 17,4 & \\
\hline Graduação Mills (N=46) & 22 & 47,8 & 0,04 \\
Grau I & 16 & 34,8 & \\
Grau II & & & \\
Grau III & 6 & 13 & \\
Subtipo Molecular (N=46) & 1 & 2,2 & \\
Luminal B HER2 (-) & 8 & 17,4 & \\
Luminal B HER2 (+) & 14 & 30,4 & \\
HER2 (+) & 17 & 37 & \\
TNBL & & & \\
TNNL & 42 & 91,3 & $\mathbf{0 , 0 0 1}$ \\
\hline Mastectomia (N=46) & 4 & 8,7 & \\
Bilateral & & & \\
Unilateral & 13 & 50 & 1,0 \\
\hline Quimioterapia (N=26) & 13 & 50 & \\
Sim & & & \\
Não & &
\end{tabular}

Fonte: Manoel, V. C. (2019).

SRD: sem raça definida; E\&E: Elston \& Elis; TNBL: triplo negativo "basal-like"; TNNL: triplo negativo "normal-like"; HER2: receptor 2 do fator de crescimento epidérmico humano.

\subsection{MARCADORES DE RESISTÊNCIA À MÚLTIPLAS DROGAS}

Os escores da imunoexpressão das proteínas de resistência à múltiplas drogas (GlicoP, LRP e MT) encontram-se sumarizados na tabela 3, assim como as avaliações individuais quanto a porcentagem e intensidade de células marcadas para cada amostra encontram-se descritas na tabela 4.

A glicoproteína $\mathrm{P}$ apresentou imunomarcação com padrão, predominantemente, em membrana celular (Figura 1). A imunoexpressão de GlicoP foi considerada intensa em $21(47,7 \%)$ casos, moderada em 7 (15,2\%) casos, seguida por discreta marcação em 15 (32,6\%) casos e negativa em $3(6,5 \%)$ casos. A LRP demonstrou marcação em todos os 46 casos, sendo que $22(47,8 \%)$ apresentaram marcação intensa, seguida por 18 (39,1\%) com marcação moderada e 6 (13\%) com marcação considerada discreta. A imunoexpressão da LRP foi, 
predominantemente, membranosa nas células neoplásicas dos carcinomas mamários (Figura 2). Por fim, a análise da MT demonstrou uma marcação grosseira citoplasmática, por vezes também foi detectada marcação nuclear (Figura 3). A marcação intensa da MT foi detectada em 3 (6,5\%) casos, moderada em 18 (39,1\%) casos, discreta em $21(45,7 \%)$ casos e negativa em $4(8,7 \%)$ casos analisados.

Tabela 3- Avaliação imunohistoquímica semiquantitativa (escores de imunoexpressão) dos marcadores de resistência à múltiplas drogas em 46 carcinomas mamários em felinos. São Paulo, 2019.

\begin{tabular}{lccc}
\hline Escore de Imunoexpressão & $\mathbf{N}$ & \% do total & Valor $\boldsymbol{P}$ \\
\hline Glicoproteína P & 3 & 6,5 & \\
(0) Negativo & 15 & 32,6 & $\mathbf{0 , 0 0 1}$ \\
(1) Discreto & 7 & 15,2 & \\
(2) Moderado & 21 & 45,6 & \\
(3) Intenso & & & \\
\hline LRP & 0 & 0 & \\
(0) Negativo & 6 & 13,1 & $<\mathbf{0 , 0 0 1}$ \\
(1) Discreto & 18 & 39,1 & \\
(2) Moderado & 22 & 47,8 & \\
(3) Intenso & & & \\
\hline Metalotioneina & 4 & 8,7 & \\
(0) Negativo & $\mathbf{0 , 0 1 1}$ \\
(1) Discreto & 18 & 45,7 & \\
(2) Moderado & 3 & $6,5,1$ & \\
(3) Intenso & & & \\
\hline
\end{tabular}

Fonte: Manoel, V. C. (2019).

Tabela 4- Descrição das avaliações imunohistoquímicas dos marcadores de resistência à múltiplas drogas em 46 carcinomas mamários em felinos. São Paulo, 2019.

\begin{tabular}{c|cc|c|ccc|c|c|c}
\hline \multirow{2}{*}{ Animal } & \multicolumn{3}{|c|}{ GlicoP } & \multicolumn{3}{c|}{ LRP } & \multicolumn{3}{c}{ MT } \\
& $\%$ & I & E & $\%$ & I & E & $\%$ & I & E \\
\hline $\mathbf{1}$ & 40 & 1 & 1 & 80 & 3 & 3 & 30 & 3 & 1 \\
\hline $\mathbf{2}$ & 80 & 2 & 3 & 90 & 3 & 3 & 10 & 3 & 1 \\
\hline $\mathbf{3}$ & 70 & 1 & 3 & 70 & 2 & 3 & 20 & 2 & 2 \\
\hline $\mathbf{4}$ & 0 & 0 & 0 & 80 & 3 & 3 & 20 & 2 & 2 \\
\hline $\mathbf{5}$ & 30 & 3 & 1 & 80 & 2 & 2 & 10 & 3 & 1 \\
\hline $\mathbf{6}$ & 40 & 2 & 2 & 20 & 2 & 2 & 40 & 3 & 1 \\
\hline $\mathbf{7}$ & 50 & 2 & 2 & 20 & 2 & 2 & 10 & 2 & 1 \\
\hline $\mathbf{8}$ & 70 & 2 & 3 & 80 & 2 & 3 & 5 & 2 & 1 \\
\hline $\mathbf{9}$ & 60 & 3 & 3 & 30 & 2 & 2 & 20 & 3 & 2 \\
\hline
\end{tabular}




\begin{tabular}{|c|c|c|c|c|c|c|c|c|c|}
\hline 10 & 10 & 1 & 1 & 50 & 2 & 3 & 5 & 2 & 1 \\
\hline 11 & 60 & 2 & 3 & 40 & 2 & 2 & 50 & 2 & 2 \\
\hline 12 & 5 & 2 & 1 & 70 & 2 & 2 & 10 & 2 & 1 \\
\hline 13 & 30 & 2 & 1 & 60 & 1 & 2 & 20 & 2 & 2 \\
\hline 14 & 50 & 1 & 3 & 70 & 2 & 3 & 20 & 3 & 1 \\
\hline 15 & 70 & 3 & 3 & 50 & 2 & 2 & 20 & 3 & 1 \\
\hline 16 & 0 & 0 & 0 & 60 & 2 & 3 & 5 & 1 & 2 \\
\hline 17 & 40 & 2 & 2 & 40 & 2 & 3 & 10 & 3 & 2 \\
\hline 18 & 60 & 3 & 1 & 90 & 3 & 2 & 30 & 3 & 2 \\
\hline 19 & 50 & 1 & 2 & 60 & 2 & 3 & 20 & 3 & 2 \\
\hline 20 & 20 & 2 & 1 & 70 & 3 & 1 & 30 & 2 & 1 \\
\hline 21 & 20 & 1 & 1 & 30 & 1 & 1 & 20 & 3 & 1 \\
\hline 22 & 40 & 4 & 3 & 70 & 2 & 2 & 20 & 3 & 2 \\
\hline 23 & 20 & 2 & 3 & 30 & 2 & 2 & 10 & 2 & 2 \\
\hline 24 & 20 & 2 & 1 & 30 & 2 & 2 & 50 & 2 & 2 \\
\hline 25 & 80 & 2 & 3 & 75 & 2 & 2 & 25 & 3 & 2 \\
\hline 26 & 10 & 2 & 1 & 40 & 1 & 2 & 20 & 2 & 1 \\
\hline 27 & 0 & 0 & 0 & 69 & 1 & 2 & 50 & 2 & 2 \\
\hline 28 & 70 & 3 & 3 & 80 & 2 & 3 & 40 & 2 & 2 \\
\hline 29 & 10 & 1 & 1 & 50 & 1 & 2 & 60 & 3 & 3 \\
\hline 30 & 80 & 2 & 3 & 85 & 2 & 3 & 50 & 1 & 1 \\
\hline 31 & 5 & 2 & 1 & 30 & 1 & 1 & 40 & 2 & 2 \\
\hline 32 & 40 & 3 & 3 & 30 & 1 & 1 & 10 & 1 & 1 \\
\hline 33 & 51 & 2 & 3 & 70 & 2 & 3 & 80 & 3 & 3 \\
\hline 34 & 75 & 2 & 3 & 80 & 2 & 3 & 50 & 1 & 1 \\
\hline 35 & 80 & 2 & 3 & 90 & 3 & 3 & 10 & 2 & 1 \\
\hline 36 & 30 & 2 & 2 & 60 & 2 & 3 & 25 & 2 & 1 \\
\hline 37 & 65 & 3 & 3 & 60 & 3 & 3 & 25 & 2 & 1 \\
\hline 38 & 85 & 1 & 2 & 95 & 3 & 3 & 5 & 1 & 1 \\
\hline 39 & 19 & 2 & 1 & 30 & 2 & 2 & 45 & 3 & 3 \\
\hline 40 & 75 & 2 & 3 & 95 & 3 & 3 & 0 & 0 & 0 \\
\hline 41 & 60 & 2 & 3 & 20 & 1 & 1 & 40 & 2 & 2 \\
\hline 42 & 40 & 2 & 2 & 95 & 2 & 3 & 0 & 0 & 0 \\
\hline 43 & 50 & 1 & 1 & 30 & 1 & 1 & 10 & 2 & 1 \\
\hline 44 & 90 & 3 & 3 & 60 & 2 & 3 & 10 & 3 & 2 \\
\hline 45 & 19 & 1 & 1 & 30 & 2 & 2 & 0 & 0 & 0 \\
\hline 46 & 90 & 3 & 3 & 60 & 3 & 3 & 0 & 0 & 0 \\
\hline
\end{tabular}

Fonte: Manoel, V. C. (2019).

$\%$ : porcentagem de células marcadas. I: intensidade de células marcadas. E: Escore total - resultado do produto das variáveis anteriores. 
Figura 1- Marcação imunohistoquímica para Glicoproteína P em carcinomas mamários felinos
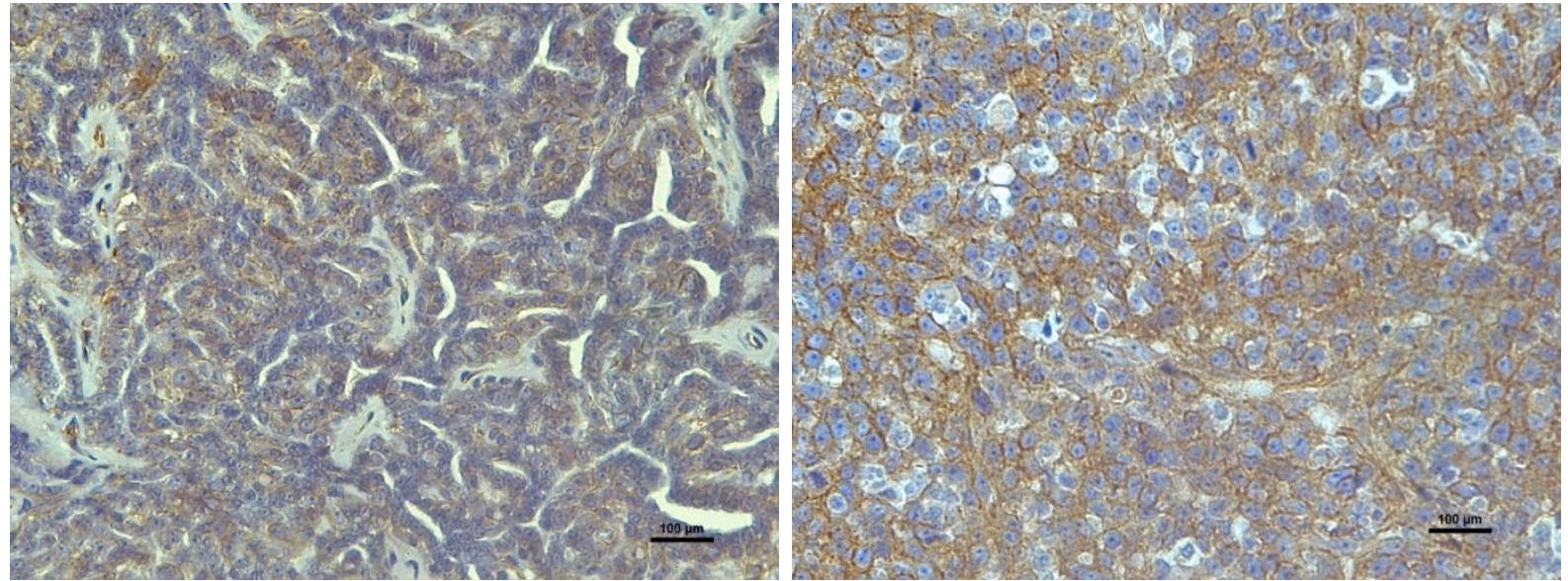

Fonte: Manoel, V. C. (2019).

A) Baixa imunoexpressão de Glicoproteina $\mathrm{P}$ em tumor mamário felino. B) Alta imunoexpressão de Glicoproteina P em tumor mamário felino. Obj. 40x.

Figura 2- Marcação imunohistoquímica para LRP em carcinomas mamários felinos
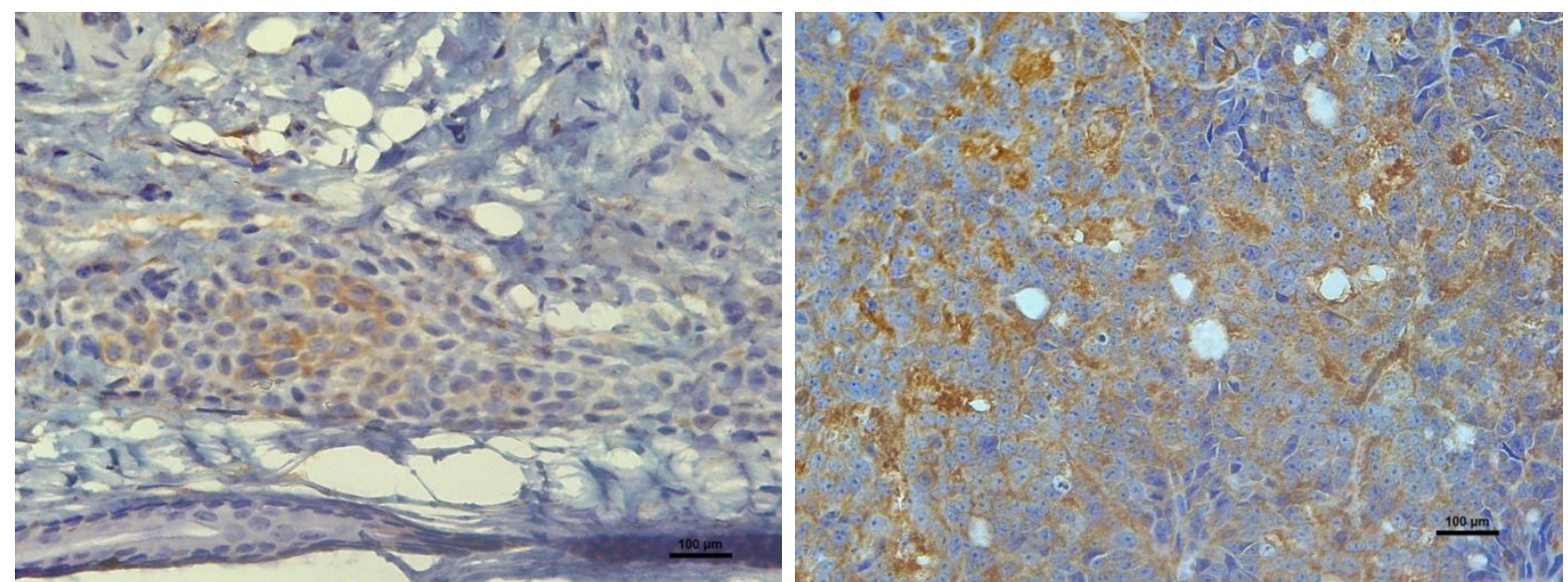

Fonte: Manoel, V. C. (2019).

A) Baixa imunoexpressão de LRP em tumor mamário felino. B) Alta imunoexpressão de LRP em tumor mamário felino. Obj. 40x.

Figura 3- Marcação imunohistoquímica para Metalotioneína em carcinomas mamários felinos
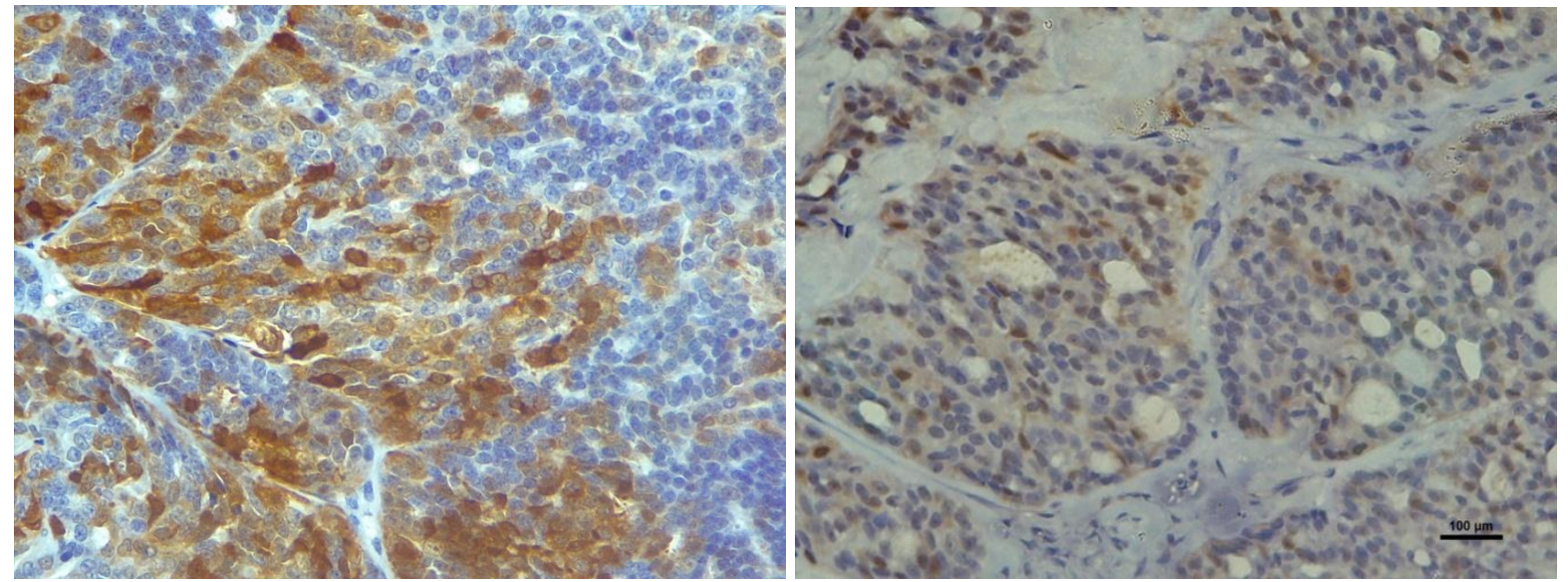

Fonte: Manoel, V. C. (2019).

A) Imunoxpressão citoplasmática de Metalotioneína em tumor mamário felino. B) Imunoexpressão nuclear de Metalotioneína em tumor mamário felino. (obj. 40x). 
$\mathrm{Na}$ figura 4, observa-se que pelo menos duas proteínas foram identificadas em todos os tumores analisados. Ou seja, nenhuma amostra apresentou apenas um ou nenhum marcador de resistência à múltiplas drogas. Do total, $85 \%$ dos tumores apresentaram imunoexpressão das 3 proteínas, concomitantemente, enquanto $15 \%$ apresentaram somente a expressão de duas proteínas. A LRP este presente em todos os tumores. Em relação aos escores, a maioria das neoplasias apresentou intensa imunoexpressão para GlicoP (45,6\%) e LRP (47,8\%), porém discreta expressão para MT (45,7\%) (Figura 5).

Figura 4- Expressão simultânea das proteínas de resistência à múltiplas drogas nos 46 carcinomas mamários felinos.

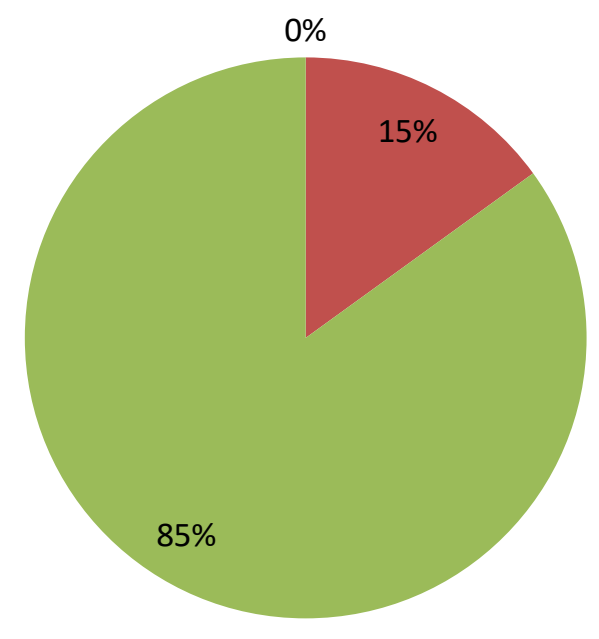

Um marcador

Dois marcadores

Três marcadores

Fonte: Manoel, V. C. (2019).

Figura 5- Porcentagens equivalentes aos escores de imunoexpressão das proteínas de resistência à múltiplas drogas nos 46 carcinomas mamários felinos.

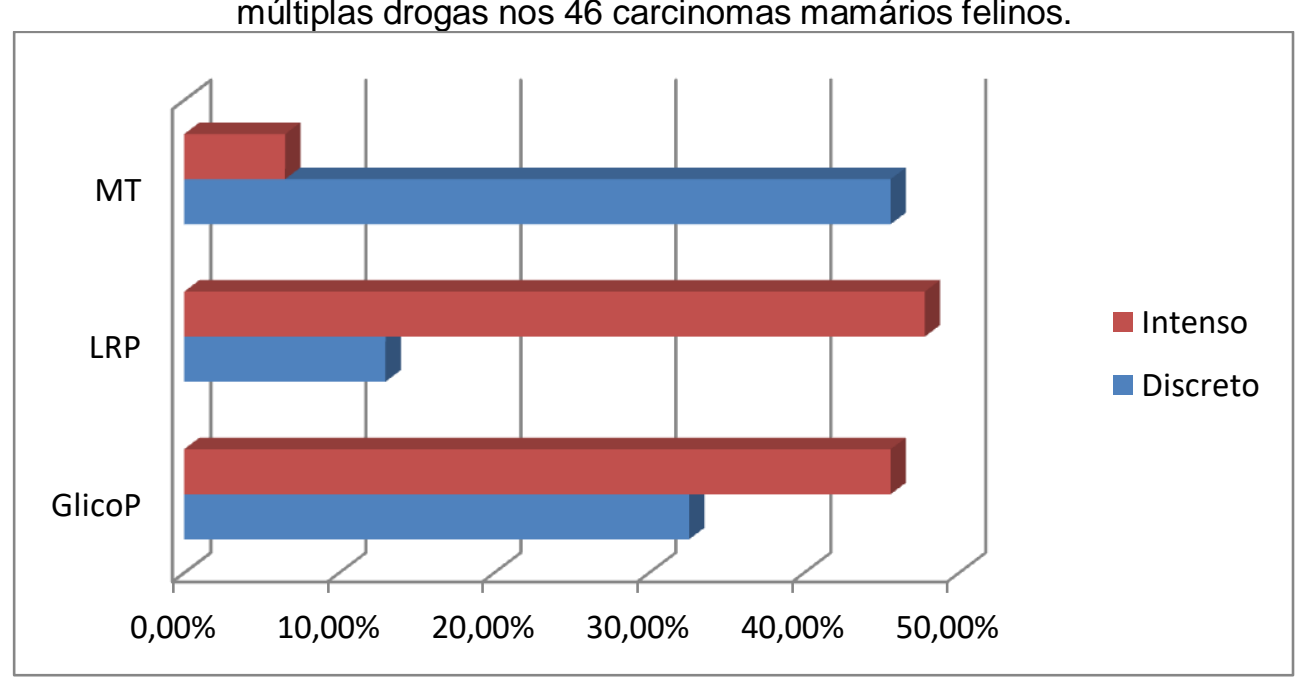

Fonte: Manoel, V. C. (2019). 


\subsection{ASSOCIAÇÃO COM PARÂMETROS CLÍNICO-PATOLÓGICOS}

\subsubsection{Glicoproteína P}

Todas as associações realizadas entre a imunoexpressão da GlicoP e os parâmetros clínico-epidemiológicos e anatomopatológicos estão representados na tabela 5. Após análise estatística, a imunoexpressão de GlicoP apresentou diferença significativa apenas com o sistema de graduação histológica de Elston e Ellis (1991) $(P=0,049)$. Os demais parâmetros não mostram associações significativas.

Tabela 5- Associação entre a imunoexpressão da Glicoproteina $P$ e os parâmetros clínicoepidemiológicos e anatomopatológicos em carcinomas mamários felinos. São Paulo, 2019.

\begin{tabular}{|c|c|c|c|c|c|c|c|c|c|c|}
\hline \multirow{3}{*}{$\begin{array}{l}\text { Parâmetros } \\
\text { Raça }\end{array}$} & \multicolumn{10}{|c|}{ Imunoexpressão da Glicoproteina P } \\
\hline & \multicolumn{2}{|c|}{ Negativo } & \multicolumn{2}{|c|}{ Discreto } & \multicolumn{2}{|c|}{ Moderado } & \multicolumn{2}{|c|}{ Intenso } & \multirow{2}{*}{$\begin{array}{c}\mathbf{n} \\
\text { Total }\end{array}$} & \multirow{2}{*}{$\begin{array}{c}\text { Valor } \\
P\end{array}$} \\
\hline & $n$ & $\%$ & $n$ & $\%$ & $\bar{n}$ & $\%$ & $n$ & $\%$ & & \\
\hline$S R D$ & 3 & 8,1 & 12 & 32,4 & 6 & 16,2 & 16 & 43,2 & 37 & \\
\hline Siamês & 0 & 0 & 0 & 0 & 0 & 0 & 6 & 100 & 6 & 0,242 \\
\hline Persa & 0 & 0 & 2 & 4,3 & 1 & 33,3 & 0 & 0 & 3 & \\
\hline \multicolumn{11}{|l|}{ ldade } \\
\hline$<11$ anos & 1 & 3,8 & 8 & 30,8 & 3 & 11,5 & 14 & 53,8 & 26 & \multirow{2}{*}{0,546} \\
\hline$\geq 11$ anos & 2 & 10 & 7 & 35 & 4 & 20 & 7 & 35 & 20 & \\
\hline \multicolumn{11}{|l|}{ Peso } \\
\hline$<3,5 \mathrm{~kg}$ & 3 & 12,5 & 6 & 25 & 5 & 20,8 & 10 & 41,7 & 24 & \multirow{2}{*}{0,322} \\
\hline$>3,5 \mathrm{~kg}$ & 0 & 0 & 7 & 41,2 & 2 & 11,8 & 8 & 47,1 & 17 & \\
\hline \multicolumn{11}{|c|}{ Status Reprodutivo } \\
\hline Castrada & 2 & 6,1 & 11 & 33,3 & 4 & 12,1 & 16 & 48,5 & 33 & \multirow{2}{*}{0,937} \\
\hline Inteira & 1 & 10 & 4 & 40 & 1 & 10 & 4 & 40 & 10 & \\
\hline \multicolumn{11}{|c|}{ Progestágenos } \\
\hline Sim & 1 & 11,1 & 3 & 33,3 & 1 & 11,1 & 4 & 44,4 & 9 & \multirow{2}{*}{0,885} \\
\hline Não & 1 & 4,2 & 9 & 37,5 & 2 & 8,3 & 12 & 50 & 24 & \\
\hline \multicolumn{11}{|l|}{ Multiplicidade } \\
\hline Únicos & 2 & 8,7 & 9 & 34,1 & 2 & 8,7 & 10 & 43,5 & 23 & \multirow{2}{*}{0,519} \\
\hline Múltiplos & 1 & 4,3 & 6 & 26,1 & 5 & 21,7 & 11 & 47,8 & 23 & \\
\hline \multicolumn{11}{|l|}{ Tamanho } \\
\hline$T 1$ & 0 & 0 & 4 & 28,6 & 3 & 21,4 & 7 & 50 & 14 & \multirow{3}{*}{0,605} \\
\hline$T 2$ & 1 & 9,1 & 4 & 36,4 & 0 & 0 & 6 & 54,5 & 11 & \\
\hline T3 & 2 & 10 & 7 & 35 & 4 & 20 & 7 & 35 & 20 & \\
\hline
\end{tabular}




\begin{tabular}{|c|c|c|c|c|c|c|c|c|c|c|}
\hline \multicolumn{11}{|l|}{ Volume } \\
\hline$<10,5 \mathrm{~cm}^{3}$ & 1 & 4,2 & 8 & 33,3 & 3 & 12,5 & 12 & 50 & 24 & \multirow{2}{*}{0,766} \\
\hline$\geq 10,5 \mathrm{~cm}^{3}$ & 2 & 9,5 & 7 & 33,3 & 4 & 19 & 8 & 38,1 & 21 & \\
\hline \multicolumn{11}{|l|}{ Ulceração } \\
\hline Sim & 3 & 18,8 & 3 & 18,8 & 2 & 12,5 & 8 & 50 & 16 & \multirow{2}{*}{0,120} \\
\hline Não & 0 & 0 & 9 & 45 & 3 & 15 & 8 & 40 & 20 & \\
\hline \multicolumn{11}{|l|}{ Aderência } \\
\hline Sim & 2 & 40 & 1 & 20 & 1 & 20 & 1 & 20 & 5 & \multirow{2}{*}{0,080} \\
\hline Não & 0 & 0 & 10 & 38,5 & 3 & 11,5 & 13 & 50 & 26 & \\
\hline \multicolumn{11}{|c|}{ Metástase em Linfonodo } \\
\hline Sim & 1 & 5,3 & 4 & 21,1 & 2 & 10,5 & 12 & 63,2 & 19 & \multirow{2}{*}{0,688} \\
\hline Não & 1 & 7,1 & 4 & 28,6 & 3 & 21,4 & 6 & 42,9 & 14 & \\
\hline \multicolumn{11}{|c|}{ Metástase a distância } \\
\hline Sim & 0 & 0 & 6 & 46,2 & 4 & 30,8 & 3 & 23,1 & 13 & \multirow{2}{*}{0,094} \\
\hline Não & 3 & 11,1 & 9 & 33,3 & 2 & 7,4 & 13 & 48,1 & 27 & \\
\hline \multicolumn{11}{|l|}{ Estágio Clínico } \\
\hline l & 0 & 0 & 2 & 50 & 0 & 0 & 2 & 50 & 4 & \multirow{4}{*}{0,432} \\
\hline II & 0 & 0 & 0 & 0 & 0 & 0 & 1 & 100 & 1 & \\
\hline III & 2 & 12,5 & 3 & 18,8 & 2 & 12,5 & 9 & 56,3 & 16 & \\
\hline IV & 0 & 0 & 5 & 41,7 & 4 & 33,3 & 3 & 9,1 & 12 & \\
\hline \multicolumn{11}{|c|}{ Tipos Histológicos } \\
\hline Sólido & 2 & 16,7 & 3 & 25 & 1 & 8,3 & 6 & 50 & 12 & \multirow{3}{*}{0,120} \\
\hline Túbulopapilar & 0 & 0 & 5 & 35,7 & 5 & 35,7 & 4 & 28,6 & 14 & \\
\hline Cribiforme & 1 & 5 & 7 & 35 & 1 & 5 & 11 & 55 & 20 & \\
\hline \multicolumn{11}{|l|}{ Invasão Dérmica } \\
\hline Sim & 2 & 13 & 1 & 6,7 & 3 & 20 & 9 & 60 & 15 & \multirow{2}{*}{0,124} \\
\hline Não & 1 & 4 & 10 & 40 & 3 & 12 & 11 & 44 & 25 & \\
\hline \multicolumn{11}{|c|}{ Graduação de E\&E } \\
\hline Grau I & 0 & 0 & 0 & 0 & 1 & 100 & 0 & 0 & 1 & \multirow{3}{*}{0,049} \\
\hline Grau II & 0 & 0 & 11 & 45,8 & 3 & 12,5 & 10 & 41,7 & 24 & \\
\hline Grau III & 3 & 14,3 & 4 & 19 & 3 & 14,3 & 11 & 52,4 & 21 & \\
\hline \multicolumn{11}{|c|}{ Graduação de Mills } \\
\hline Grau I & 0 & 0 & 4 & 50 & 0 & 0 & 4 & 50 & 8 & \multirow{3}{*}{0,666} \\
\hline Grau II & 1 & 4,5 & 7 & 31,8 & 4 & 18,2 & 10 & 45,5 & 22 & \\
\hline Grau III & 2 & 12,5 & 4 & 25 & 3 & 18,8 & 7 & 43,8 & 16 & \\
\hline \multicolumn{11}{|c|}{ Subtipo Molecular } \\
\hline LB HER2 (-) & 0 & 0 & 1 & 16,7 & 1 & 16,7 & 4 & 8,7 & 6 & \multirow{5}{*}{0,922} \\
\hline LB HER2 (+) & 0 & 0 & 1 & 100 & 0 & 0 & 0 & 0 & 1 & \\
\hline HER2 (+) & 1 & 12,5 & 2 & 25 & 2 & 25 & 3 & 37,5 & 8 & \\
\hline TNBL & 1 & 7,1 & 6 & 42,9 & 2 & 14,3 & 5 & 37,7 & 13 & \\
\hline TNNL & 1 & 5,9 & 5 & 29,4 & 2 & 11,8 & 9 & 52,9 & 17 & \\
\hline
\end{tabular}




\begin{tabular}{lcccccccccc}
\hline Mastectomia & & & & & & & & & & \\
$\quad$ Unilateral & 0 & 0 & 1 & 25 & 1 & 25 & 2 & 50 & 4 & 0,883 \\
Bilateral & 3 & 7,1 & 14 & 33,3 & 6 & 14,3 & 19 & 45,2 & 42 & \\
\hline Quimioterapia & & & & & & & & & & \\
Sim & 1 & 7,7 & 4 & 30,8 & 4 & 30,8 & 4 & 30,8 & 13 & 0,247 \\
Não & 0 & 0 & 4 & 30,8 & 1 & 7,7 & 8 & 61,5 & 13 & \\
\hline
\end{tabular}

Fonte: Manoel, V. C. (2019).

SRD: sem raça definida; E\&E: Elston \& Elis; LB: Luminal B; TNBL: triplo negativo "basal-like"; TNNL: triplo negativo "normal-like"; HER2: receptor 2 do fator de crescimento epidérmico humano.

\subsubsection{LRP}

Todas as associações realizadas entre a imunoexpressão da LRP e os parâmetros clínico-epidemiológicos e anatomopatológicos estão representados na tabela 6. Esta proteína não apresentou qualquer associação significativa com nenhum dos parâmetros analisados.

Tabela 6- Associação entre a imunoexpressão da LRP e os parâmetros clínico-epidemiológicos e anatomopatológicos em carcinomas mamários felinos. São Paulo, 2019.

\begin{tabular}{|c|c|c|c|c|c|c|c|c|c|c|}
\hline \multirow{3}{*}{$\begin{array}{l}\text { Parâmetros } \\
\text { Raça }\end{array}$} & \multicolumn{10}{|c|}{ Imunoexpressão da LRP } \\
\hline & \multicolumn{2}{|c|}{ Negativo } & \multicolumn{2}{|c|}{ Discreto } & \multicolumn{2}{|c|}{ Moderado } & \multicolumn{2}{|c|}{ Intenso } & \multirow{2}{*}{$\begin{array}{c}\mathbf{n} \\
\text { Total }\end{array}$} & \multirow{2}{*}{$\begin{array}{c}\text { Valor } \\
P\end{array}$} \\
\hline & $n$ & $\%$ & $n$ & $\%$ & $n$ & $\%$ & $\bar{n}$ & $\%$ & & \\
\hline$S R D$ & 0 & 0 & 4 & 10,8 & 16 & 42,2 & 17 & 45,9 & 37 & 0,079 \\
\hline Siamês & 0 & 0 & 2 & 20 & 0 & 0 & 4 & 80 & 6 & \\
\hline Persa & 0 & 0 & 0 & 0 & 2 & 66,7 & 1 & 33,3 & 3 & \\
\hline \multicolumn{11}{|l|}{ Idade } \\
\hline$<11$ anos & 0 & 0 & 4 & 15,4 & 12 & 46,2 & 10 & 38,5 & 26 & \multirow{2}{*}{0,350} \\
\hline$\geq 11$ anos & 0 & 0 & 2 & 10 & 6 & 30 & 12 & 60 & 20 & \\
\hline \multicolumn{11}{|l|}{ Peso } \\
\hline$<3,5 \mathrm{~kg}$ & 0 & 0 & 5 & 20,8 & 8 & 33,3 & 11 & 45,8 & 24 & \multirow{2}{*}{0,288} \\
\hline$>3,5 \mathrm{~kg}$ & 0 & 0 & 1 & 5,9 & 9 & 52,9 & 7 & 41,2 & 17 & \\
\hline \multicolumn{11}{|c|}{ Status Reprodutivo } \\
\hline Castrada & 0 & 0 & 3 & 9,1 & 12 & 36,4 & 18 & 54,5 & 33 & \multirow{2}{*}{0,245} \\
\hline Inteira & 0 & 0 & 3 & 30 & 3 & 30 & 4 & 40 & 10 & \\
\hline \multicolumn{11}{|c|}{ Progestágenos } \\
\hline Sim & 0 & 0 & 1 & 11,1 & 3 & 33,3 & 5 & 55,6 & 9 & \multirow{2}{*}{0,564} \\
\hline Não & 0 & 0 & 2 & 8,3 & 13 & 54,2 & 9 & 37,5 & 24 & \\
\hline
\end{tabular}




\begin{tabular}{|c|c|c|c|c|c|c|c|c|c|c|}
\hline Únicos & 0 & 0 & 3 & 13 & 9 & 39,1 & 11 & 47,8 & 23 & \multirow{2}{*}{1,000} \\
\hline Múltiplos & 0 & 0 & 3 & 13 & 9 & 39,1 & 11 & 47,8 & 23 & \\
\hline \multicolumn{11}{|l|}{ Tamanho } \\
\hline$T 1$ & 0 & 0 & 1 & 7,1 & 7 & 50 & 6 & 42,9 & 14 & \multirow[t]{3}{*}{0,749} \\
\hline$T 2$ & 0 & 0 & 1 & 9,1 & 4 & 36,4 & 6 & 54,5 & 11 & \\
\hline T3 & 0 & 0 & 4 & 20 & 7 & 35 & 9 & 45 & 20 & \\
\hline \multicolumn{11}{|l|}{ Volume } \\
\hline$<10,5 \mathrm{~cm}^{3}$ & 0 & 0 & 2 & 8,3 & 13 & 52,2 & 9 & 37,5 & 24 & \multirow{2}{*}{0,107} \\
\hline$\geq 10,5 \mathrm{~cm}^{3}$ & 0 & 0 & 4 & 19 & 5 & 23,8 & 12 & 57,1 & 21 & \\
\hline \multicolumn{11}{|l|}{ Ulceração } \\
\hline Sim & 0 & 0 & 3 & 18,8 & 2 & 12,5 & 11 & 68,8 & 16 & \multirow{2}{*}{0,455} \\
\hline Não & 0 & 0 & 3 & 15 & 6 & 30 & 11 & 55 & 20 & \\
\hline \multicolumn{11}{|l|}{ Aderência } \\
\hline Sim & 0 & 0 & 2 & 40 & 1 & 20 & 2 & 40 & 5 & \multirow{2}{*}{0,455} \\
\hline Não & 0 & 0 & 3 & 11,5 & 12 & 46,2 & 11 & 42,3 & 26 & \\
\hline \multicolumn{11}{|c|}{ Metástase em Linfonodo } \\
\hline Sim & 0 & 0 & 3 & 15,8 & 7 & 36,8 & 9 & 47,4 & 19 & \multirow{2}{*}{0,723} \\
\hline Não & 0 & 0 & 1 & 7,1 & 5 & 35,7 & 8 & 57,1 & 14 & \\
\hline \multicolumn{11}{|c|}{ Metástase a distância } \\
\hline Sim & 0 & 0 & 2 & 15,4 & 8 & 61,5 & 3 & 23,1 & 13 & \multirow{2}{*}{0,222} \\
\hline Não & 0 & 0 & 3 & 11,1 & 10 & 37 & 14 & 51,9 & 27 & \\
\hline \multicolumn{11}{|l|}{ Estágio Clínico } \\
\hline I & 0 & 0 & 0 & 0 & 3 & 75 & 1 & 25 & 4 & \multirow{4}{*}{0,404} \\
\hline II & 0 & 0 & 0 & 0 & 0 & 0 & 1 & 100 & 1 & \\
\hline III & 0 & 0 & 2 & 12,5 & 5 & 31,3 & 9 & 56,3 & 16 & \\
\hline IV & 0 & 0 & 1 & 8,3 & 8 & 66,7 & 3 & 25 & 12 & \\
\hline \multicolumn{11}{|c|}{ Tipos Histológicos } \\
\hline Sólido & 0 & 0 & 2 & 16,7 & 2 & 16,7 & 8 & 66,7 & 12 & \multirow[t]{3}{*}{0,206} \\
\hline Túbulopapilar & 0 & 0 & 1 & 7,1 & 5 & 35,7 & 8 & 57,1 & 14 & \\
\hline Cribiforme & 0 & 0 & 3 & 15 & 11 & 55 & 6 & 30 & 20 & \\
\hline \multicolumn{11}{|l|}{ Invasão Dérmica } \\
\hline Sim & 0 & 0 & 1 & 6,7 & 3 & 20 & 11 & 73,3 & 15 & \multirow{2}{*}{0,122} \\
\hline Não & 0 & 0 & 3 & 12 & 12 & 48 & 10 & 40 & 25 & \\
\hline \multicolumn{11}{|c|}{ Graduação de E\&E } \\
\hline Grau I & 0 & 0 & 0 & 0 & 0 & 0 & 1 & 100 & & \multirow[t]{3}{*}{0,574} \\
\hline Grau II & 0 & 0 & 4 & 16,7 & 11 & 45,8 & 9 & 35,5 & 24 & \\
\hline Grau III & 0 & 0 & 2 & 9,5 & 7 & 33,3 & 12 & 57,1 & 21 & \\
\hline \multicolumn{11}{|c|}{ Graduação de Mills } \\
\hline Grau I & 0 & 0 & 2 & 25 & 3 & 37,5 & 3 & 37,5 & 8 & \multirow[t]{3}{*}{$0,57<$} \\
\hline Grau II & 0 & 0 & 3 & 13,6 & 9 & 40,9 & 10 & 45,5 & 22 & \\
\hline Grau III & 0 & 0 & 2 & 9,5 & 7 & 33,3 & 12 & 57,1 & 21 & \\
\hline
\end{tabular}




\begin{tabular}{|c|c|c|c|c|c|c|c|c|c|c|}
\hline \multicolumn{11}{|c|}{ Subtipo Molecular } \\
\hline LB HER2 (-) & 0 & 0 & 2 & 33,3 & 0 & 0 & 4 & 66,7 & 6 & \multirow{5}{*}{0,114} \\
\hline LB HER2 (+) & 0 & 0 & 0 & 0 & 1 & 100 & 0 & 0 & 1 & \\
\hline HER2 (+) & 0 & 0 & 0 & 0 & 5 & 62,5 & 3 & 37,5 & 8 & \\
\hline$T N B L$ & 0 & 0 & 3 & 21,4 & 7 & 50 & 4 & 28,6 & 14 & \\
\hline TNNL & 0 & 0 & 1 & 5,9 & 5 & 29,4 & 11 & 64,7 & 17 & \\
\hline \multicolumn{11}{|l|}{ Mastectomia } \\
\hline Unilateral & 0 & 0 & 0 & 0 & 1 & 25 & 3 & 75 & 4 & \multirow{2}{*}{0,479} \\
\hline Bilateral & 0 & 0 & 6 & 14,3 & 17 & 40,5 & 19 & 45,2 & 42 & \\
\hline \multicolumn{11}{|l|}{ Quimioterapia } \\
\hline Sim & 0 & 0 & 0 & 0 & 1 & 25 & 3 & 75 & 4 & \multirow{2}{*}{0,667} \\
\hline Não & 0 & 0 & 6 & 14,3 & 17 & 40,5 & 19 & 45,2 & 42 & \\
\hline
\end{tabular}

Fonte: Manoel, V. C. (2019).

SRD: sem raça definida; E\&E: Elston \& Elis; LB: Luminal B; TNBL: triplo negativo "basal-like"; TNNL: triplo negativo "normal-like"; HER2: receptor 2 do fator de crescimento epidérmico humano.

\subsubsection{Metalotioneína}

Todas as associações realizadas entre a imunoexpressão da MT e os parâmetros clínico-epidemiológicos e anatomopatológicos estão representados na tabela 7. Esta proteína apresentou correlação significativa somente quanto aos subtipos moleculares dos tumores $(P=0,023)$. Os demais parâmetros não mostram associações significativas.

Tabela 7- Associação entre a imunoexpressão da MT e os parâmetros clínico-epidemiológicos e anatomopatológicos em carcinomas mamários felinos. São Paulo, 2019.

\begin{tabular}{|c|c|c|c|c|c|c|c|c|c|c|}
\hline \multirow{3}{*}{$\begin{array}{l}\text { Parâmetros } \\
\text { Raça }\end{array}$} & \multicolumn{10}{|c|}{ Imunoexpressão da MT } \\
\hline & \multicolumn{2}{|c|}{ Negativo } & \multicolumn{2}{|c|}{ Discreto } & \multicolumn{2}{|c|}{ Moderado } & \multicolumn{2}{|c|}{ Intenso } & \multirow{2}{*}{$\begin{array}{c}\mathbf{n} \\
\text { Total }\end{array}$} & \multirow{2}{*}{$\begin{array}{c}\text { Valor } \\
P\end{array}$} \\
\hline & $\bar{n}$ & $\%$ & $\bar{n}$ & $\%$ & $n$ & $\%$ & $n$ & $\%$ & & \\
\hline$S R D$ & 3 & 8,1 & 16 & 43,2 & 16 & 43,2 & 2 & 5,4 & 37 & \\
\hline Siamês & 0 & 0 & 5 & 801 & 20 & 0 & 0 & & & 0,290 \\
\hline Persa & 1 & 33,3 & 0 & 0 & 1 & 100 & 0 & 0 & 3 & \\
\hline \multicolumn{11}{|l|}{ Idade } \\
\hline$<11$ anos & 2 & 7,7 & 11 & 11 & 11 & 42,3 & 2 & 7,7 & 26 & \multirow{2}{*}{0,920} \\
\hline$\geq 11$ anos & 2 & 10 & 10 & 50 & 7 & 35 & 1 & 5 & 20 & \\
\hline \multicolumn{11}{|l|}{ Peso } \\
\hline$<3,5 \mathrm{~kg}$ & 1 & 4,2 & 12 & 50 & 9 & 37,5 & 2 & 8,3 & 24 & \multirow{2}{*}{0,264} \\
\hline$>3,5 \mathrm{~kg}$ & 3 & 17,6 & 6 & 35,3 & 8 & 47,1 & 0 & 0 & 17 & \\
\hline
\end{tabular}




\begin{tabular}{|c|c|c|c|c|c|c|c|c|c|c|}
\hline \multicolumn{11}{|c|}{ Status Reprodutivo } \\
\hline Castrada & 3 & 9,1 & 16 & 48,5 & 13 & 39,4 & 1 & 3 & 33 & \multirow{2}{*}{0,288} \\
\hline Inteira & 1 & 10 & 3 & 30 & 4 & 40 & 2 & 20 & 10 & \\
\hline \multicolumn{11}{|l|}{ Progestágenos } \\
\hline Sim & 1 & 11,1 & 3 & 33,3 & 5 & 55,6 & 0 & 0 & 9 & \multirow{2}{*}{0,524} \\
\hline Não & 2 & 8,3 & 11 & 45,8 & 8 & 33,3 & 3 & 12,5 & 24 & \\
\hline \multicolumn{11}{|l|}{ Multiplicidade } \\
\hline Únicos & 1 & 4,3 & 12 & 52,2 & 10 & 43,5 & 0 & 0 & 23 & \multirow{2}{*}{0,199} \\
\hline Múltiplos & 3 & 13 & 9 & 39,1 & 8 & 34,8 & 3 & 13 & 23 & \\
\hline \multicolumn{11}{|l|}{ Tamanho } \\
\hline$T 1$ & 2 & 14,3 & 5 & 35,7 & 5 & 35,7 & 2 & 14,3 & 14 & \multirow{3}{*}{0,241} \\
\hline$T 2$ & 1 & 9,1 & 8 & 72,2 & 2 & 18,2 & 0 & 0 & 11 & \\
\hline T3 & 1 & 5 & 7 & 35 & 11 & 55 & 1 & 5 & 20 & \\
\hline \multicolumn{11}{|l|}{ Volume } \\
\hline$<10,5 \mathrm{~cm}^{3}$ & 2 & 8,3 & 12 & 50 & 8 & 33,3 & 2 & 4,4 & 24 & \multirow{2}{*}{0,762} \\
\hline$\geq 10,5 \mathrm{~cm}^{3}$ & 2 & 9,5 & 8 & 38,1 & 10 & 47,6 & 1 & 4,8 & 21 & \\
\hline \multicolumn{11}{|l|}{ Ulceração } \\
\hline Sim & 0 & 0 & 8 & 50 & 8 & 50 & 0 & 0 & 16 & \multirow{2}{*}{0,062} \\
\hline Não & 4 & 20 & 8 & 40 & 5 & 25 & 3 & 15 & 20 & \\
\hline \multicolumn{11}{|l|}{ Aderência } \\
\hline Sim & 0 & 0 & 1 & 20 & 4 & 80 & 0 & 0 & 5 & \multirow{2}{*}{0,368} \\
\hline Não & 4 & 15,4 & 10 & 38,5 & 10 & 38,5 & 2 & 7,7 & 26 & \\
\hline \multicolumn{11}{|c|}{ Metástase em Linfonodo } \\
\hline Sim & 0 & 0 & 12 & 63,2 & 6 & 31,6 & 1 & 5,3 & 19 & \multirow{2}{*}{0,201} \\
\hline Não & 1 & 7,1 & 4 & 28,6 & 8 & 57,1 & 1 & 7,1 & 14 & \\
\hline \multicolumn{11}{|c|}{ Metástase a distância } \\
\hline Sim & 0 & 0 & 6 & 46,2 & 6 & 46,2 & 1 & 7,7 & 13 & \multirow{2}{*}{0,704} \\
\hline Não & 2 & 7,4 & 14 & 51,9 & 9 & 33,3 & 2 & 7,4 & 27 & \\
\hline \multicolumn{11}{|l|}{ Estágio Clínico } \\
\hline l & 1 & 25 & 2 & 50 & 1 & 25 & 4 & 12,1 & 8 & \multirow{4}{*}{0,827} \\
\hline II & 1 & 100 & 0 & 0 & 0 & 0 & 0 & 0 & 1 & \\
\hline III & 8 & 50 & 7 & 43,8 & 1 & 6,3 & 16 & 48,5 & 32 & \\
\hline IV & 6 & 50 & 5 & 41,7 & 1 & 8,3 & 12 & 36,4 & 24 & \\
\hline \multicolumn{11}{|c|}{ Tipos Histológicos } \\
\hline Sólido & 2 & 16,7 & 4 & 33,3 & 6 & 50 & 0 & 0 & 12 & \multirow{3}{*}{0,471} \\
\hline Túbulopapilar & 2 & 14,3 & 7 & 50 & 4 & 28,6 & 1 & 7,1 & 14 & \\
\hline Cribiforme & 0 & 0 & 10 & 50 & 8 & 40 & 2 & 10 & 20 & \\
\hline \multicolumn{11}{|l|}{ Invasão Dérmica } \\
\hline Sim & 1 & 6,7 & 8 & 53,3 & 6 & 40 & 0 & 0 & 15 & \multirow{2}{*}{0,479} \\
\hline Não & 3 & 12 & 10 & 40 & 9 & 36 & 3 & 12 & 25 & \\
\hline
\end{tabular}




\begin{tabular}{lllllllllll} 
Grau I & 0 & 0 & 1 & 100 & 0 & 0 & 0 & 0 & 1 & \\
Grau II & 2 & 50 & 9 & 35,7 & 11 & 45,8 & 2 & 8,3 & 24 & 0,875 \\
Grau III & 2 & 9,5 & 11 & 52,4 & 7 & 33,3 & 1 & 4,8 & 21 & \\
\hline Graduação de Mills & & & & & & & & & \\
Grau I & 0 & 0 & 3 & 37,5 & 3 & 37,5 & 2 & 25 & 8 & \\
Grau II & 3 & 13,6 & 9 & 40,9 & 9 & 40,9 & 1 & 4,5 & 22 & 0,282 \\
Grau III & 1 & 6,5 & 9 & 56,3 & 6 & 37,5 & 0 & 0 & 16 & \\
\hline Subtipo Molecular & & & & & & & & & \\
LB HER2 (-) & 1 & 16,7 & 2 & 33,3 & 2 & 33,3 & 1 & 16,7 & 6 & \\
LB HER2 (+) & 0 & 0 & 0 & 0 & 0 & 0 & 1 & 100 & 1 & \\
HER2 (+) & 0 & 0 & 4 & 50 & 4 & 50 & 0 & 0 & 8 & 0,023 \\
TNBL & 0 & 0 & 6 & 42,9 & 8 & 57,1 & 0 & 0 & 14 & \\
TNNL & 3 & 17,6 & 9 & 52,9 & 4 & 23,5 & 1 & 5,9 & 17 & \\
\hline Mastectomia & & & & & & & & & & \\
Unilateral & 0 & 0 & 3 & 75 & 0 & 0 & 1 & 25 & 4 & 0 \\
Bilateral & 4 & 9,5 & 18 & 42,9 & 18 & 42,9 & 2 & 4,8 & 42 & 0,157 \\
\hline Quimioterapia & & & & & & & & & & \\
Sim & 2 & 15,4 & 7 & 53,8 & 4 & 30,8 & 0 & 0 & 13 & \multirow{2}{*}{0,403} \\
Não & 2 & 15,4 & 4 & 30,8 & 5 & 38,5 & 2 & 15,4 & 13 & \\
\hline Fã
\end{tabular}

Fonte: Manoel, V. C. (2019).

SRD: sem raça definida; E\&E: Elston \& Elis; LB: Luminal B; TNBL: triplo negativo "basal-like"; TNNL: triplo negativo "normal-like"; HER2: receptor 2 do fator de crescimento epidérmico humano.

\subsection{ANÁLISE DE SOBREVIDA}

Do total de 46 pacientes incluídos no estudo, foi possível obter os dados de seguimento em $43(93,5 \%)$ casos. Para os demais casos, a recuperação das informações não foi possível pela perda de contato com os tutores dos pacientes. $O$ período de seguimento foi de $288,93 \pm 252,7$ ( 1 - 1078) dias. Do total de 43 animais com seguimento, $34(73,9 \%)$ vieram a óbito e $9(19,6 \%)$ permanecem vivos. Dos pacientes que vieram à óbito, $14(30,4 \%)$ morreram em decorrência do tumor. A sobrevida global dos animais que morreram em decorrência do tumor foi de $395 \pm$ $68,9(259,9-530)$ dias (Figura 6). 
Figura 6- Curva de sobrevida (Kaplan Meier) dos animais em função do tempo de morte em decorrência do tumor.

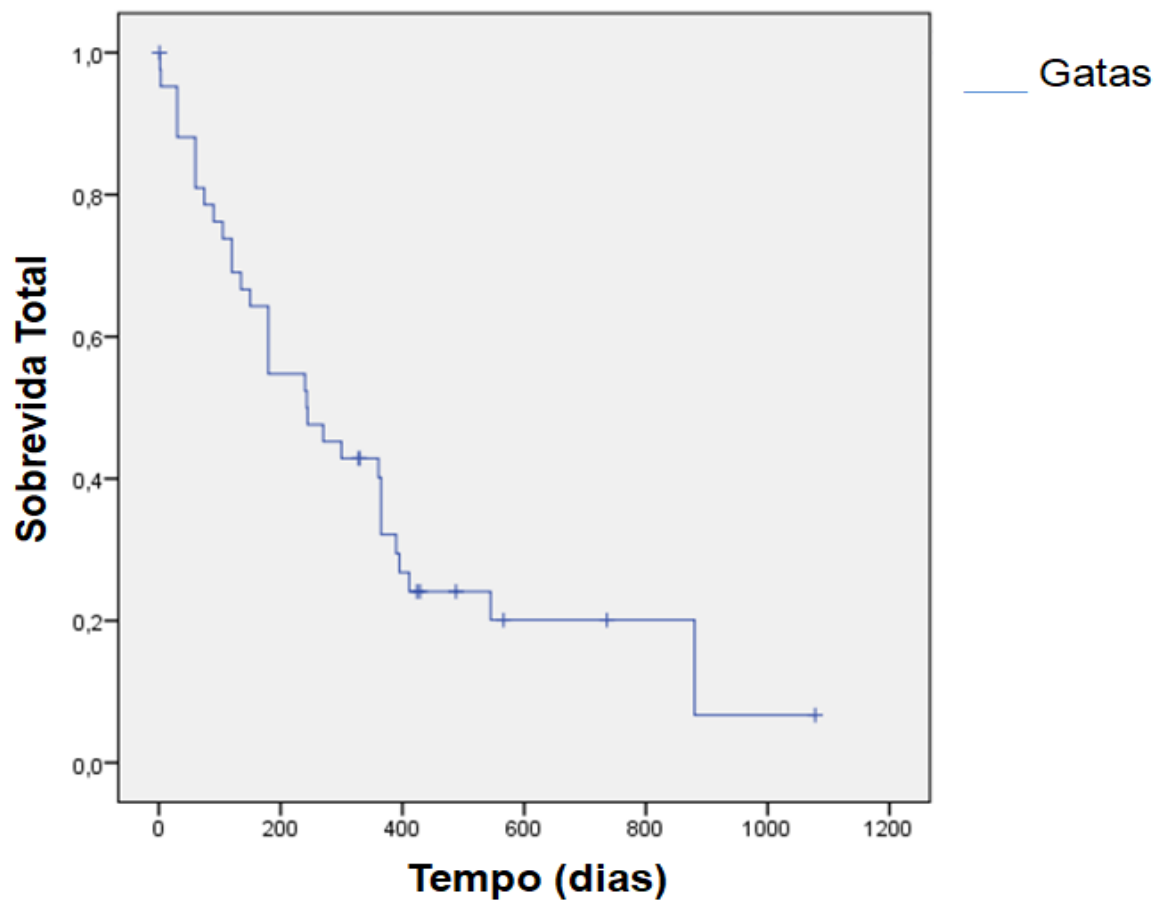

Fonte: Manoel, V. C. (2019).

Em relação ao tamanho tumoral, não houve diferença significativa com a sobrevida dos animais (Tabela 8). Porém, observou-se um menor tempo de sobrevida nos animais com tumores maiores do que $3 \mathrm{~cm}$ (T3) (Figura 7).

Tabela 8- Correlação do tamanho tumoral com a sobrevida dos animais pelo teste estatístico de Logrank. São Paulo, 2019.

\begin{tabular}{lllll}
\hline Tamanho do tumor & Tumores & Mortes & Mortalidade & Mediana \\
\hline T1 & 9 & 4 & $44,4 \%$ & 411 \\
T2 & 4 & 1 & $25 \%$ & - \\
T3 & 12 & 6 & $50 \%$ & 243 \\
& & & & \\
Log-rank & 0,265 & & & \\
Há diferença significativa? & NÃO & & & \\
\hline
\end{tabular}

Fonte: Manoel, V. C. (2019). 
Figura 7- Curva de sobrevida (Kaplan Meier) dos animais estudos em função do tamanho do tumor.

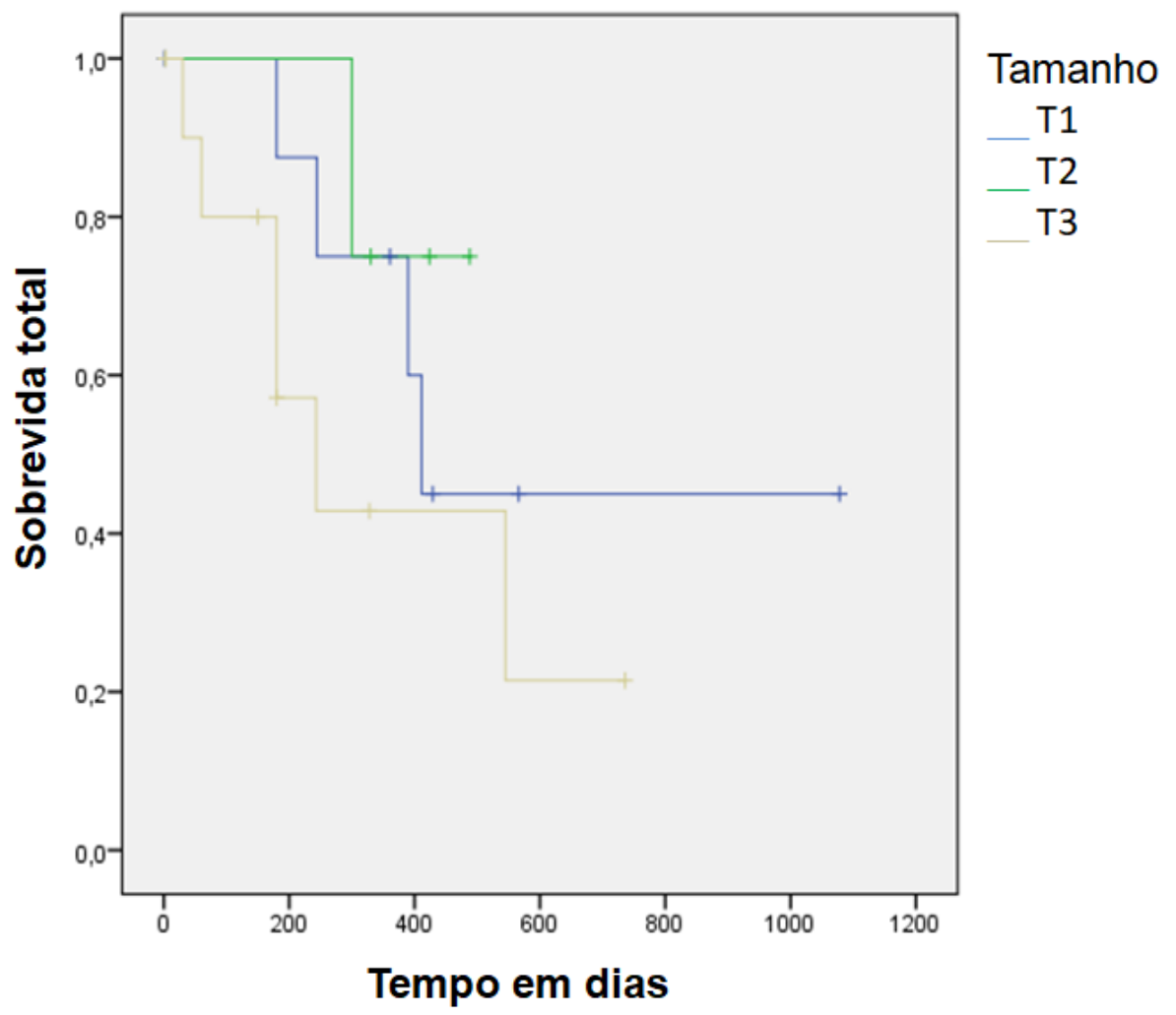

Fonte: Manoel, V. C. (2019).

Em relação ao uso de progestágenos, não houve diferença significativa com a sobrevida dos animais que foram tratados com estes anticoncepcionais (Tabela 9). Porém, observou-se um menor tempo de sobrevida nos animais que receberam as injeções de progestágenos (Figura 8).

Tabela 9- Correlação do uso de progestágenos com a sobrevida dos animais pelo teste estatístico de Log-rank. São Paulo, 2019.

\begin{tabular}{ccccc}
\hline Uso de Progestágenos & Tumores & Mortes & Mortalidade & Mediana \\
\hline Sim & 5 & 3 & $60 \%$ & 180 \\
Não & 16 & 6 & $37,5 \%$ & - \\
& & & & \\
Log-rank & 0,256 & & & \\
Há diferença significativa? & NÃO & & & \\
\hline
\end{tabular}

Fonte: Manoel, V. C. (2019). 
Figura 8- Curva de sobrevida (Kaplan Meier) dos animais estudos em função do uso de progestágenos.

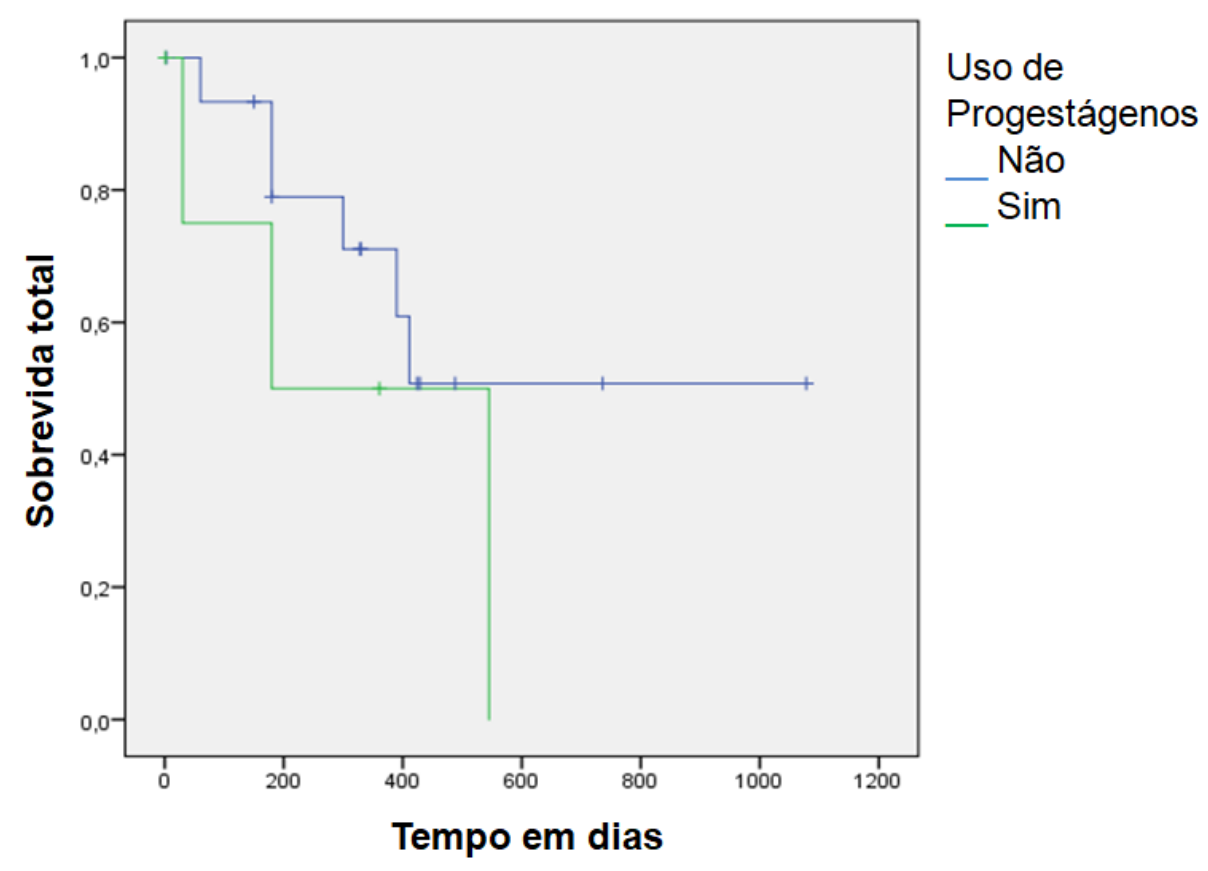

Fonte: Manoel, V. C. (2019).

Em relação a presença ou ausência de ulceração tumoral, não houve diferença significativa com a sobrevida dos animais (Tabela 10). Porém, observou-se uma tendência a um menor tempo menor de sobrevida nos animais com tumores ulcerados (Figura 9).

Tabela 10- Correlação da presença ou ausência de ulceração com a sobrevida dos animais pelo teste estatístico de Log-rank. São Paulo, 2019.

\begin{tabular}{ccccc}
\hline Ulceração & Tumores & Mortes & Mortalidade & Mediana \\
\hline Sim & 10 & 5 & $50 \%$ & 300 \\
Não & 13 & 4 & $30,8 \%$ & 545 \\
& & & & \\
Log-rank & 0,098 & & & \\
Há diferença significativa? & NÃO & & & \\
\hline
\end{tabular}

Fonte: Manoel, V. C. (2019). 
Figura 9- Curva de sobrevida (Kaplan Meier) dos animais estudados em função da presença de ulceração.

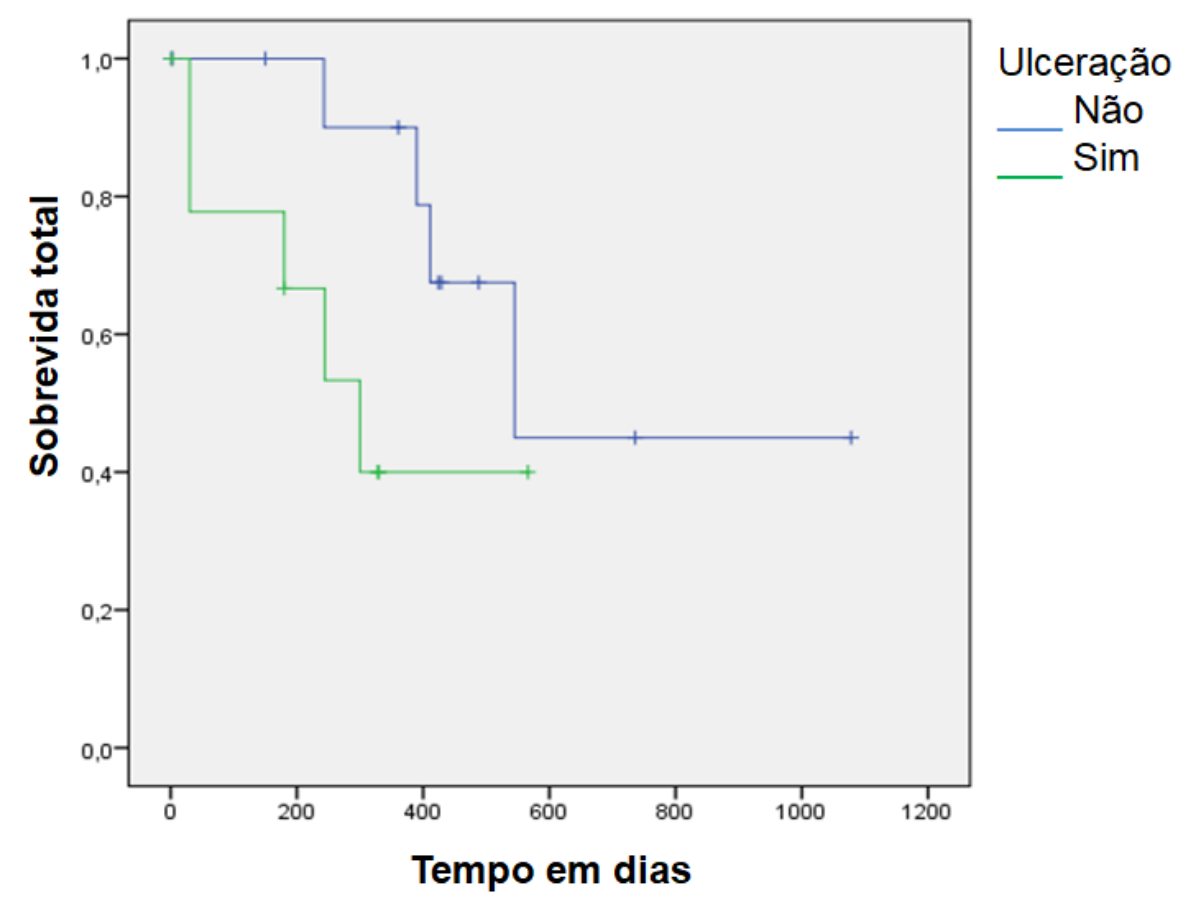

Fonte: Manoel, V. C. (2019).

Foi analisada a presença de metástase em linfonodos com a sobrevida dos animais, porém não houve diferença significativa (Tabela 11). Porém, observou-se um menor tempo de sobrevida nos animais linfonodos comprometidos (Figura 10).

Tabela 11- Correlação da presença de metástase em linfonodos com a sobrevida dos animais pelo teste estatístico de Log-rank. São Paulo, 2019.

\begin{tabular}{ccccc}
\hline Metástase em linfonodos & Tumores & Mortes & Mortalidade & Mediana \\
\hline Sim & 11 & 3 & $37,5 \%$ & 333 \\
Não & 8 & 5 & $45,5 \%$ & 654 \\
& & & & \\
Log-rank & 0,392 & & & \\
Há diferença significativa? & NÃO & & & \\
\hline
\end{tabular}

Fonte: Manoel, V. C. (2019). 
Figura 10- Curva de sobrevida (Kaplan Meier) dos animais estudados em função da presença de metástase em linfonodos.

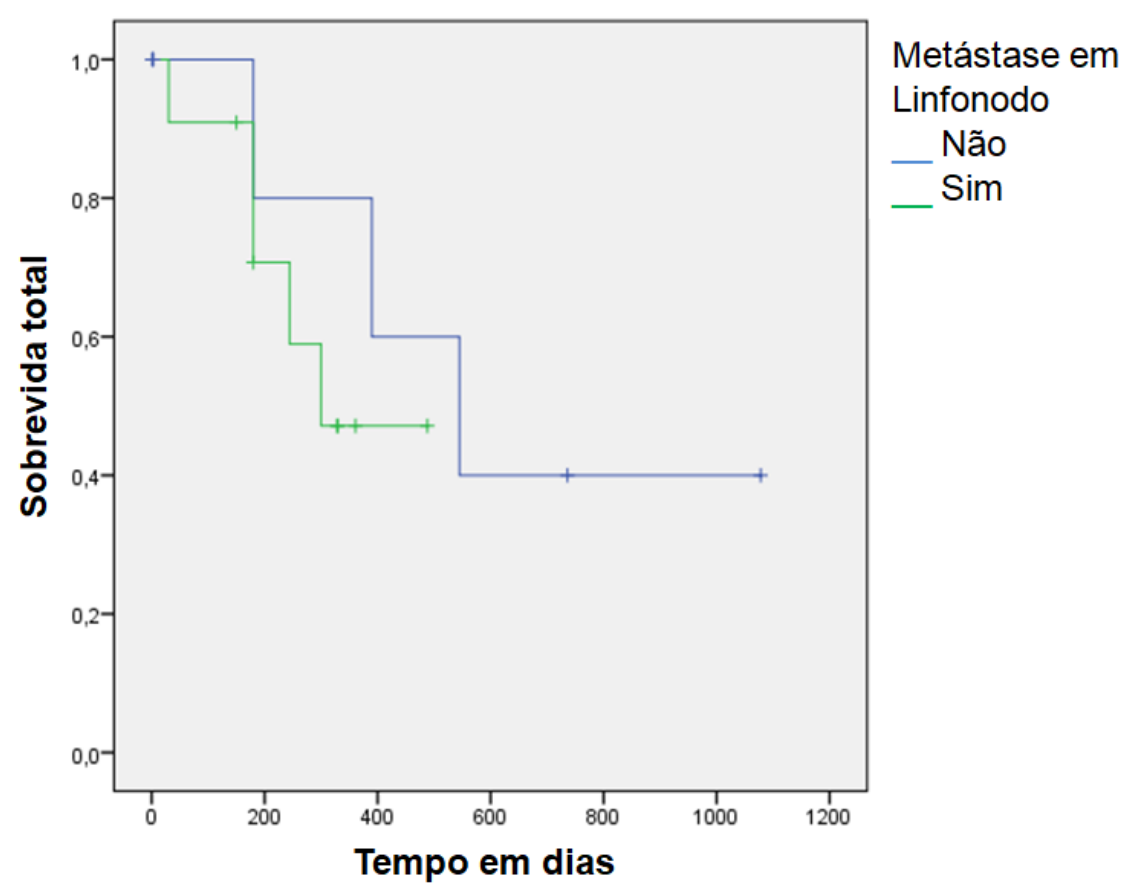

Fonte: Manoel, V. C. (2019).

Quanto a presença de metástase distante do sítio primário no momento da cirurgia, houve diferença significativa com a sobrevida dos animais $(P=0,001)$ (Tabela 12; Figura 11).

Tabela 12- Correlação da presença ou ausência de sítios de metástase distantes do tumor primário com a sobrevida dos animais pelo teste estatístico de Log-rank. São Paulo, 2019.

\begin{tabular}{ccccc}
\hline Metástase Distante & Tumores & Mortes & Mortalidade & Mediana \\
\hline Sim & 13 & 2 & $15,4 \%$ & NA \\
Não & 9 & 9 & $0 \%$ & 180 \\
& & & & \\
Log-rank & $\mathbf{0 , 0 0 1}$ & & & \\
Há diferença significativa? & SIM & & & \\
\hline
\end{tabular}

Fonte: Manoel, V. C. (2019). 
Figura 11- Curva de sobrevida (Kaplan Meier) dos animais estudados em função da presença de metástase à distância.

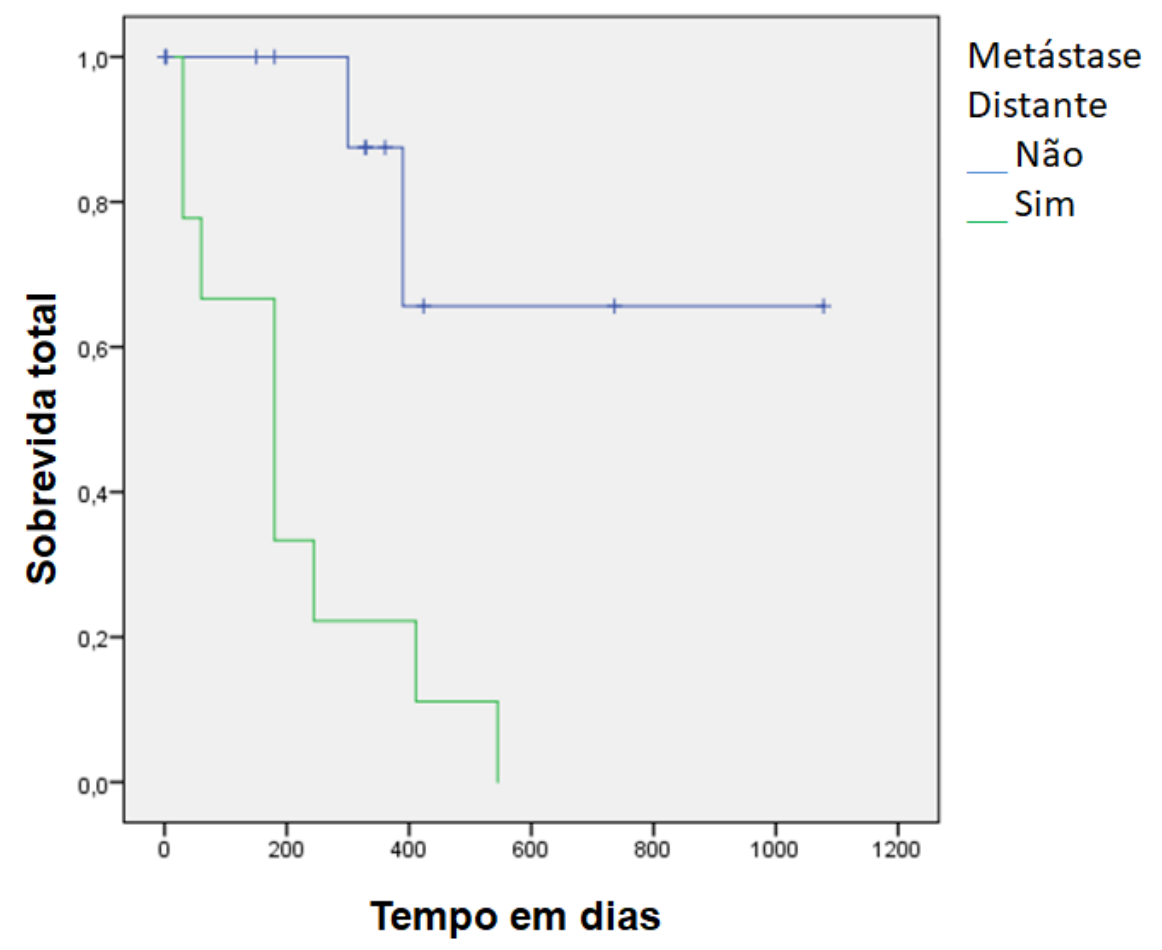

Fonte: Manoel, V. C. (2019).

Em relação ao estágio da doença no momento da cirurgia, houve diferença significativa com a sobrevida dos animais $(P=0,040)$ (Tabela 13; Figura 12).

Tabela 13- Correlação do estágio da doença no momento do diagnóstico com a sobrevida dos animais pelo teste estatístico de Log-rank. São Paulo, 2019.

\begin{tabular}{ccccc}
\hline Estágio & Tumores & Mortes & Mortalidade & Mediana \\
\hline 1 & 2 & 1 & $50 \%$ & 390 \\
3 & 10 & 2 & $20 \%$ & NA \\
4 & 8 & 8 & $0 \%$ & 180 \\
& & & & \\
Log-rank & $\mathbf{0 , 0 4 0}$ & & & \\
Há diferença significativa? & $\mathrm{SIM}$ & & & \\
\hline
\end{tabular}

Fonte: Manoel, V. C. (2019). 
Figura 12- Curva de sobrevida (Kaplan Meier) dos animais estudados em função do estágio da doença.

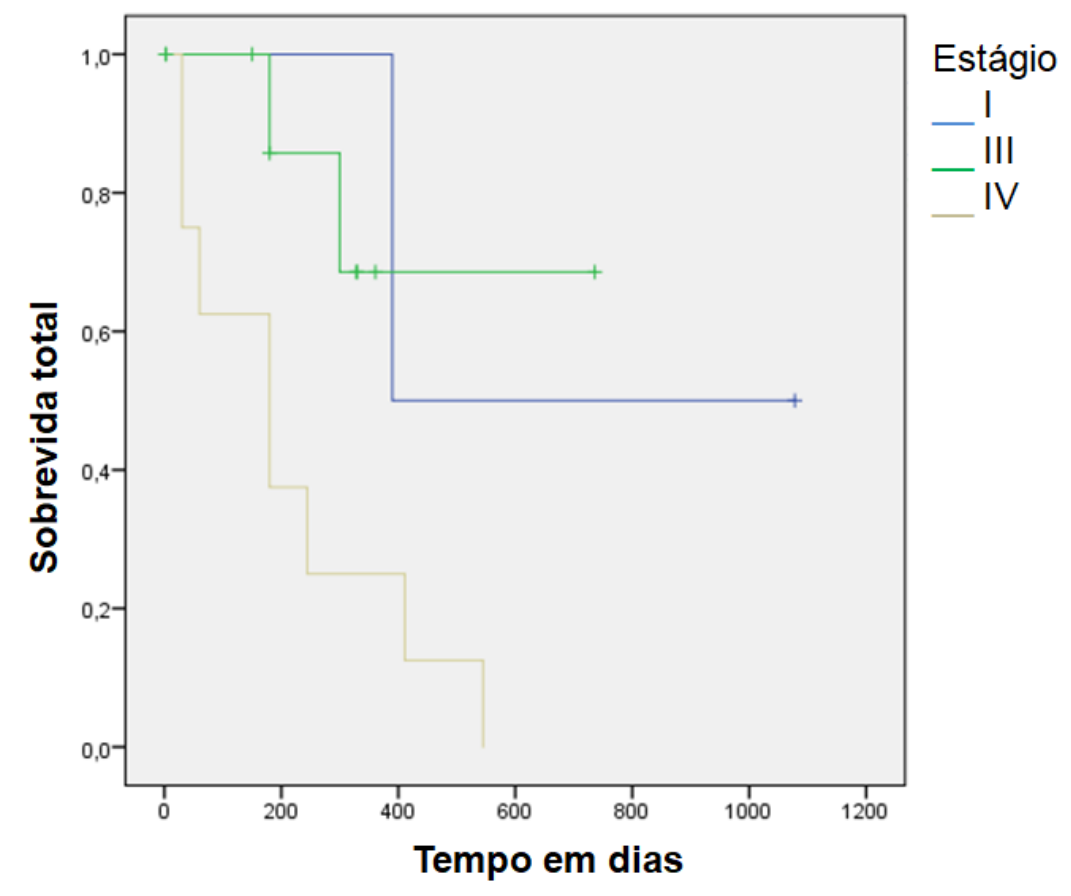

Fonte: Manoel, V. C. (2019).

Em relação aos subtipos moleculares, não houve diferença significativa com a sobrevida dos animais (Tabela 14; Figura 13).

Tabela 14- Correlação dos quatros subtipos moleculares e a sobrevida dos animais pelo teste estatístico de Log-rank. São Paulo, 2019.

\begin{tabular}{lcccc}
\hline Subtipos Moleculares & Tumores & Mortes & Mortalidade & Mediana \\
\hline Luminal B HER2 negativo & 4 & 1 & $25 \%$ & \\
Luminal B HER2 positivo & 1 & 0 & $0 \%$ & \\
HER2 positivo & 4 & 1 & $25 \%$ & \\
Triplo Negativo "basal-like" & 5 & 4 & $80 \%$ & \\
Triplo Negativo "normal-like" & 12 & 6 & $50 \%$ & \\
$\quad$ & & & & \\
Log-rank & 0,303 & & \\
Há diferença significativa? & NÃO & & & \\
\hline
\end{tabular}

Fonte: Manoel, V. C. (2019). 
Figura 13- Curva de sobrevida (Kaplan Meier) dos animais estudados em função dos subtipos moleculares.

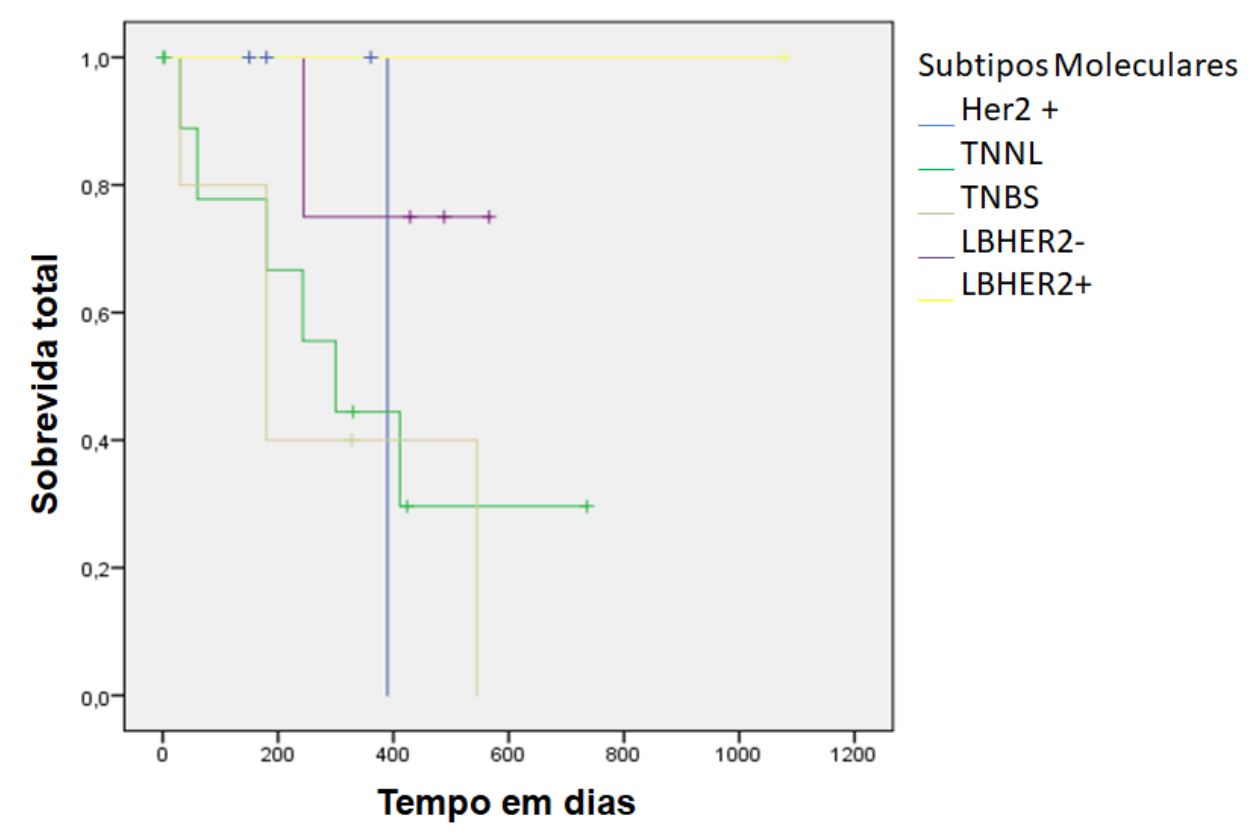

Fonte: Manoel, V. C. (2019).

LBHER2-: Luminal B HER2 negativo; LBHER2+: Luminal B HER2 positivo TNBL: triplo negativo "basal-like"; TNNL: triplo negativo "normal-like"; HER2: receptor 2 do fator de crescimento epidérmico humano.

Analisamos a correlação da sobrevida ao tipo de cirurgia instituída, que apresentou valor significativo com a sobrevida dos animais $(P=0,049)$ (Tabela 15). Dessa maneira, os animais que fizeram a mastectomia unilateral apresentaram um menor tempo de sobrevida quando comparados aos animais que realizaram a mastectomia bilateral (Figura 14).

Tabela 15- Correlação do tipo de cirurgia adotado e a sobrevida dos animais pelo teste estatístico de Log-rank. São Paulo, 2019.

\begin{tabular}{ccccc}
\hline Cirurgia & Tumores & Mortes & Mortalidade & Mediana \\
\hline Unilateral & 4 & 2 & $100 \%$ & 244 \\
Bilateral & 22 & 8 & $36,6 \%$ & 545 \\
& & & & \\
Log-rank & $\mathbf{0 , 0 4 9}$ & & & \\
Há diferença significativa? & SIM & & & \\
\hline
\end{tabular}

Fonte: Manoel, V. C. (2019). 
Figura 14- Curva de sobrevida (Kaplan Meier) dos animais estudados em função do tipo de cirurgia implementada.

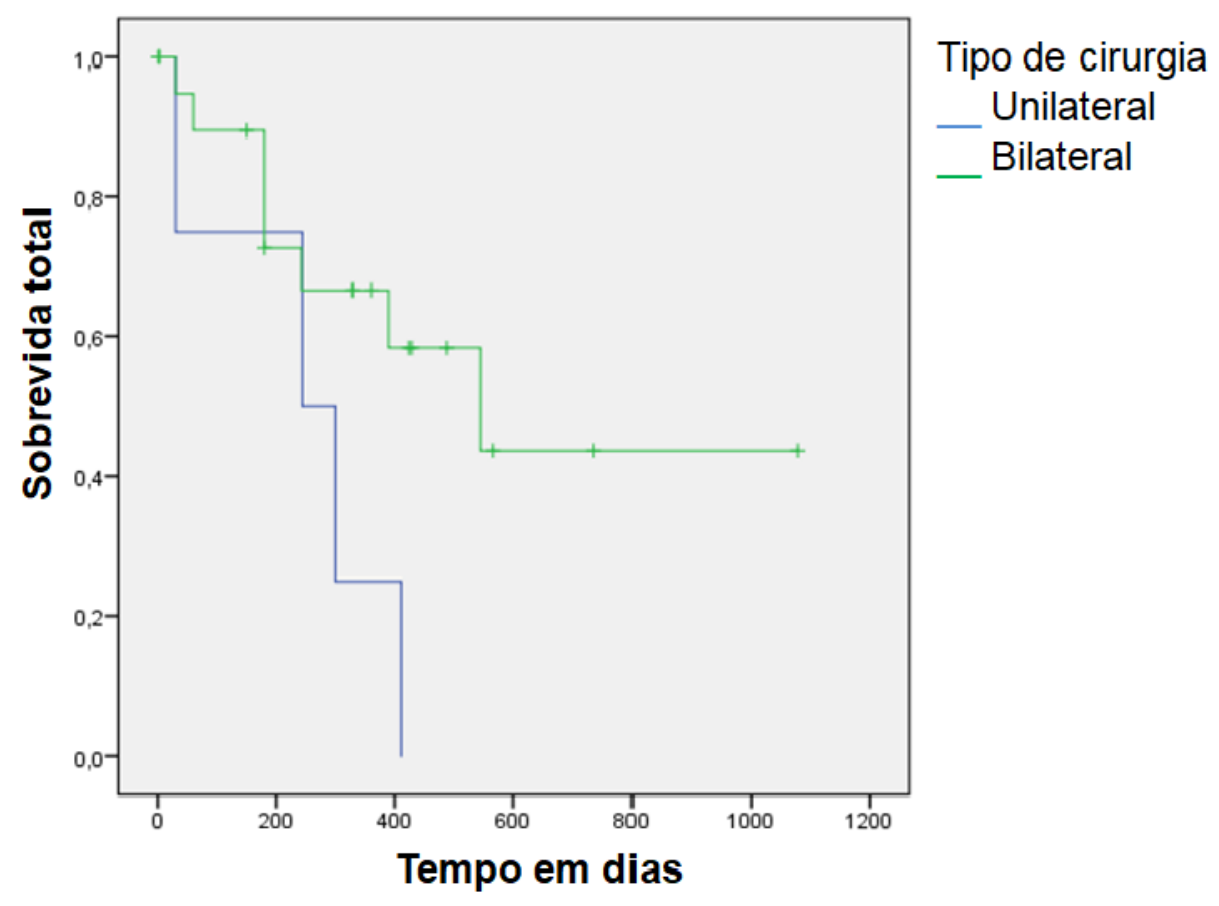

Analisamos a correlação da sobrevida com a terapia quimioterápica adjuvante, a qual apresentou diferença significativa quanto a sobrevida dos animais $(P=0,004)$ (Tabela 16). Os animais que receberam a quimioterapia adjuvante apresentaram uma menor sobrevida em relação aos que não foram tratados (Figura 15).

Tabela 16- Correlação da quimioterapia e a sobrevida dos animais pelo teste estatístico de Log-rank. São Paulo, 2019.

\begin{tabular}{ccccc}
\hline Quimioterapia & Tumores & Mortes & Mortalidade & Mediana \\
\hline Sim & 7 & 4 & $30,8 \%$ & NA \\
Não & 13 & 6 & $85,7 \%$ & 180 \\
$\quad$ Log-rank & $\mathbf{0 , 0 0 4}$ & & & \\
Há diferença significativa? & SIM & & & \\
\hline
\end{tabular}

Fonte: Manoel, V. C. (2019). 
Figura 15- Curva de sobrevida (Kaplan Meier) dos animais estudados em função do uso de quimioterapia adjuvante.

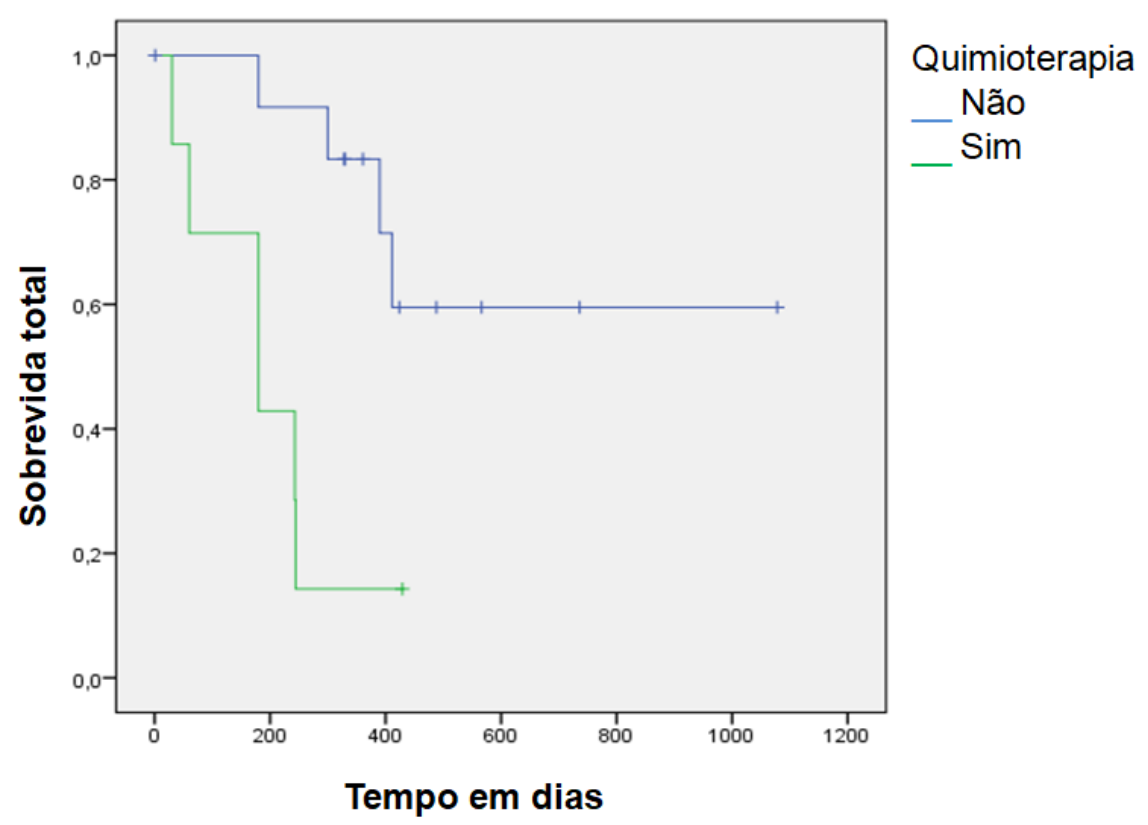

Fonte: Manoel, V. C. (2019).

Para as proteínas de resistência à múltiplas drogas, a imunoexpressão da GlicoP não apresentou diferença significativa com a sobrevida dos animais (Tabela 17; Figura 16).

Tabela 17- Correlação da Glicoproteína P e a sobrevida dos animais pelo teste estatístico de Logrank. São Paulo, 2019.

\begin{tabular}{lcccc}
\hline $\begin{array}{c}\text { Imunoexpressão de } \\
\text { Glicoproteína P }\end{array}$ & Tumores & Mortes & Mortalidade & Mediana \\
\hline 0 & 2 & 0 & $0 \%$ \\
1 & 8 & 4 & $50 \%$ \\
2 & 4 & 3 & $75 \%$ \\
3 & 12 & 5 & $41,7 \%$ & \\
& & & & \\
Log-rank & 0,868 & & & \\
Há diferença significativa? & $\mathrm{NÃO}$ & & & \\
\hline
\end{tabular}

Fonte: Manoel, V. C. (2019). 
Figura 16- Curva de sobrevida (Kaplan Meier) dos animais estudados em função da imunoexpressão da Glicoproteina P.

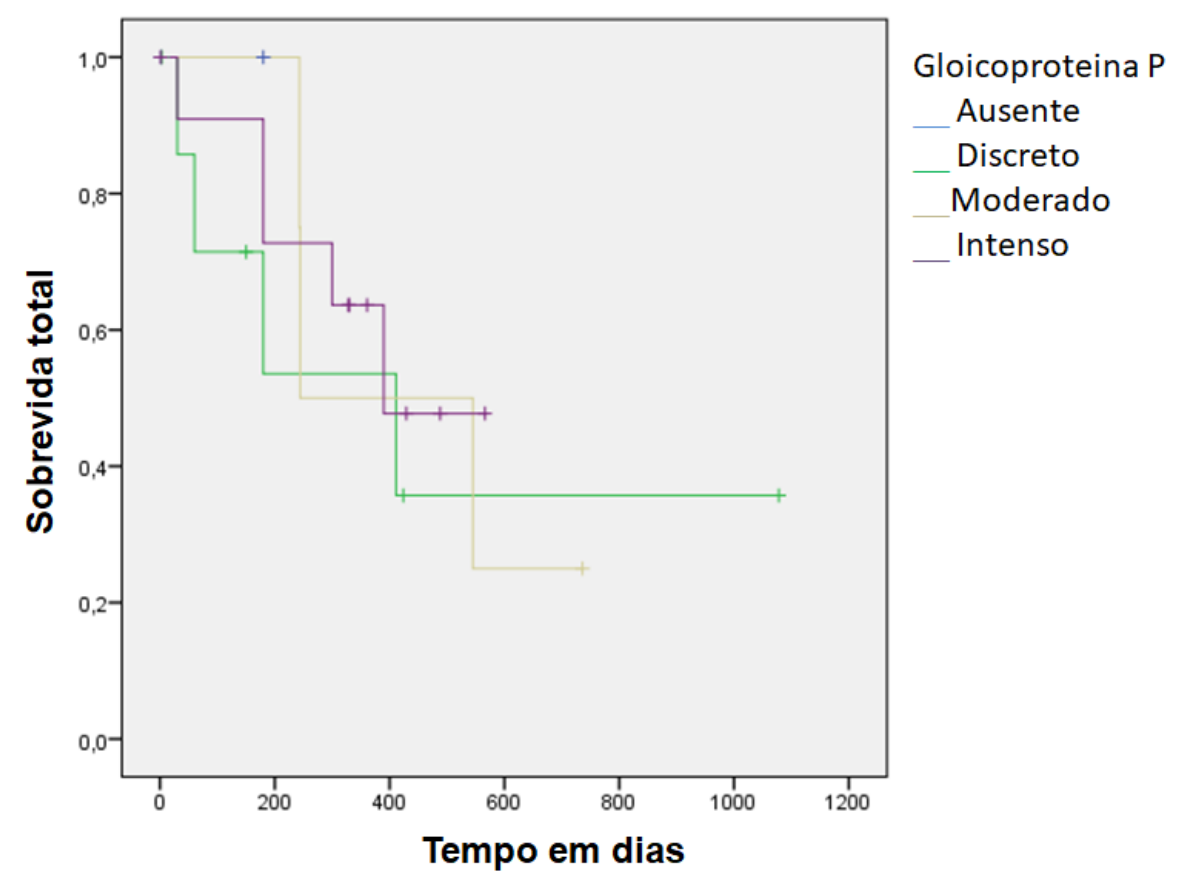

Fonte: Manoel, V. C. (2019).

A imunoexpressão da LRP também não apresentou diferença significativa com a sobrevida dos animais (Tabela 18; Figura 17).

Tabela 18- Correlação da LRP e a sobrevida dos animais pelo teste estatístico de Log-rank. São Paulo, 2019.

\begin{tabular}{ccccc}
\hline Imunoexpressão de LRP & Tumores & Mortes & Mortalidade & Mediana \\
\hline 1 & 2 & 1 & $50 \%$ & 180 \\
2 & 11 & 6 & $54,5 \%$ & 390 \\
3 & 13 & 5 & $38,5 \%$ & 545 \\
& & & & \\
Log-rank & 0,588 & & & \\
Há diferença significativa? & NÃO & & & \\
\hline
\end{tabular}

Fonte: Manoel, V. C. (2019). 
Figura 17- Curva de sobrevida (Kaplan Meier) dos animais estudados em função da imunoexpressão da LRP.

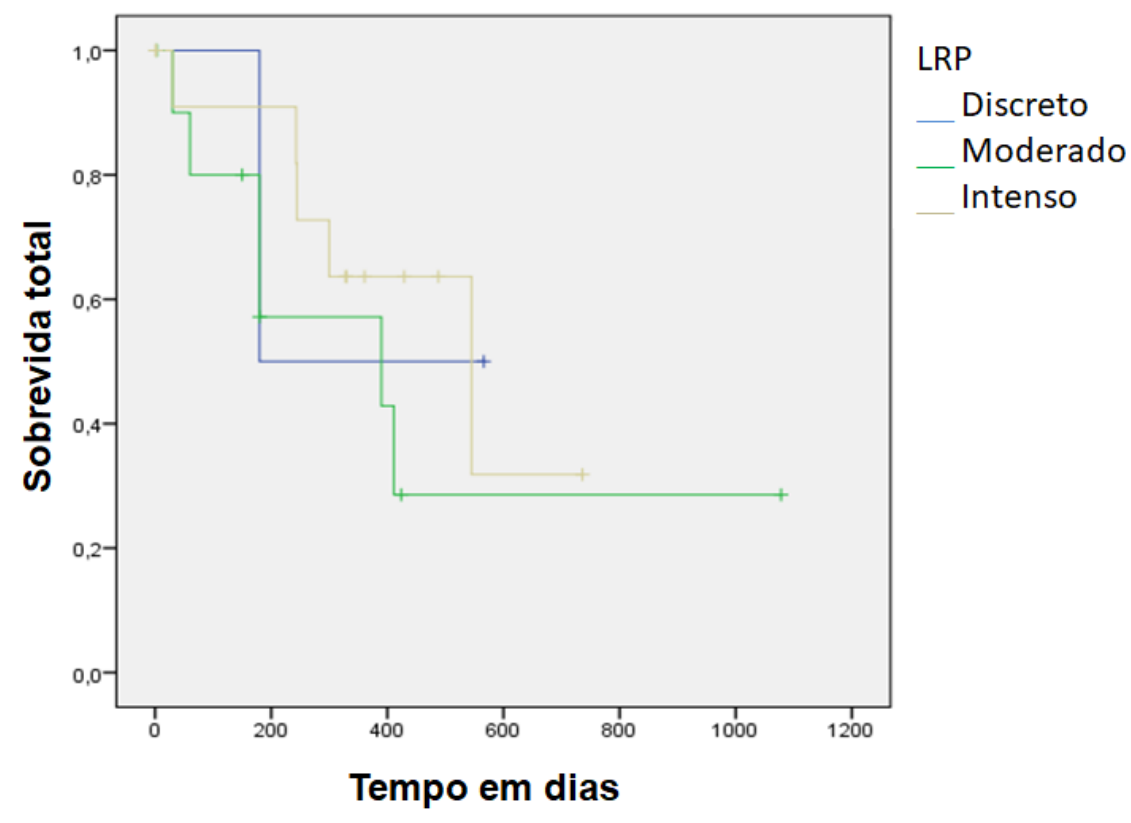

Fonte: Manoel, V. C. (2019).

Por fim, a metalotioneína também não apresentou diferença significativa com a sobrevida dos animais (Tabela 19; Figura 18).

Tabela 19- Correlação da metalotioneína e a sobrevida dos animais pelo teste estatístico de Logrank. São Paulo, 2019.

\begin{tabular}{ccccc}
\hline $\begin{array}{c}\text { Imunoexpressão de } \\
\text { Metalotioneína }\end{array}$ & Tumores & Mortes & Mortalidade & Mediana \\
\hline 0 & 4 & 1 & $25 \%$ & NA \\
1 & 7 & 3 & $42,9 \%$ & 300 \\
2 & 13 & 7 & $53,8 \%$ & 390 \\
3 & 2 & 1 & $50 \%$ & 411 \\
& & & & \\
Há diferença significativa? & 0,738 & & & \\
\hline
\end{tabular}

Fonte: Manoel, V. C. (2019). 
Figura 18- Curva de sobrevida (Kaplan Meier) dos animais estudados em função da imunoexpressão da Metalotioneína.

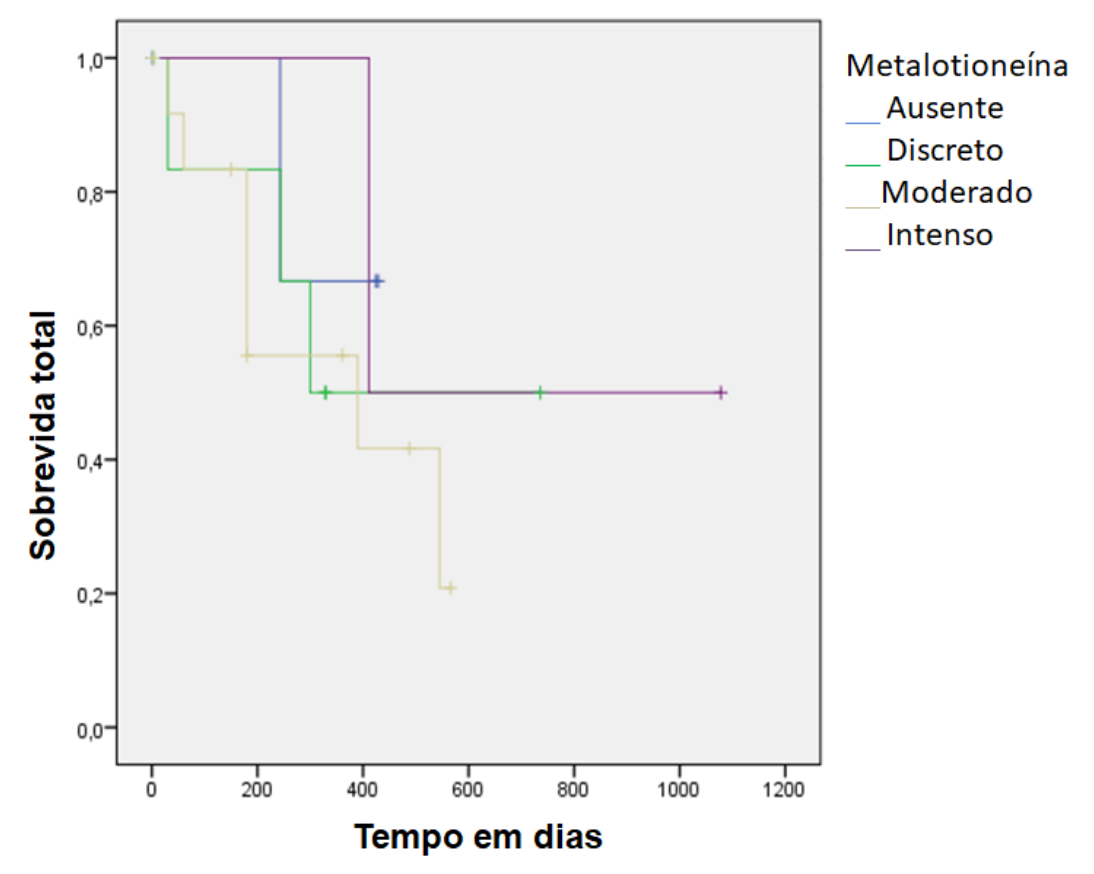

Fonte: Manoel, V. C. (2019).

Com relação às demais variáveis elencadas durante este estudo, foram analisadas e correlacionadas com a sobrevida como raça $(P=2,622)$, idade $(P=0,044)$, peso $(P=0,160)$, estado reprodutivo $(P=1,051)$, uso de progestágenos $(P=1,291)$, multiplicidade tumoral $(P=1,286)$, tamanho tumoral $(P=2,655)$, volume tumoral $(P=0,032)$, ulceração $(P=2,742)$, metástase em linfonodo $(P=0,732)$, metástase distante $(P=10,124)$, estágio $(P=6,435)$, tipo histológico $(P=0,647)$, invasão dérmica $(P=0,142)$, graduação de Elston e Ellis $(P=1,461)$, graduação de Mills $(P=3,315)$, subtipos moleculares $(P=4,854)$ e $\mathrm{KI} 67 \quad(P=0,344)$; porém como demonstrado, não apresentaram significância estatística, e, por esse motivo não estão representadas graficamente. 


\section{DISCUSSÃO}

O objetivo deste estudo foi avaliar a imunoexpressão de proteínas relacionadas com a resistência à múltiplas drogas no carcinoma mamário em felinos e correlacionar estes achados com os dados clínico-epidemiológicos, anatomopatológicos e de sobrevida destes animais. Para tanto, uma casuística de 46 gatas com carcinomas mamários foi incluída neste estudo, as quais foram submetidas à mastectomia para remoção do tumor e linfonodos regionais. Os animais acometidos apresentaram idade média de 12,15 \pm 2,8 anos, valor muito próximo ao intervalo de 10 a 12 anos relatado na literatura (WEIJER; HART, 1983b; MISDORP; ROMIJN; HART, 1991; HUGHES; ZAPPULLI, 2015). Apesar de alguns estudos relatarem uma maior predisposição em gatas da raça siamesa para o desenvolvimento das neoplasias mamárias, a presente casuística mostrou que a maioria dos animais acometidos era sem raça definida $(80,4 \% ; \quad P<0,001)$, corroborando dados recentemente avaliados no Brasil (CUNHA et al., 2016). Os animais da raça Siamesa foram o segundo padrão racial mais afetado, representando $13,1 \%$ dos animais. Esse achado deve-se a uma maior representatividade de animais sem raça definida na população de felinos domésticos brasileiros (CUNHA et al., 2016).

Sabe-se que o carcinoma mamário em gatas tende a apresentar um comportamento agressivo, com alta capacidade metastática (MISDORP et al., 1999; FILGUEIRA et al., 2014). Neste estudo, 57,5\% dos linfonodos coletados apresentaram metástase, reforçando sua capacidade de rápida infiltração e disseminação neoplásica. Apesar de não haver diferença significativa $(P=0,392)$, observou-se que os animais com metástase em linfonodo apresentaram uma sobrevida cerca de $50 \%$ inferior aos animais sem comprometimento dos linfonodos regionais. Adicionalmente, as metástases à distância foram observadas em 32,5\% das pacientes, agravando o estágio clínico destes animais. Assim como observado por OVERLEY et al., (2005), a presença de metástases em sítios distantes apresentou associação com a sobrevida dos pacientes $(P=0,001)$, sendo considerado um importante fator prognóstico para os carcinomas mamários em felinos. 
O maior tamanho tumoral (T3) foi apresentado na maioria (44,5\%) das gatas deste estudo, porém ao contrário do relatado por BORREGO et al. (2009), não foi observado correlação significativa com a sobrevida destes animais, mesmo apresentando um tempo de sobrevida cerca de 50\% inferior aos animais com menor tamanho tumoral (T1). A partir das informações sobre tamanho tumoral, comprometimento de linfonodos regionais e metástases à distância, o estadiamento foi realizado em 33 gatas, pelo sistema TNM (MORRIS et al.; 2013). Desta casuística, a maioria dos animais foi classificada como estágio III (48,5\%), seguida pelo estágio IV (36,3\%). Dessa forma, 84,5\% $(P=0,001)$ dos animais apresentaramse nos estágios mais avançados da doença, sugerindo um pior prognóstico. De fato, estes resultados foram corroborados pela associação significativa com a sobrevida dos animais, indicando um menor tempo de sobrevida nos estágios mais avançados da doença $(P=0,04)$. Estes dados estão de acordo com diversos estudos anteriores, os quais demonstraram correlação prognóstica do estadiamento clínico TNM em gatas com neoplasias mamárias (OWEN, 1980; BORREGO et al., 2009; MCNEILL et al., 2009).

Foi observada diferença significativa entre animais inteiros e castrados, sendo que a presente casuística foi composta, predominantemente, por animais castrados $(76,7 \% ; P<0,001)$. Sabe-se que a OSH traz diversos benefícios na prevenção das neoplasias mamárias em felinos quando realizada precocemente, preferencialmente antes dos seis meses de vida (OVERLEY et al., 2005). No entanto, como muitos animais deste estudo foram resgatados ou vieram de ONGs, a castração foi realizada na vida adulta; ou, ainda, alguns tutores não sabiam informar a idade dos mesmos na ocasião da castração. Por outro lado, a castração ou não destes animais não incluenciou diretamente na sobrevida dos mesmos $(P=0,305)$. Em relação ao uso de progestágenos, a maioria dos tutores $(72,7 \% ; P=0,009)$ afirma nao ter feito uso destes medicamentos em nenhum momento. Apesar de relatado por alguns autores (HAYDEN; BARNES; JOHNSON, 1989; MISDORP, W., 1991; SKORUPSKI et al., 2005), não observamos associação com a sobrevida destes animais $(P=0,256)$. Dessa maneira, não foi possível determinar a participação destes importantes fatores de risco na carcinogênese mamária nessa população.

A presença de ulceração tumoral foi evidenciada em $44,5 \%$ dos animais, porém sem diferença significativa em relação ao número de tumores não ulcerados 
$(P=0,505)$. Ademais, esta variável não apresentou associação significativa com a sobrevida $(P=0,098)$. Soares et al. (2016) demonstraram que tumores ulcerados estão correlacionados a um menor tempo de sobrevida, porém no presente trabalho observou-se apenas uma tendência que sugere uma menor sobrevida dos pacientes com tumores ulcerados. A maioria dos tumores $(86,8 \% ; \quad P<0,001)$ não se apresentaram aderidos à pele ou musculatura dos animais, assim como não houve correlação com a sobrevida ( $P=0,942)$. Sabe-se que tumores malignos, invasivos e de maior volume, tendem a aderir a musculatura e a pele e apresentar ulceração (CASSALI et al.; 2018).

A cirurgia é considerada o método de eleição para o tratamento das neoplasias mamárias em felinos (MORRIS, 2013; SORENMO; WORLEY; GOLDSCHMIDT, 2013; ZAPPULLI et al., 2015). Neste sentido, todos os animais deste estudo foram submetidos à mastectomia bilateral ou unilateral, sendo que a maioria $(91,3 \%$; $P<0,001)$ realizou a cirurgia bilateral (radical). $O$ tipo de cirurgia instituída apresentou correlação com a sobrevida $(P=0,049)$, indicando que os animais que fizeram a mastectomia unilateral apresentaram um menor tempo de sobrevida quando comparados aos submetidos à mastectomia bilateral. Estes dados corroboram diversos estudos, os quais apontam que a mastectomia radical representa a melhor opção terapêutica nestes pacientes.

Em relação ao uso de protocolos quimioterápicos pós-cirúrgicos, metade $(50 \%$, $P=1,000)$ dos animais receberam a quimioterapia, que apresentou correlação com sobrevida dos animais $(P=0,004)$. Porém, de forma contraditória ao descrito na literatura (NOVOSAD, 2003; DE CAMPOS et al., 2014), os animais que receberam a quimioterapia adjuvante apresentaram um menor tempo de sobrevida em relação aos que não foram tratados. Este resultado pode ser explicado pela seleção de pacientes com estadiamento clínico mais avançado para receberem os protocolos quimioterápicos. Ainda, outros fatores como o pequeno número amostral de pacientes que receberam a quimioterapia, além dos protocolos variados utilizados ou mesmo a descontinuação do tratamento pode ter influenciado neste resultado.

Os subtipos e a graduação histológica dos carcinomas mamários felinos tem seu valor prognóstico apresentados em alguns estudos, os quais evidenciam a importância destes parâmetros na sobrevida dos animais (ELSTON, C.W.; ELLIS, 1991; SEIXAS et al., 2011; MILLS et al., 2015; DE CAMPOS et al., 2016). Mills et al. 
(2015) relataram uma menor sobrevida em animais portadores de carcinomas dos subtipos sólidos ou cribiformes. No presente estudo, foram identificados os subtipos túbulo-papilar, cribiforme e sólido, sem diferença significativa entre eles $(P=0,323)$. Além disso, não houve correlação dos subtipos histológicos com a sobrevida dos animais $(P=0,723)$. A graduação histológica foi realizada por duas metodologias distintas. Uma delas, conhecida como sistema de Nottingham e amplamente aplicada nos tumores mamários, apresenta forte correlação com o prognóstico em felinos (ELSTON, ELLIS, 1991). Nesta casuística, a maioria dos animais apresentou tumores com graus II e III (97,9\%; $\mathrm{P}<0,001)$, indicando uma alta agressividade tumoral. A outra metodologia adotada foi desenvolvida especificamente para felinos, chamada aqui de metodologia de Mills (Mills et al., 2015). Da mesma forma, esta avaliação demonstrou que a maioria dos animais também apresentaram tumores com graduação II e III (82,6\%; $P=0,040)$. Estes dados estão de acordo com os relatados na literatura, que afirma que a grande parte dos carcinomas mamários em felinos apresentam elevado grau de malignidade (BOSTOCK, 1986; MISDORP, W et al., 1999). No entanto, a avaliação da sobrevida não demonstrou correlação com nenhum dos dois sistemas de graduação histológica aplicados $(P=0,482$ e $P=0,191$, respectivamente). Estes dados contradizem diversos estudos que os indicam como confiáveis fatores prognósticos, estudos estes que investigaram a associação entre estadiamento clínico e sobrevida, e demonstraram um maior período livre de doença, portanto maior sobrevida (SEIXAS et al., 2011; HUGHES; DOBSON, 2012).

Foi realizado um painel imuno-histoquímico para a classificação molecular dos carcinomas mamários felinos, baseado em marcadores imunofenotípicos, tais como receptor de estrógeno, receptor de progesterona, HER-2, CK5/6 e Ki-67 (SOARES et al., 2016). No presente estudo, o subtipo molecular mais frequente foi o triplo negativo "normal-like" $(37 \% ; P=0,001)$, seguido pelo triplo negativo "basal-like" (30,4\%), HER-2 positivo (17,4\%), Luminal B HER2 negativo (13\%) e, por último, Luminal B HER2 positivo (2,2\%). Entretanto, os subtipos moleculares não apresentaram correlação com a sobrevida dos animais $(P=0,303)$. Estes dados contrariam os estudos de Soares et al. $(2016 a, b)$, nos quais os autores identificaram os carcinomas luminal B HER2 negativo como os mais frequentes. Ainda, os autores identificaram correlação dos subtipos moleculares Luminal A com uma maior 
sobrevida destes animais, sugerindo-os como importantes fatores prognósticos (SOARES et al.; 2016).

Diante do principal objetivo deste estudo, a saber identificar a expressão das proteínas Glicoproteína $P$ (GlicoP), proteína relacionada a resistência de pulmão (LRP) e metalotioneína (MT) nos carcinomas mamários em felinos, e correlacionar com os dados clínico-epidemiológicos, anatomopatológicos e de sobrevida destes animais, este estudo apresentou poucos dados significativos. A literatura sobre 0 tema ainda é escassa na medicina veterinária e, assim como em humanos, as correlações das proteínas com fatores associados a sobrevida foi considerado um desafio. Nesta casuística, nenhum destes marcadores apresentaram correlação com sobrevida.

A GlicoP é uma proteína que atua como bomba de efluxo e participa ativamente de muitas ações fisiológicas e patológicas (GOTTESMAN, 2002; HEYDEN; CHIERS; DUCATELLE, 2009). Em felinos, sabe-se que não há imunoexpressão da GlicoP em tecido mamário normal (VAN DER HEYDEN et al., 2009), porém, imunorreatividade da GlicoP em tumores mamários felinos, com marcação em células metastáticas no linfonodo (VAN DER HEYDEN et al., 2011). No presente estudo, houve correlação significativa da expressão de GlicoP com a graduação histológica de Elston e Ellis (1991), conhecido como o sistema de Nottinghann $(P=0,049)$. Dessa forma, os carcinomas mamários com maior graduação histológica, ou seja, considerados mais agressivo, apresentaram maior imunoexpressão da GlicoP. Estes dados sugerem uma associação deste marcador à um pior prognóstico, porém, todas as demais correlações não foram significativas, inclusive com a sobrevida.

Há poucos estudos relacionados a função da LRP e o câncer. O que se sabe até o momento é que a expressão da LRP vem associada com uma baixa e ou moderada resistência as drogas antineoplásicas (Izquierdo et al., 1996). Em felinos, inexistem relatos sobre a expressão desta proteína. Neste trabalho, a maioria das amostras tumorais apresentaram expressão moderada a intensa, porém não houve correlação com nenhum parâmetro clínico-patológico, anatomopatológico ou com a sobrevida destes animais. Até onde se sabe, inexiste associação da expressão desta proteína e a sobrevida e prognósticos em pacientes humanos (Arts et al.; 1999). 
Em relação à $M T$, alguns autores sugerem que padrões de expressão estejam correlacionadas com o tipo tumoral, prognóstico ruim e menor tempo de sobrevida em mulheres com neoplasias mamárias (CHERIAN; JAYASURYA; BAY, 2003; JIN et al., 2004; HIFUMl et al., 2010). No entanto, mesmo com a proteína apresentando sua expressão na maioria das amostras, não houve correlação significativa com a sobrevida dos animais. A exceção foi observada quanto aos subtipos moleculares $(P=0,023)$. Esta correlação da expressão da MT junto aos subtipos moleculares com prognósticos sabidamente ruins corrobora a literatura, que associa a presença da MT com um pior prognóstico em animais 


\section{CONCLUSÃO}

O presente estudo demonstrou que a grande maioria dos carcinomas mamários em felinos apresentaram imunoexpressão dos três marcadores de resistência à múltiplas drogas analisados. No entanto, as proteínas GlicoP e LRP apresentaram marcação mais intensa nos tecidos mamários neoplásicos em comparação à MT. Ademais, as proteínas GlicoP e MT apresentaram correlação com alguns parâmetros histológicos e moleculares relacionados à agressividade tumoral. Porém, nenhum deles apresentou correlação com a sobrevida. Estes dados indicam a presença de múltiplas proteínas de resistência aos antineoplásicos em carcinomas mamários em felinos, além de sua correlação com o alto grau de malignidade destas neoplasias. Apesar de não haver correlação com a sobrevida, estes marcadores podem indicar um pior prognóstico destes pacientes, além de uma possível falha terapêutica na quimioterapia adjuvante devido aos mecanismos de resistência existentes nas células neoplásicas dos carcinomas mamários em felinos. 


\section{REFERÊNCIAS}

AMBUDKAR, S. V.; et al. Biochemical, Cellular, and Pharmacological Aspects of the Multidrug Transporter. Annual. Review Pharmacology and Toxicology, San Diego, v. 39, n. 1, p. 361-398, 1999.

Arts, H. J. G.; et al. Drug Resistance-associated Markers P-Glycoprotein, Multidrug Resistance-associated Protein 1, Multidrug Resistance-associated Protein 2, and Lung Resistance Protein as Prognostic Factors in Ovarian Carcinoma. Clinical Cancer Research, Amsterdam. v. 5, n. 10, p. 2798-2805, 1999.

BAGULEY, B. C. Multiple drug resistance mechanisms in cancer. Molecular Biotechnology, Nova Zelândia, v. 46, n. 3, p. 308-316, 2010.

BENTUBO, H. D. L.; et al. Expectativa de vida e causas de morte em cães na área metropolitana de São Paulo (Brasil). Ciência Rural, São Paulo, v. 37, n. 4, p. 10211026, 2007.

BERGMAN, P. J. Mechanisms of anticancer drug resistance. The Veterinary clinics. Nova lorque, v. 33, p. 651-667, 2003.

BERGMAN, P. J., et al. Retrospective Evaluation of Adjunctive Doxorubicin for the Treatment of Feline Mammary Gland Adenocarcinoma : 67 Cases. Journal of the American Animal Hospital Association, Dallas, v. 42, p. 110-120, 2006.

BAY, B.; JIN, R.; HUANG, J.; TAN, P. Metallothionein as a Prognostic Biomarker in Breast Cancer. Experimental Biology and Medicine, Singapura p. 1516-1521, 2006.

BOSTOCK, D. E. Canine and feline mammary neoplasms. The British Veterinary Journal, Cambridge. v. 142, n. 6, p. 506-515, 1986.

BORREGO, J. F.; CARTAGENA, J. C.; Engel. J.; Treatment of feline mammary tumours using chemotherapy, surgery and a COX-2 inhibitor drug (meloxicam ): a retrospective study of 23 cases $(2002-2007)^{*}$. Veterinary and Comparative Oncology, Medison. v. 7, n. 4, p. 213-221, 2009.

BONADONNA, G.; et al. Modulation of Resistance to Anticancer Drugs by Inhibition of Metallothionein. Cancer Research, Toquio. v.54, p. 5255-5257, 1994 
BRUGNATELLI, L.; et al. Combination chemotherapy as an adjuvant treatment in operable breast cancer. The New England Journal of Medicine, Milão. v. 272, n. 24, p. 1263-1268, 1965.

CANNON, C. M. Cats, Cancer and Comparative Oncology. Veterinary Sciences, Knoxville, v. 2, p. 111-126, 2015.

CASSALI, G. D.; et al. Consensus for the diagnosis, prognosis and treatment of feline mammary tumors. Brazilian Journal of Veterinary Research and Animal Science, Belo Horizonte. n. 2014, p. 1-17, 2018.

CHERIAN, M. G.; JAYASURYA, A.; BAY, B. Metallothioneins in human tumors and potential roles in carcinogenesis. Mutation Research. Ontário. v. 533, p. 201-209, 2003.

CIRILLO, J. V. Tratamento quimioterápico das neoplasias mamárias em cadelas e gatas. Revista do Instituto de Ciências Saúde. São Paulo. v. 26, n. 3, p. 325-327, 2008.

COLEY, H. M. Mechanisms and consequences of chemotherapy resistance in breast cancer. European Journal of Cancer Supplements, Guildford. v. 7, n. 1, p. 3-7, 2009.

CUNHA, S.; et al. Survival and Disease-free Interval of Cats with Mammary Carcinoma Treated with Chain Mastectomy. Acta Scientiae Veterinariae. Porto Alegre. v. 44, n. April, p. 1-8, 2016.

DE ALMEIDA, V. L.; et al. Câncer e agentes antineoplásicos ciclo-celular específicos e ciclo-celular não específicos que interagem com o DNA: Uma introdução. Quimica Nova. Belo Horizonte. v. 28, n. 1, p. 118-129, 2005.

DE CAMPOS, C. B.; et al. Evaluation of prognostic factors and survival rates in malignant feline mammary gland neoplasms. Journal of Feline Medicine and Surgery. São Paulo. v. 18, n. 12, p. 1003-1012, 2016.

DEAN, M.; FOJO, T.; BATES, S. Tumor stem cellsand drug resistance.

Nature Rewiews Cancer. Mariland. v. 5, n. April, 2005.

DEELEY, R. G.; COLE, S. P. Function, evolution and structure of multidrug resistance protein (MRP). Seminars in cancer biolog. Ontário v. 8, n. 3, p. 193204, 1997. 
DINCER, Z.; et al. Metallothionein expression in canine and feline mammary and melanotic tumours. Journal of Comparative Pathology.

Liverpool. v. 125, n. 2-3, p. 130-136, 2001.

DORN, C. R.; et al. Survey of Animal Neoplasms in Alameda and Contra Costa Counties, California. Cancer Morbidity in Dogs and Cats. Califória. p. 2014, 1967.

DOYLE, A. L.; et al. A multidrug resistance transporter from human MCF-7 breast cancer cells. Proceedings of the National Academy of Sciences of the United of States of America. Massachussets. v. 95, n. lane 2, p. 15665-15670, 1998.

DZIEGIEL, P. Expression of Metallothioneins in Tumor Cells.Polish Journal of Pthology. Wroclaw. v. 55, n. 4, p. 3-12, 2004.

ELSTON, C. W.; ELLIS, O. Pathological prognostic factors in breast cancer. The value of histological grade in breast cancer : experience from a large study with longterm follow-up. Histopathology. Nottingham. p. 403-410, 1991.

ERGINSOY, S. D.; et al. Metallothionein expression in benign and malignant canine mammary gland tumours. Research in Veterinary Science, Kars. v. 81, p. 46-50, 2006.

FILGUEIRA, K. D.; et al. Comportamento metastático das neoplasias mamárias malignas da espécie felina. Acta Veterinaria Brasilica, São Paulo. v. 8, n. 3, p. 209-214, 2014.

FLETCHER, J. I.; et al. ABC transporters in cancer: more than just drug efflux pumps. Nature Reviews Cancer, Randwick. v. 10, n. 2, p. 147-156, 2010.

FREIRE, L, H, M.; ALVES, F. Ação De Extratos Naturais Sobre O Câncer Natural Extracts of Action on Cancer. Europian Journal of Human Genome, Belo Horizonte. p. 7-14, 2014.

GIMÉNEZ, F.; et al. Early Detection, Aggressive Therapy: Optimizing the Management of Feline Mammary Masses. Journal of Feline Medicine and Surgery. La Plata. 2010.

GOMULKIEWICZ, A.; et al. Correlation between metallothionein ( MT ) expression and selected prognostic factors in ductal breast cancers. Folia Histochemica Et Cytobiologica. Wroclaw. v. 48, n. 2, p. 242-248, 2010. 
GOTTESMAN, M. M. Mechanisms of Cancer Drug Resistance. Annual Review of Medicine, Maryland. v. 53, n. 1, p. 615-627, 2002.

GROENEVELD, L. F.; et al. Domesticated Animal Biobanking: Land of Opportunity. PLoS Biology. Upsala, v. 14, n. 7, p. 1-6, 2016.

Hahn, A. K.; Admas, W, H. Feline mammary neoplasia: Biological behavior, diagnosis, and treatment alternatives. Feline Practice. Tenesse, v. 25, p. 5-10, 1997.

HAYDEN, D. W.; BARNES, D. M.; JOHNSON, K. H. Morphologic changes in the mammary gland of megestrol acetate-treated and untreated cats: a retrospective study. Veterinary Pathology, Connecticut. v. 26, n. 2, p. 104-113, 1989.

HAYDEN, D. W.; NIELSEN, S. W. Feline mammary turnours. Journal of Small Animal Practice. Storrs. v. 12, n. 12, p. 687-698, 1971.

HAYES, A. A.; MOONEY, S. Feline Mammary Tumors. Veterinary Clinics of North America: Small Animal Practice. Califórnia. v. 15, n. 3, p. 513-520, 1985.

HEYDEN, S. V. D.; CHIERS, K.; DUCATELLE, R. Tissue Distribution of PGlycoprotein in Cats. Journal of Veterinary Medicina. Merrelbeke. n. 38. v. 460, p. 455-460, 2009.

HIFUMI, T.; et al. Immunohistochemical Detection of Proteins Associated with Multidrug Resistance to Anti-Cancer Drugs in Canine and Feline Primary Pulmonary Carcinoma. Journal of Veterinary Medical Science, Osaka. v. 72, n. 5, p. 665-668, 2010.

HONSCHA, k.; et al. Expression of ABC-Transport Proteins in Canine Mammary Cancer: Consequences for Chemotherapy. Reproduction in domestic animals. Leipzig. v. 44, n.2, p. 218-223, 2009.

HUGHES, K.; DOBSON, J. M. Prognostic histopathological and molecular markers in feline mammary neoplasia. The Veterinary Journal, Cambridge. v. 194, n. 1, p. 1926, $2012 b$.

IZQUIERDO, M. A.; et al. Relationship of LRP-human major vault protein to in vitro and clinical resistance to anticancer drugs. Cytotechnology, Amsterdam. v. 19, n. 3, p. 191-197, 1996a. 
IZQUIERDO, M. A.; et al. Major Vault Protein LRP-related Multidrug Resistance.Europian Journal of Cancer. Amsterdam. n. 7, v. 32, $1996 \mathrm{~b}$.

JIN, R.; et al. MINIREVIEW Clinicopathological Significance of Metallothioneins in Breast Cancer. Pathology Oncology Research. Singapura. v. 10, n. 2, p. 74-79, 2004.

JULIANO, R. L.; LING, V. A surface glycoprotein modulating drug in chinese hamster ovary cell mutants permeability. Biochimica et Biophysica Acta. Toronto. v. 455, p. 152-162, 1976.

KEDERSHA, N. L.; ROME, L, H. Isolation and Characterization of a Novel Ribonucleoprotein Particle : Large Structures Contain a Single Species of Small RNA. The Journal of Cell Biology. Los Angeles. v. 103, September, p. 699-709, 1986.

$\mathrm{KIM}, \mathrm{N}$; ; et al. P-glycoprotein expression in canine mammary gland tumours related with myoepithelial cells. Research in Veterinary Science. Toquio. v. 93, p. 13461352, 2012.

KLOPFLEISCH, R.; KOHN, B.; GRUBER, A. D. Mechanisms of tumour resistance against chemotherapeutic agents in veterinary oncology. Veterinary Journal. Berlin. v. 207, p. 63-72, 2016.

LESLIE, E. M.; DEELEY, R. G.; COLE, S. P. C. Multidrug resistance proteins: Role of P-glycoprotein, MRP1, MRP2, and BCRP (ABCG2) in tissue defense. Toxicology and Applied Pharmacology. Carolina do Norte. v. 204, n. 3, p. 216-237, 2005.

LINN, S. C.; et al. Expression of Drug Resistence proteins in Breast Cancer. Jounal of Cancer. Amsterdam. v. 795, n. December 1996, p. 787-795, 1997.

LUQMANI, Y. A. Mechanisms of Drug Resistance in Cancer Chemotherapy. Medical Principles and Practice. Kuwait. v. 14, n. 1, p. 35-48, 2008.

MAULDIN, G. N. et al. Efficacy and Toxicity of Doxorubicin and Cyclophosphamide Used in the Treatment of Selected Malignant Tumors in 23 Cats. Journal of Veterinary Internal Medicine. Nova lorque. v. 2, n. 2, p. 60-65, 1988.

MCNEILL, C. J.; et al. Evaluation of adjuvant doxorubicinbased chemotherapy for the treatment of feline mammary carcinoma. Journal of Veterinary Internal Medicine, Philadelphia. v. 23, n. 1, p. 123-129, 2009. 
MILLS, S. W.; et al. Prognostic Value of Histologic Grading for Feline Mammary Carcinoma. Veterinary Pathology. Sakatoon. v. 52, n. 2, p. 238-249, 2015.

MISDORP, W. Progestagens and mammary tumours in dogs and cats. Acta Endocrinologica, Copenhagen. v. 125 Suppl 1, n., p. 27-31, 1991.

MISDORP, W.; et al. Histological classification of the mammary tumors of the dog and the cat. Secundary Tittle. Washington, 1999. 7, p. 1-59.

MISDORP, W.; WEIJER, K. Animal model of Human Disease. American Journal of Pathology. Amsterdam. v 8, n. 1, p. 269-298, 2013.

MOLLAZADEH, S.; et al. Structural and functional aspects of P-glycoprotein and its inhibitors. Life Sciences. Mashad. v. 214, n. October, p. 118-123, 2018.

MORENTE, M. M.; FERNÁNDEZ, P. L.; DE ALAVA, E. Biobanking: old activity or young discipline? Seminars in Diagnostic Pathology. Salamanca.v. 25, n. 4, p. 317-322, 2008.

MORRIS, J. Mammary tumours in the cat: size matters, so early intervention saves lives. Journal of Feline Medicine and Surgery, v. 15, n. 5, p. 391-400, 2013a.

MULEYA, J. S.; et al. In-vitro anti-proliferative effects of some anti-tumour drugs on feline mammary tumour cell lines. Research in Veterinary Science. Miyazaki. v. 66, n. 3, p. 169-174, 1999.

NIERO, E. L.; et al. The multiple facets of drug resistance : one history, different approaches.Journal of Experimental and Clinical Cancer Research. São Paulo. p. 1-14, 2014.

NOVOSAD, C. A. Principles of Treatment for Mammary Gland Tumors. Clinical Techniques in Small Animal Parctice. Dallas. v. 18, n. 2, p. 107-109, 2003.

OVERLEY, B.; et al. Association between ovarihysterectomy and feline mammary carcinoma. Journal of veterinary internal medicine / American College of Veterinary Internal Medicine. Nova lorque. v. 19, n. 4, p. 560-563, 2005. Organization. Veterinary Public Health Unit \& WHO Collaborating Center for Comparative Oncology. (1980). 
PAOLONI, M.; KHANNA, C. Translation of new cancer treatments from pet dogs to humans. Nature reviews. Cancer, Maryland. v. 8, n. 2, p. 147-56, 2008.

PAWLOWSKI, K. M.; et al. Expression and role of PGP , BCRP , MRP1 and MRP3 in multidrug resistance of canine mammary cancer cells. BMC Veterinary Research. Warsaw. p. 1-10, 2013.

PEREZ-TOMAS, R. Multidrug Resistance: Retrospect and Prospects in Anti-Cancer Drug Treatment. Current Medicinal Chemistry, Barcelona. v. 13, n. 16, p. 18591876, 2006.

QUEIROZ, R. A.; et al. Mastectomia parcial ou radical como tratamento de neoplasia mamária em cadelas e gatas atendidas no hospital veterinário. XIII Jornada de Ensino, Pesquisa e Extensão - JEPEX. Recife. p. 4-6, 2013.

RAHARISON, F.; SAUTET, J. Lymph Drainage of the Mammary Glands in Female Cats. Journal of Morphology. Toulouse. v. 299, n. December 2005, p. 292-299, 2006.

RANIERI, G.; et al. A model of study for human cancer: Spontaneous occurring tumors in dogs. Biological features and translation for new anticancer therapies.

Critical Reviews in Oncology/Hematology. Bari Bari. v. 88, n. 1, p. 187-197, 2013.

RUDAS, M. ; et al. Expression of MRP1, LRP and Pgp in breast carcinoma patients treated with preoperative chemotherapy. Breast Cancer Research and treatment. Viena. v. 81, p. 149-157, 2003.

SEIXAS, F.; et al. Grade is an independent prognostic factor for feline mammary carcinomas: a clinicopathological and survival analysis. The Veterinary Journal, Vila Real. v. 187, n. 1, p. 65-71, 2011.

SCHECK, A. C. Chemotherapy Resistance Mechanisms. Handbook of Brais Tumor Chemotherapy. Elsevier. 1996.

SCHEFFER, G. L.; et al. Lung resistance-related protein / major vault protein and vaults in multidrug-resistant cancer. Current Opinion in Oncology. Amsterdam. v. 12. p. 550-556. 2000.

SCHEPER, R. J.; et al. Overexpression of a Mr 110,000 Vesicular Protein in Non-PGlycoprotein-mediated Multidrug Resistance1. Cancer Research. Amsterdam. v. 53, p. 1475-1480, 1993. 
SKORUPSKI, K. A.; et al. Clinical characteristics of mammary carcinoma in male cats. Journal of Veterinary Internal Medicine, Philadelphia. v. 19, n. 1, p. 52-55, 2005.

SOARES, M.; et al. Feline HER2 protein expression levels and gene status in feline mammary carcinoma: optimization of immunohistochemistry $(\mathrm{IHC})$ and in situ hybridization (ISH) techniques. Microscopy and Microanalysis, Lisboa. v. 19, n. 4, p. 876-882, 2013.

SOARES, M.; et al. St Gallen molecular subtypes in feline mammary carcinoma and paired metastases-disease progression and clinical implications from a 3-year followup study. Tumor Biology, Lisboa. v. 37, n. 3, p. 4053-4064, 2016.

SOARES, M.; et al. Molecular based subtyping of feline mammary carcinomas and clinicopathological characterization. The Breast. Lisboa. v. 27, p. 44-51, 2016

SOARES, M.; et al. Ki-67 as a Prognostic Factor in Feline Mammary Carcinoma: What Is the Optimal Cutoff Value? Veterinary Pathology, Lisboa. v. 53, n. 1, p. 37$43,2016 d$.

TAKARA, K.; SAKAEDA, T.; OKUMURA, K. Carvedilol: a new candidate for reversal of MDR1/P-glycoprotein-mediated multidrug resistance An update on overcoming MDR1-mediated multidrug resistance in cancer chemotherapy. Anti-Cancer Drugs. Kioto. v. 15, n. 4, p. 303-309, 2004.

THAMM, D.; DOW, S. How companion animals contribute to the fight against cancer in humans. Veterinaria italiana. Fort Colins. v. 45, n. 1, p. 111-120, 2009.

THEOCHARIS, S. E.; MARGELI, A. P.; KOUTSELINIS, A. Metallothionein : A multifunctional protein from toxicity to cancer. The International Journal of Biological Markers. Atenas. v. 18, n. 3, p. 162-169, 2003.

THIRUMOORTHY, N.; et al. Metallothionein : An overview. World Journal of Gastroenterology. Tamilnadu. v. 13, n. 7, p. 993-996, 2007.

TOGNI, M.; et al. Estudo retrospectivo de 207 casos de tumores mamários em gatas ${ }^{1}$. Pesquisa Veterinária Brasileira. Santa Maria. v. 33, n. 3, p. 353-358, 2013.

TRÉDAN, O.; et al. Drug Resistance and the Solid Tumor Microenvironment. Jounal of National Cancer Institute. Toronto. v. 99, p. 1441-1454, 2007. 
VAIL, D. M.; MACEWEN, E. G. Spontaneously occurring tumors of companion animals as models for human cancer. Cancer investigation, Wisconsin. v. 18, n. 8, p. 781-792, 2000.

VAN DER HEYDEN, S.; et al. Expression of Multidrug Resistance-Associated PGlycoprotein in Feline Tumours. Journal of Comparative Pathology, v. 144, n. 2-3, p. 164-169, 2011.

VERRELLE, P.; et al. Clinical Relevance of Immunohistochemical Detedtion of Multidrug Resistance P-Glycoprotein in Breast Carcinoma. Journal of the National Cancer Institute. Clemont-Ferrand Cedex. p. 111-116, 1991.

VIRKEL, G. BALLENT, M.; LANUSSE, C.; LIFSCHITZ, A. Role of ABC Transporters in Veterinary Medicine: Pharmaco-Toxicological Implications.Current Medicinal Chemistry. Buenos Aires. n.7, v. 26, p. 1251-1269, 2017.

ZANDVLIET, M.; TESKE, E. Mechanisms of Drug Resistance in Veterinary Oncology - A Review with an Emphasis on Canine Lymphoma. Veterinary Sciences, Utrecht. v. 2, n. 3, p. 150-184, 2015.

ZAPPULLI, V.; et al. Feline mammary tumours in comparative oncology. Journal of Dairy Research, Padua. v. 72, n. SPEC. ISS., p. 98-106, 2005.

ZON, A.; et al. The Vault Complex. Cellular and Molecular Life Sciences. Rotterdam. v. 60, p. 1828-1837, 2003. 